\title{
Laugh With Me: Effects of Shortcoms on Students' Motivation, Confidence, and Cultural Understanding in the French Classroom
}

Juliette Duthoit

Follow this and additional works at: https://researchrepository.wvu.edu/etd

\section{Recommended Citation}

Duthoit, Juliette, "Laugh With Me: Effects of Shortcoms on Students' Motivation, Confidence, and Cultural Understanding in the French Classroom" (2016). Graduate Theses, Dissertations, and Problem Reports. 5520.

https://researchrepository.wvu.edu/etd/5520

This Thesis is protected by copyright and/or related rights. It has been brought to you by the The Research Repository @WVU with permission from the rights-holder(s). You are free to use this Thesis in any way that is permitted by the copyright and related rights legislation that applies to your use. For other uses you must obtain permission from the rights-holder(s) directly, unless additional rights are indicated by a Creative Commons license in the record and/ or on the work itself. This Thesis has been accepted for inclusion in WVU Graduate Theses, Dissertations, and Problem Reports collection by an authorized administrator of The Research Repository @ WVU. For more information, please contact researchrepository@mail.wvu.edu. 
Laugh With Me: Effects of Shortcoms on Students' Motivation, Confidence, and Cultural Understanding in the French Classroom

\author{
Juliette Duthoit
}

\author{
Thesis submitted \\ To the Eberly College of Arts and Sciences \\ at West Virginia University \\ in partial fulfillment of the requirements for the degree of \\ Masters of Arts in \\ TESOL
}
Cynthia Chalupa, Ph.D., Chair
Maria Amores, Ph.D.
Jennifer Orlikoff, Ph.D.

Department of World Languages, Literatures, and Linguistics

$$
\begin{gathered}
\text { Morgantown, West Virginia } \\
\text { Spring } 2016
\end{gathered}
$$

Keywords: French Language Learning; Humor; Audio-visual material; Motivation; Confidence; Culture 


\begin{abstract}
Laugh With Me: Effects of Shortcoms on Students' Motivation, Confidence, and Cultural Understanding in the French Classroom
\end{abstract}

\title{
Juliette Duthoit
}

Research has shown that authentic audio-visual materials have had a positive effect in foreign language classroom on learners' motivation and their confidence. Studies have also shown that humor can aid learners' memorization and improve their motivation, whether it is used in course material or through the instructor's interaction with the learners. Few researchers have focused, however, on the effect of humorous audio-visual material on foreign language learning. The aim of this thesis is to research the effects of humor in authentic video programming on the learning of French. In particular it examines the genre of the shortcom and how its use in French language instruction can positively impact learners' (1) motivation, (2) affective filter, and (3) cultural understanding. This study shows that humorous videos motivate students to learn the language, help them feel more comfortable in class, and develop tolerance toward the target culture. All of these factors make the short-com an ideal for promoting students' interest in the target language and culture outside of the classroom and helping them to become lifelong learners. 


\section{Dedication}

This thesis is dedicated to my homonymous best friend Juliette, who loves a good French comedy at least as much as I do and taught me to enjoy every side of French humor, from the darkest part to its silliest bits.

It is also dedicated to my awesome roommate Kristina, who had to bear with my showing her every clip of TV programming for acknowledgement of its funniness. Here is the results of this pain and suffering, Kris! 


\section{Acknowledgements}

I would like to thank everyone who has supported me in this endeavor.

First and foremost, I would like to thank my committee for their expertise and guidance through this process, as well as for their patience. I would like to give special thanks to my committee chair, Dr. Cynthia Chalupa, without whom this project would have never been born. Thank you for your encouragement that has been vital for this project, and all this time you spent helping me make this work better, even though I know your schedule is very busy. You are my new hero and a definite role-model. I aspire to become like you one day! (It's going to take me some time to get there, though.)

Thank you Dr. Amores for your support, enthusiasm, and critical eye - without your help, this thesis would have been a haven for contradictions. Your comments and advice helped make my research stronger, and I am very grateful for it.

And lastly, thank you Dr. Orlikoff for your guidance ever since I entered this university. Without you, I would have never even imagine writing a research.

I would like to thank Dr; Shimanskaya, the French Program Coordinator, for providing me the opportunity to teach and conduct this research. I would also like to thank all of my students who participated in the research willingly and even enthusiastically sometimes. Furthermore, I would like to extend my gratitude to my colleagues from the language department in general and the French department in particular, for their support and patience, as well as their help in choosing the shortcom extracts. I do believe they enjoyed watching those funny scenes as much as I did using them in class.

I would also like to thank Dr Stjepanovic, my academic advisor and the Graduate Programs Coordinator, for her guidance, advice, and assistance throughout my studies, and for my application to the conclusion of this project. 
Lastly, I would like to express my sincere thanks to my friends and family. Thank you to Josh Dougherty, a former colleague, who took the time to proof-read all of my work before submission. Without you, this thesis might very well have been in Frenglish. Special thanks to Josiane, Marjorie, and Rita, who encouraged and supported me during the whole process, to my friend and roommate Kristina, who kept me motivated every day, and her one then two tiny monsters - Annemarii for making sure to be loud enough in the mornings so that I would wake up to work on my thesis, and Keiriin for motivating me to work fast by the perpetual threat of her coming birth.

Nothing would have been possible without you, and I thank you all from the bottom of my heart. 


\section{Table of Contents}

Abstract.

ii

Dedication

iii

Acknowledgements iv

Table of Contents ..vi

Chapter I: The Use of Authentic Video Material in Language Classrooms 1

1. Introduction: Rationale of the study 1

2. Audio-Visual Materials in the Second Language Classroom up to this Day 2

3. Audio-Visual Material as a Solution to Challenges in the Classroom...... .5

4. Previous Studies on the Use of Audio-visual Material in the Classroom .5

5. The Mental Benefits: Motivation, and Affective Filter, and Confidence .8

6. Potential Drawbacks of Teaching with Authentic Video Programming

7. The Use of the ShortComs in French Instruction 12

8. The Proposed Study 13

Chapter II: What's So Funny? A Comparison of French and U.S. Approaches to Humor 16

1. French Humor .16

2. Humor in the United States

3. Ambiguous Reactions to French Humor in the United States .25

Chapter III: Methodology 30

1. Setting and Participants. 


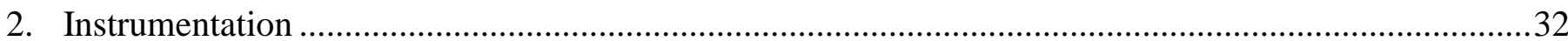

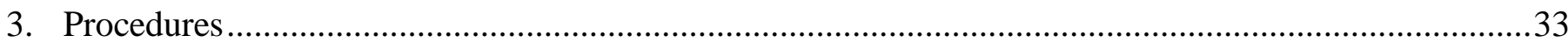

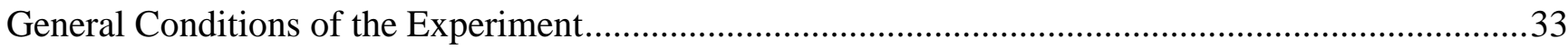

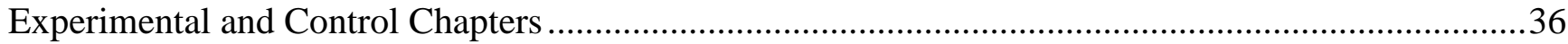

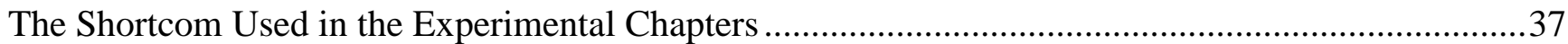

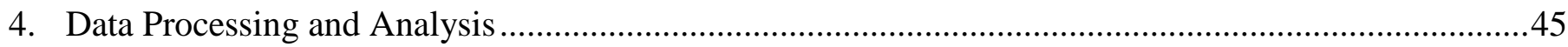

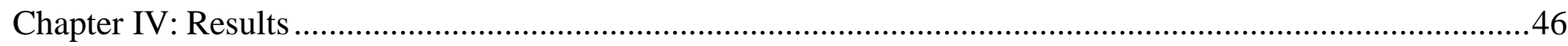

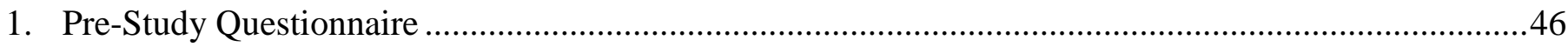

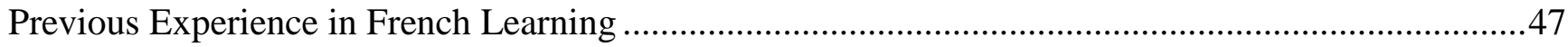

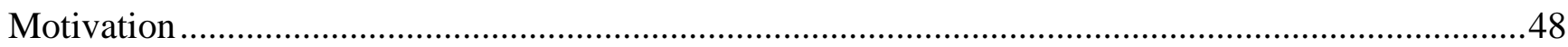

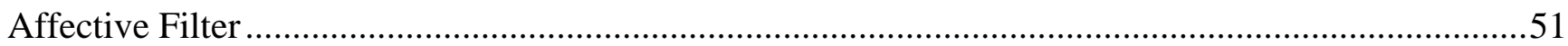

Cultural understanding and Attitude Toward French T.V. Shows...................................................53

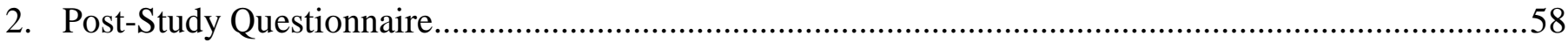

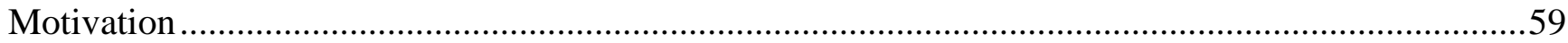

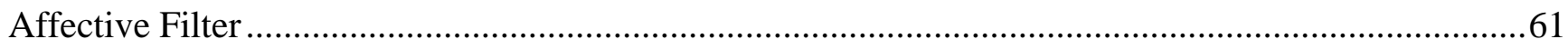

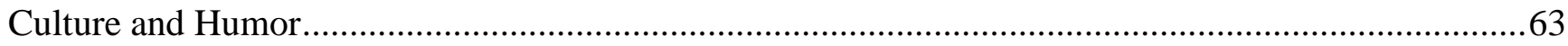

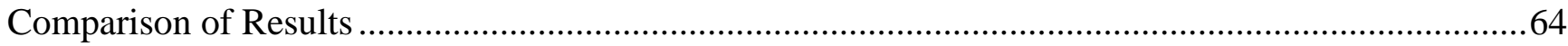

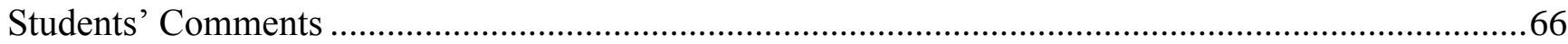

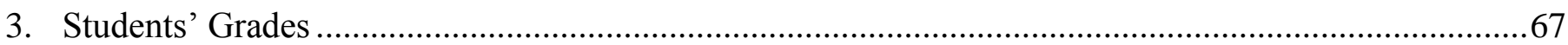

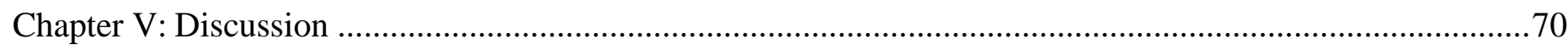

1. Discussion of Results by Research Question ...................................................................... 


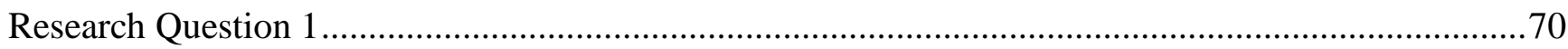

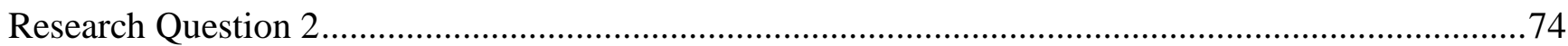

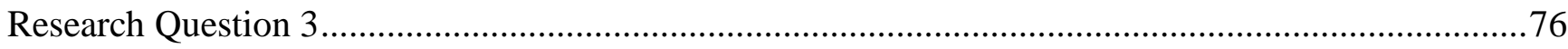

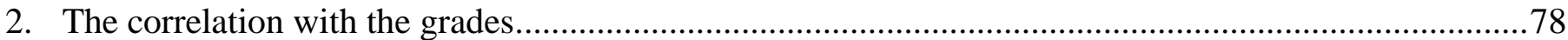

3. Limitations of the Study and Directions for Future Research ..............................................................

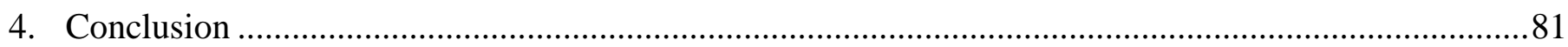

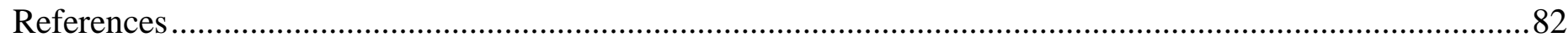

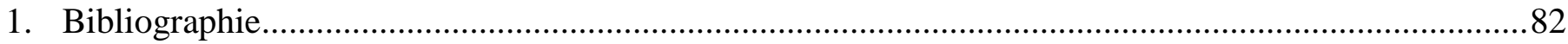

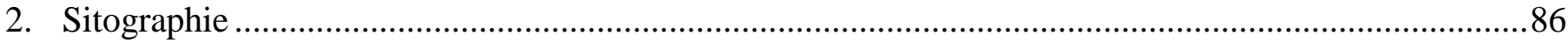

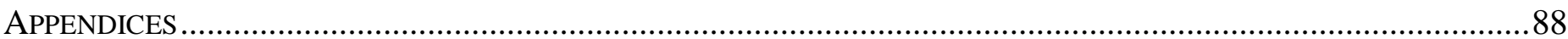

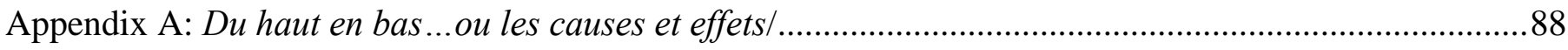

Appendix B: The Little Man with a Great Appetite Sitting down to Dinner ...................................................89

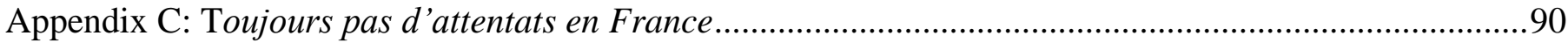

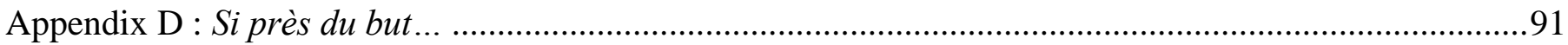

Appendix E: Preuve que l'Europe est Chrétienne .....................................................................................

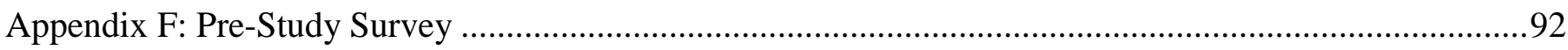

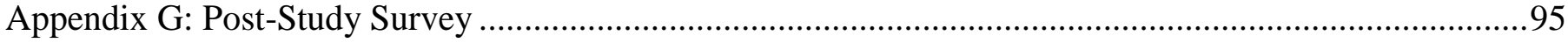




\section{Chapter I: The Use of Authentic Video Material in Language Classrooms}

\section{Introduction: Rationale of the study}

Authentic materials have been an important aspect of foreign language instruction for decades, particularly since the advent of communicative language teaching in the 1970s. Many studies have demonstrated the benefits of authentic materials on comprehension, motivation and confidence, and the size of students' vocabulary (Al-Surmi, 2012; Gilmore, 2007; Weyers, 1999). Although not all researchers agree on the definition of authentic material because of their wide variety, from YouTube videos and one-line advertisements to literary works (Al-Surmi, 2012), the effect of using materials that are created for native speakers and occur naturally in the target culture have been shown to influence positively second language acquisition in learners.

In particular, authentic video programming, in the form of films and T.V. shows, have been shown to add to the success of foreign language (FL) learners, in terms of language acquisition and/or retention (Weyers, 1999; Washburn, 2001; Grant \& Starks, 2001). Humor, as demonstrated, for example, in comedic television programs, is an important part of authentic culture (Guyon, 2002; Collès, 2004), and its use in FL classrooms has met consistently with success (Schmitz, 2002; Wagner \& Urios-Aparisi, 2011). This success is attributable to the fact that classroom resources including humor as part of their content or delivery increase students' engagement, help memorization, and improve the students' proficiency (Muñoz- Basols, 2005; Schmitz, 2002).

Given that humor has clearly been shown to have a positive impact on foreign language learning and target-language video programming has been shown to bolster student learning, a further study of the combination of these two components in the form of the shortcom is necessary in order to prove that the said combination is at least as effective in class than the two separated components. Among the television programs that have been implemented in the classroom, including sitcoms, comedies, and dramas, little attention has been paid to the shortcom, a genre that consists of short comedic vignettes involving a familiar recurring cast of characters. This study will examine, in particular, the effects of using well-known video programming, the 
French shortcom titled Scènes de ménage in the U.S. college French classroom (Francis Duquet and M6 studio, 2009 to present). More specifically, this study will analyze the effect of this shortcom on learners' beliefs on their enjoyment and motivation, their self-confidence and affective filter, and their cultural understanding by examining the following research questions: 1) Did the use of humorous videos of Scènes de ménage improve the students' motivation for the class and regarding the four basic skills of language learning? 2) Did the use of humorous videos of Scènes de ménage improve the students' self-confidence, therefore lowering their affective filter? 3) Did the use of humorous videos of Scènes de ménage expand the students' understanding of the target culture?

\section{Audio-Visual Materials in the Second Language Classroom up to this Day}

The use of audio or visual material in language classrooms was first explored in the 1960s through the 1970s as part of the audio-lingual (U.S.) and audio-visual teaching methods (France). Both methods were based on behaviorism, the theory that individuals develop language by means of environmental influence (Skinner, 1957). Therefore in the aforementioned studies, the participants were trained through reinforcement thanks to positive and negative feedbacks. In the 1950s, the audio-lingual methods consisted of teachers drilling students with grammar structures using only the target language (Cherpack, 2012), and the audio-visual method was very similar but used pictures to support the learning. New technologies came through in the 1960s and those two methods evolved. Baradaran Torabi and Poordaryaie Nejad (2014) explains, that in the mid-1960s:

Three new technological aids came into general use in the classroom-language laboratory, portable tape-recorder and film-strip projector. All these were greeted with euphoria in all modern language departments. Extensive use of tapes and equipment was revolutionary for language teachers. Instead of buying sets of books to equip a class, teachers were demanding most expensive boxes of film-strips and sets of tapes. Blackout facilities and electric points had to be installed. (Baradaran Torabi and Poordaryaie Nejad, 2014, p. 11) 
In the mid-1960s, teachers were able to use recordings of native speakers thanks to tape recorders, and could even edit the recordings or ask the learners to self-record in laboratories. The teachers also used taped dialogs in class, supported by short film strips designed to aid the learners and elicit responses in the target language.

Videos were abandoned as teaching devices once these methods were replaced through the cognitive approach, which opposes behaviorism in the way that language is no longer a habit and the result of environmental influences but the result of conscious thinking about the mechanisms behind language and its functions. The genre made a comeback in the 1990s, when classroom use became easier through the VCR. According to Tschirner (2001), rich authentic input was missing in language classrooms at the time, and for him, audio-visual materials were the perfect solution to the problem. The main advantage was, as during the audio-lingual and audio-visual methods, the introduction of native speaker's speech in class and visual aid. However, an additional advantage was that the teacher had full control of the video and could fast forward, rewind, or pause at will (Weyers, 1999; Tschirner, 2001; Lin, 2010) which helped managing activities without losing a precious time, and thusly opened the door for a new range of activities that were impossible before (for instance, simply pausing in the middle of a video on a specific picture and ask the learners to describe one character).

Around 1998, the DVD player came into use in classrooms and further simplified the process of incorporating videos. Today, multimedia are a practical component of FL classrooms because of drops in cost (Williams \& Lutes, 2007), and accessibility. Based on the introduction of websites such as YouTube ${ }^{1}$ and DailyMotion, ${ }^{2}$ authentic source materials are readily available to anyone with internet access. It has also become very easy to record programs online or on television. As a result of the abundance of choice and the ease of access, videos are more and more present in language curricula (Lin, 2010). Most studies to date focus on their implementation rather than on the effectiveness on listening comprehension skills, as it seems to be a given. Some studies have examined the use of videos in different components of language acquisition (Joynt, 
2008) and concluded it was beneficial for vocabulary acquisition, grammar skills, speaking, reading and writing skills, and even cultural knowledge.

The main advantage of audio-visual material is its authentic nature. The teacher chooses videos in the target language, which means that by watching and listening to the video, the students are exposed to the target language as spoken by native speakers, but also to a variety of native speakers with different accents. It is a common understanding that by watching and listening to various native speakers, learners train their ears to understand various accents instead of simply acclimating themselves solely to their teacher. The content of authentic audio visual material is also naturally rich (Weyers, 1999). The students are exposed to an important source of information, verbal and nonverbal at a linguistic and pragmatic level from the para-verbal information (prosodic, mimic, gestures) to the sociocultural level (role signals, signs of politeness) (Tschirner, 2001; Lin, 2010). In addition, this abundance of target language is presented in context, thanks to the imaging (Weyers, 1999; Canning-Wilson \& Wallace, 2000). According to Tschirner (2001), one of the main factors of foreign language acquisition is situated learning, or learning in context, with a reason for communication. Video material, especially authentic, presents everyday life, human interactions, mimics and gestures, but also examples of how to approach a problem linguistically. By watching videos, students are exposed to linguistic and behavioristic models of how to react in a given situation. Furthermore, audio-visual materials are the best representative of today's use of language, as they are the first to present the current linguistic changes, contrary to print materials which take longer to adapt to the linguistic changes (Weyers; 1999).

Another natural advantage of audio-visual resources is the fact that students associate both sound and picture in only one piece of material. A critical difference from traditional materials is that the teacher traditionally presented single pictures to accompany audio material in order to aid comprehension. Today, these pictures are animated in a video that fits the audio contextually (Lin, 2010). The imaging brings a visual stimulus to the audio content (Wayers, 1999; Tschirner, 2001; Lin, 2010), and students rely on these visual cues to guide their comprehension. This association of picture and sound is thus extremely beneficial for students. 


\section{Audio-Visual Material as a Solution to Challenges in the Classroom}

Audio-visual material can solve the dilemma of finding authentic target-language materials. Videos not only expose students to real language, which is not simplified and is spoken at a normal pace, with a genuine accent (Morat \& Abidin, 2011), but they also help present situations that move beyond the classroom. Through using videos, the instructor overcomes the obstacles of real interaction, such as the physical location of the students and the lack of opportunity to speak with a native speaker audience (Williams \& Lutes, 2007). The wide variety of topics covered by videos also ensures that the learners are exposed to a wide variety of context that are not always possible to recreate in a classroom (Williams \& Lutes, 2007).

Audio-visual material helps solve the problem of comprehension when dealing with aural material that has no visual support or visual stimuli (Al Surmi, 2012). The combination of visual and aural stimuli allows the students to "see the language" (Morat \& Abidin, 2011), and linguistic or paralinguistic elements (Morat \& Abidin, 2011; Al Surmi, 2012) enhance the overall comprehension process. In addition, videos come with a context; for instance, the episodes of a T.V. show are formed around a plot which gives a common background to the episodes of the series (Al Surmi, 2012).

Similarly, Ramirez-Salas (2003) points out that the use of videos is ideal for beginner classes if utilized as a medium in which learners focus on understanding the general gist of the message rather than individual words.

\section{Previous Studies on the Use of Audio-visual Material in the Classroom}

Many studies have focused on the effect of using authentic audio-visual material in foreign language classrooms, but most frequently to practice students' listening comprehension skills. For instance, LiskinGasparro \& Verguez (1990) proved that using videos in classrooms positively impacted the listening comprehension of students if they performed pre-listening activities such as brainstorming exercises in order to highlight the vocabulary used in the video. Later on, Secules, Herron \& Tomasello (1992) gave classic drills to one group of students while another group was given the same information through teacher-controlled videotapes presenting a native speaker in everyday situations. The video group outperformed the other group in 
the listening comprehension test items, while getting the same average score in the reading comprehension and writing test items. The clues and cues in the videos (both verbal and non-verbal) were associated with a familiar topic aid in the comprehension of uninstructed authentic language samples (Weyers, 1999). Nevertheless, Morat \& Abidin (2011) points out that a good implementation of audio-visual material such as videos can help enhance other skills among which speaking, writing, reading, and grammar. If the content can be used to focus on grammar or vocabulary, supplemented activities can be oral or written productive activities, such as discussion, dialog, essay, or role -playing.

The second well-studied area of improvement in foreign or second language acquisition with authentic audio-visual material is vocabulary acquisition. An audio-visual method activity from the 1960s that worked rather well in improving vocabulary acquisition consisted of presenting a picture of an object (which the learners already knew in their native language), then showing the written word in the target language. During the experience, this process of showing pictures of a concept and its written form was repeated several times with the help of a slide projector (Ford, 1972). This method can easily be reproduced nowadays with a video in a more authentic manner.

Some studies researched the topic further and tried to explain why vocabulary acquisition was improved through the use of authentic video programming. One benefit of authentic video materials is that they bring object and verbal availability to learners (Tomlinson \& Avila, 2007) by combining audio and visual stimuli. Visual imaging is "one of the main means of achieving understanding, interpretation, representation, retention, and recall of the language experience," (Tomlinson \& Avila, 2007, pp. 61) and it is the combination of audio and video that helps learners retain vocabulary and make connections in their mind between a word and a situation (Akbulut, 2007). A study by McCombs (1969) demonstrated that children learned a lot of vocabulary in their native language through watching television because videos often present an object, later accompanied of its name. The new object would then first exist in the child's mind, and then be available verbally. This principle of using videos was adapted to second language learners, as first language acquisition is often the base of second language acquisition. 
In addition, Schmidt (1990) hypothesized that the first step of acquiring language is to notice what is new in the input and needs to be learnt and acquired; to have a certain awareness. By showing an object in a certain context, videos bring the learner's attention to the object and its name, fulfilling the "noticing" part of language acquisition (Hu \& Deng, 2007). A study by Jones (2004) also tested and confirmed the hypothesis that vocabulary retention is even maximal if the written form of a new word is available, in the video, as a subtitle, or written on the board by the teacher.

Finally, authentic audio-visual material is a vital tool for teaching culture. As mentioned earlier, authentic video material present everyday life and the habits of the speakers of the target language, which implies the inherent presentation of the target culture to the learners (Tschirner, 2001; Joynt, 2008). Authentic videos are a source of target culture and expose the learners to cultural information as well as socio-cultural interactions (Richards, 2001; Al Surmi, 2012). Each and every element in a video from obvious elements such as attire to less obvious cultural elements such as body language brings learners to a cross-cultural awareness (Flowerdew \& Miller, 2005; Morat \& Abidin, 2011). As I have observed myself in class, the learners tend to have questions after watching a video about what they saw and seek explanation for what struck them as unusual in comparison to their own culture: the set-up of a household or a classroom, the size of a car or the side of the road the car is driving on, etc. Consequently, they improve their socio-cultural and socio-linguistic competences, consciously or not, by observing the social, contextual, affective, and discourse aspects of language use (Flowerdew \& Miller, 2005). Ramirez-Salas (2003) presents the example of the implementation of a news broadcast in an ESL classroom: it fulfills the learners' communication needs thanks to the richness of vocabulary that they might encounter in any social situation, and also develops their socio-cultural competence by showing examples of native speakers talking differently among peers or in a more formal situation, such as with a journalist. It also broadens their cultural knowledge with cultural aspects such as holidays, celebrities, or important social issues (to cite a few recent French social issues: political tensions between official parties, debates on the immigration or education, the evolution of the school crisis). 
Using authentic video material in classrooms has the benefit of improving the learner's listening comprehension. It also exposes them to culture and current language, demonstrates the use of grammatical forms or vocabulary in context, and even aids the learner in vocabulary retention. In addition, Williams \& Lutes (2007) calls attention on the fact that by giving a chance to learners to test their comprehension skills and demonstrate their comprehension of a material, videos are an opportunity for learners to observe and participate, and be engaged in the learning process. Videos are thus an excellent medium for active learning - a type of learning in which learners participate in the process of learning by solving problems for instance, instead of passively listening.

\section{The Mental Benefits: Motivation, and Affective Filter, and Confidence}

Audio-visual material is not only beneficial for language learning, it also has positive effects on classroom atmosphere, which directly impacts language acquisition. A poll by Narvaez (1992) showed that both teachers and students enjoy the use of audio-visual materials in the classroom, in a general way of speaking. Enjoyment usually results in motivation -from the learners and the instructor in that case. With more motivation, learners participate more and motivate one another, which in turn creates a nice learning atmosphere during the class. On the other hand, as Williams and Lutes states (2007), without motivation, learners will simply not be able to acquire language:

A well-planned and executed curriculum developed according to sound theoretical methodology and instructional methods still hinges on the ability of the instructor to motivate learners in order to be successful. If the students lack motivation or the instructor is unable to motivate them and maintain a certain level of motivation, any attempt to lead students through all the phases of learning will result in failure. (Williams \& Lutes, 2007, p. 6)

Consequently, motivation of the learners is a very important component in language acquisition. Williams and Lutes (2007) describes motivation as intrinsic or extrinsic. Extrinsic motivation is independent of instruction and has no direct relationship to the content of the lesson; the students are motivated by a grade or an extra line 
in their resume, for instance. Intrinsic motivation on the other hand is inherent to the instruction; the learner is motivated by the idea of learning the content or learning how to do something. Audio-visual material is therefore an intrinsically motivating factor because it gathers several of the motivators related to intrinsic motivation: embellishment through visual technique to encourage a deeper cognitive processing, an explanatory environment, a challenge for the learner, and a curiosity arousal (Alessi \& Trollip, 2001). Tschirner (2001) explains the correlation between motivation and audio-visual material by saying that the motivation to learn a language comes in two forms: the need to communicate (instrumental motivation) and the identification with a people or a group of people speaking the target culture (integrative motivation). Authentic audio-visual material provides examples of satisfaction of communication needs, as well as a cultural environment that contributes to identification with speakers of the target language. Both aspects of motivation for learning a language are thus addressed.

Learners' motivation is also affected by the use of authentic audio-visual material because there has always been a connection between multimedia in any form and motivation (Joynt, 2008; Wachob, 2011). As Ramirez-Salas states:

Nobody can deny that video as a synonym of T.V. has indeed a magic power that lures people with its images and actions. For language students, of course, are not an exception to this phenomenon. They become fascinated by the idea of having some minutes of picture viewing, no matter the objective of such viewing. (Ramirez- Salas, 2003, p. 1)

Indeed, the simple fact of announcing an activity based on the viewing of a video turned to rise the attention span of the learners as well as their interest in the class.

According to Morat \& Abidin (2011), videos are motivating thanks to their association of moving visual elements and sound elements that seem to calm the learners' apprehensions of listening practice. In addition, the combination of videos with interesting activities stimulates student interest, especially if the video is meaningful and represents real world elements. Williams \& Lutes (2007) experimented on Japanese ESL learners and 
observed that the course taught with videos received more positive comments, some of which specifically mentioned the videos as a motivating factor, as compared to the same course taught without the use of videos. In another study on Japanese ESL learners, he observed that in the same course, students who learned with videos actually looked forward to class and were even disappointed if they missed a class in which videos had been used. These two studies also pointed out that the learners reported being motivated not only during class time, but also before class in anticipation of the coming video presentation, which was motivating enough for them to prepare.

Keller (1984) warns, however, that interest is the main factor of intrinsic motivation, and as such, curiosity needs to be aroused and maintained through for instance a large variety of activities or tasks. He also warns that curiosity is only one factor of intrinsic motivation and that different students may respond to different types of motivation. Consequently, the continual use of videos in class could reduce the curiosity factor and in turn impact the motivation of the learners. In a study by Collins \& Hunt (2011), Japanese ESL students exposed to videos and music videos reported a boost in confidence for listening comprehension as well as an increase in motivation and enjoyment. In their feedback, they identified the videos as a direct cause of this increase in motivation and self-confidence. Learners' affective filters are also lowered by watching audio-visual material because multimedia generally brings high levels of enjoyment, accompanied by low anxiety levels during the learning activities. This is the perfect framework to lower the affective filters of students and maximize their language acquisition (Joynt, 2008). A polling led by Lin (2010) also proved that videos foster the imagination of both good and bad learners, which appears to help the learner's memory as well as increase their interest in the class. Another study led by Wayers (1999) failed to demonstrate that videos could increase the quality of language output but incidentally proved that videos made the learners more confident when producing output: learners saw multiple models of native speakers talking in a certain context, and it made them comfortable enough to express themselves on the same topic or in the same situation.

Ultimately we have seen that audio-visual materials bring a positive learning environment to the classroom by increasing the learners' motivation and lowering their affective filters. Audio-visual material also 
increases vocabulary retention and acquisition thanks to the contextualized utilization of language, and improves the learner's listening comprehension thanks to the complex combination of verbal and non-verbal cues.

\section{Potential Drawbacks of Teaching with Authentic Video Programming}

Despite the data that positively supports the use of audio-visual materials in class, they may also have negative side effects that could be detrimental to learners if not taken into account. First, the general enthusiasm for this sort of material can make it inefficient because learners are easily distracted from the audio input (Joynt, 2008). This problem can be solved by careful management and timing of the visual and audio components of the video. Second, learners are not always all overly-enthusiastic at the idea of using videos: some learners have complained in a poll that activities linked to videos were too game-like, and they disliked it as it was not intellectual enough (Lin, 2010). Other learners have experienced a certain frustration when confronted with videos: there is so much information available in one short audio-visual sample that some learners have reported information overload. The students got lost as they did not know if they needed to focus on the dialog, the visual information, the context etc. (Joynt, 2008; Lin, 2010).

It is also important to remember that although audio-visual materials are excellent for listening comprehension and vocabulary acquisition, they cannot be used directly for every aspect of language acquisition. The effect of audio-visual input on the quantity and quality of learners' output is unproved (Wayers, 1999), and audio-visual material has very little effect on reading skills (Lin, 2010). Therefore, teachers have to associate audio-visual material with different types of activities if they wish to work on more than the learners' listening comprehension and cultural learning.

The use of audio-visual material involves time and effort on the part of the teacher to find suitable materials. The preparation of the material during the lesson planning involves searching and selecting the material, and its editing for the learners (cutting the video, adding subtitles, etc.). Its use in the classroom is also time consuming in the sense that the teacher has to manually fast forward or rewind to a specific moment, and 
the learners will need to watch the material several times before being able to use it. A basic knowledge in computers is necessary to gain time, and the right material is also needed in the classrooms to correctly present the videos. In addition, the teacher's ability to implement the video is in direct correlation to the results of the class meeting in which it was used: according to Ramirez-Salas (2003), an inexperienced teacher may not be able to use the material efficiently and will see the classroom productivity decrease. Furthermore, the choice of the video is problematic, as the video not only needs to fit the level (talking speed, accent clarity, vocabulary adequacy, overall comprehensibility, degree of visual support, as well as gathering different aids and support to the situation) and needs of the classroom and goals of the curriculum, but it also cannot be radically different from the students' way of life, and needs to avoid being offensive. The programming has to take into account the students' interests, has to be appropriate and relevant to topic and finally, it has to be studied in class.

\section{The Use of the ShortComs in French Instruction}

Television shows have long been proved to be excellent authentic teaching material in foreign-language classrooms (Narváez, 1992; Collentine, 1997; Ramírez Salas, 2003; Joynt, 2008). Several studies have used different types of audio-visual material, some of which were comic in nature, in order to prove their efficiency on language learning or acquisition, from music videos and news broadcasts to Spanish télénovelas, soap operas, and sitcoms (Weyers, 1999; Sherman, 2003; McCall \& Craig, 2009; Al Surmi, 2012). A recent comedic genre in France, the shortcom, however, has received virtually no attention in terms of its use in foreignlanguage instruction despite its qualities as an excellent choice for motivating learners and exposing them to authentic cultural material.

Shortcoms were introduced in 1999, with Un gars, une fille, ${ }^{3}$ a French adaptation of a CanadianQuébécois sitcom also called Un gars, une fille (Guy Lepage and Avanti Ciné Vidéo). Many shortcoms have been created since then, based on a wide range of topics, including the legends of Arthur and his Knights of the

\footnotetext{
${ }^{3}$ Rough translation : A guy, a girl
} 
Round Table (Kaameloot, ${ }^{4}$ 2005-2009, A. Astier et A. Kappauf, CALT studios) and office gossip at the coffee machine (Camera Café, 2001-2003, B. Solo, Y.Le Bolloc'h, et A. Kappauf, CALT studios et 121 productions). Shortcoms are made up of a series of episodes approximately ten minutes in length and one to two-minute comical vignettes. Each vignette presents a visual or verbal joke, and they are very simple. The plot centers on a comical situation, and the skit consists of a maximum of three different characters.

Scènes de ménage ${ }^{5}$ (Francis Duquet and M6 studio, 2009 to present) is one of the most successful shortcom nowadays in metropolitan France: since its beginnings in 2009, it has obtained an average of $16 \%$ of the French T.V. audience share (Spinassou, 2013; "Audience: Scènes de ménage”, 2014; "Scène de ménage”, 2014), and the first episodes of the latest season (which now let the characters leave their house) obtained $16.7 \%$ of the audience share (M6.com; "Audience du prime", 2015). This shortcom also has the advantage of using modern language and idiomatic phrases. This is not only interesting for the students, based on the humor and puns, but it is also good authentic audio-visual material that exposes them to current French expressions. This programming opens up to students a door on French culture and way of life.

\section{The Proposed Study}

As detailed in the previous section, the use of audio-visual material has been directly linked to an increase of motivation and a lowering of the learners' affective filter. However, one question remains of knowing what other component apart from the addition of picture and sound could make audio-visual material even more effective.

The present study focuses on the effect of humor in the authentic video program Scènes de ménage on various aspects of language learning in the French language classroom. It takes as its point of departure the following research questions: 1) Did the use of humorous videos of Scènes de ménage improve the students' motivation for the class and regarding the four basic skills of language learning? 2) Did the use of humorous

\footnotetext{
${ }^{4}$ Pun between Camelot, King Arthur's city, and "camelote", which means junk, trash in French.

5"Scènes de ménage" means "domestic quarrels" and/or "household scenes" in English.
} 
videos of Scènes de ménage improve the students' self-confidence, therefore lowering their affective filter? 3) Did the use of humorous videos of Scènes de ménage expand the students' understanding of the target culture? The thesis consists of five chapters with the following headings: Introduction, Literature Review, Methods, Results, and Discussion.

This chapter provided a discussion of authentic audiovisual programming and its benefits and potential drawbacks in the foreign language classroom. It demonstrated the benefits of using video as supplemental material in language learning and the implementation of humor in language classrooms. The chapter highlighted the most significant research on the use of videos and humor in language classrooms in order to underscore the motivating factor of using authentic video programming and humor in language teaching. Based on the literature review, I demonstrated how the current study fits into a larger corpus of research on the issues of motivation, the low-anxiety classroom and cultural learning.

In Chapter 2, I provide an historical overview of French and U.S. humor, their similarities and differences. By doing so, I give an argument for how to choose humorous programming that is appropriate for the language classroom and that will meet the needs of learners. Being attuned to the critical differences between French and U.S. humor allows the teacher to choose programming that is sensitive to the students' learning needs and cultural biases and that motivates the learner to continue language study outside of the classroom based on enjoyment of the comedic genre and up-to-date audio-visual programming.

In Chapter 3, I present the current study in more detail, explain the research questions, present the participants, the methods of data collection, the tasks of the participants, and the purpose of this study in the field of research on motivation factors in language classrooms. For the sake of this study, I experimented by implementing humorous videos in my own French language classes. The participation in the study was voluntary and not rewarded, and the students in the two selected classes were all at the same level academically, though they spanned a variety of learning levels, with differences not only between the two classes but inside 
each class as well. In this Chapter, I provide detailed explanations on which videos were used in class, how, and for what purpose.

In Chapter 4, I present the qualitative data collected. The data is based on answers on the pre-study and post study-questionnaires and the students comments added in those surveys. The data is interpreted in terms of motivation, culture conscience, and affective filter. In Chapter 5, I discuss the results and examine their other implications and consequences in language classrooms. In addition, I discuss the limitations of this study and directions for future research on the topic of the implementation of humorous videos in French language classrooms. Finally, I discuss the practical application of the research results and their impact on lesson planning and language teaching. 


\section{Chapter II: What's So Funny? A Comparison of French and U.S. Approaches to Humor}

\section{French Humor}

French humor has been existing for as far as we can find traces of literature. In the Middle-Ages, it concentrated on satires, often accompanied with scatology. It slowly evolved towards farce during Renaissance times (Beam, 2007) However, it is in the seventeenth century that French humor really developed and turned into what it is known for today: it gained the social function of criticizing and denouncing problems in the political, social, and educational systems (Zuroski-Jenkins and Coleman, 2014; Gardes, 2002). Important salons using critical humor, including Molière's, gained popularity and this movement of critical humor expanded to the royal court (Mathieu, 2015). Today, French humor is still considered a form of social criticism. The humorist Eric Judor (from the comic duo "Eric et Ramzy") claims that his inspiration stems from Molière himself. He notes, “L'humour français est historiquement social. Notre base d'écriture, c'est Molière, les pauvres contre les riches ${ }^{6}$ " (Mathieu, 2015). By using this comparison, Judor means that humor in France is a social weapon used to criticize the French system or the French people.

In the mid-seventeenth century, basic humor turned into esprit, bel esprit, or trait d'esprit, and became a weapon close to perciflage, a degraded form of destructive wit, close to mockery and designed to entertain by mocking others. This esprit became the cement of agreeable society in the salon and at court (Zuroski-Jenkins and Coleman, 2014) and was extremely cerebral (Vauth, 2014). The bel esprit was the first important humorous movement in France, and not having that kind of cynical wit was detrimental for the high society members, as depicted in the movie Ridicule (directed by P. Leconte, 1996): “C'est le bel esprit qui ouvre les portes." In the eighteenth century, this type of wit became the weapon of victims of a state of power, and the bel esprit turned into "antiphrastic humor," a dark sort of humor that underlined the hypocrisy of a situation. (Zuroski-Jenkins and Coleman, 2014). A famous example is that of Damiens, who in 1757 had attempted to assassinate King Louis XV and talked about a "tough day ahead" when taken to be tortured and executed by dismemberment (p.

\footnotetext{
${ }^{6}$ French humor is historically social humor. Our foundation for writing humor is Molière, the poor against the rich.
} 
511). Diderot and other Lumières expressed their admiration for this expressive power with which the weak and oppressed could, in their own mind, overpower those who tyrannized them (Zuroski-Jenkins and Coleman, 2014).

French humor evolved again in the nineteenth century with historical events. Indeed, after the French Revolution in 1789, a period of chaos ensued, which included a time of terror, when anybody could be arrested or executed at the will of different leaders. Then, in 1799, Napoleon Bonaparte made a coup in and became first consul of France. He became consul for life in 1802, and later arranged his coronation as emperor in 1804. Napoleon changed the entire French social system. He is remembered today as one of the pillars of the French legal system, given that his government re-organized everything, from the length of the French baguette to the highway code of laws. He was, however, seen as a brutal tyrant by threatened countries, as he expanded the French empire to the biggest size it had ever been. Napoleon's government was starkly criticized by monarchists who wanted the return of the heir to the throne and by various other political opponents. The times were troubled with the succession of government depending on the latest victories of the opponent - Napoleon I was arrested and sent to exile twice, and the French empire was replaced by a monarchy or a republic several times during the course of the nineteenth century. These troubled times inspired new ways for political opponents to protest their leaders. Satires ${ }^{7}$ and caricatures ${ }^{8}$ mocking the leaders' appearance (e.g., the size of the emperor) or mistakes (e.g. Napoleon's failure to invade Russia in 1812 because of a harsh winter) flourished in France and invaded countries (Vauth, 2014). Napoleon I, of course, was one of the favorite targets of both French and English caricaturists. One famous example is the anonymous caricature of Napoleon crossing a river on stilts (see Appendix A). In this caricature, Napoleon has one foot on the French side and the other one near the Moscow palace, and is falling down, losing his golden globe and golden scepter. This caricature is entitled

\footnotetext{
${ }^{7}$ Satire: a way of using humor to show that someone or something is foolish, weak, bad, etc. OR humor that shows the weaknesses or bad qualities of a person, government, society, etc (online Merriam Webster Dictionary)

${ }^{8}$ Caricature: a drawing that makes someone look funny or foolish because some part of the person's appearance is exaggerated OR someone or something that is very exaggerated in a funny or foolish way (online Merriam Webster Dictionary)
} 
“du haut en bas... ou les causes et les effets ${ }^{9}$." This caricature does not include an author's name, in order to protect the creator of the image, for it was strictly forbidden to criticize the emperor.

The caricature movement developed in other countries, especially in England, which was firmly opposed to Napoleon. "A Little Man with a Great Appetite Sitting Down for Dinner: (Appendix B) is an anonymous caricature that represents Napoleon as an insatiable emperor who is about to devour dishes inscribed with the names of the countries he already conquered but who is likewise looking at a giant roast beef titled "England." The image succinctly capture the denunciation of the emperor's greed and his thirst for more territory.

In France, however, the development of political satirical humor suddenly slowed down because of its ban from all newspapers, and could only circulate thanks to lampoons and pamphlets (Dogan, February 2010). It came back to life, however, with the creation of the satirical and anarchist newspaper Le canard enchaîné in 1915. Yet, the Second World War left a France destroyed and French people turned towards a less intellectual humor, an easy-going humor in the form of comedy: situational humor and visual gags were the main entertainment, and actors such as Louis de Funès, Fernandel, or Bourvil became the main attraction. Nevertheless, intellectual and satirical humor survived thanks to great names resolute to denounce in a poetic way the absurdity of this new society which only thrives in entertainment and consumerism. Among those great name were the anarchist song writer George Brassens, or Raymond Queneau, the author of the literary work Zazie dans le metro, written in 1959 (Dogan, February 2010).

At the end of the Algerian War (1962), the tacit truce between journalism and politics, and humorists and politicians came to an end and the main source of humor in France stemmed from political caricatures and cartoons denouncing unemployment, education, immigration, poverty (Dogan, February 2010; Vauth, 2014). In the 1990s, dark humor flourished again through illustrations or caricatures and satires in journals such as Charlie Hebdo (Vauth, 2014; Zuroski-Jenkins and Coleman, 2014). With the focus on multimedia since the 1990s, new forms of humor appeared, One example is the mock news show Les guignols de l'info, a daily short

\footnotetext{
${ }^{9}$ Translation: from the top to the bottom, or the causes and effects
} 
television program which takes the form of a news program presented by puppets representing journalists, stars, or political leaders. This show makes particular use of satirical versions of popular songs (French or other) and puppet forms of a famous performer singing it with new lyrics. For instance, a satire of "We are the World" by Michael Jackson, was sung by a G.W. Bush puppet, a F. Berlusconi puppet, and two others representing evil American capitalists. This satire was untitled "We F*** the World" (Les guignols de l'info, 2001). Creators of the show also made a caricature of Stomae's "Papaoutai" (phonetically translated as "daddy, where are you"), in which a French president F. Hollande puppet sings with his cabinet “emploioutai?" which phonetically translates as “jobs, where are you?” (Les guignols de l'info, September 2013).

This kind of provocative dark humor, which is celebrated by the French, is not appreciated or even tolerated everywhere; it is even considered insulting or discriminatory in some countries. For instance, on January $7^{\text {th }}, 2015$, the magazine Charlie Hebdo published a drawing by the cartoonist Charb entitled "Still no attack in France" (Appendix C) showing an armed Islamist Extremist justifying that "they still had until the end of January to present their wishes for the New Year.”(“Charlie Hebdo,” 2015). An attack on the offices of Charlie Hebdo on January $8^{\text {th }}$ ensued, and eleven were killed (including the satirist Charb). As reported by the online newspaper Le Parisien (2015) on their page dedicated to the events, the responsibility of the attack was claimed by AQPA (Arabian Peninsula Al-Quaïda), which had already threatened the magazine several times, including in 2006 because of the publication of twelve satirical pictures of Muhammad. According to the Islamic religion, it is forbidden to represent Mohammad the prophet, even in places of worship. More recently, a new series of caricatures of a Syrian boy who drowned while attempting to flee Syria and reach Greece with his father, mother, and brother, and washed up on a shore of Turkey on September 3 rd 2015 ("Mes enfants," 2015) shocked not only other countries, such as the United States, but also a lot of French people ("Charlie Hebdo," 2015). Published by Charlie Hebdo on September 2015, the drawing represents the widely publicized photography of the little boy face down on the sand, with the addition of a giant McDonald's billboard announcing "two kid meals for the price of one." This drawing is titled "so close..." (Appendix D). According to Maajid Nawaz, the founder of the think-tank Quilliam, the cartoon is a damning indictment on Europe's anti- 
refugee sentiment, and "the McDonald's image is a searing critique of heartless European consumerism in the face of one of the worst human tragedies of our times" (Harrold, 2015). Yet, many only saw a mockery of the little boy's death instead of seeing a critique of French society. Another picture, even darker, was published in the same issue of the magazine: it was untitled "Proof that Europe is Christian - Christians float, Muslims drown” (Appendix E). This caricature was similarly strongly criticized. Today, Charlie Hebdo’s offices and main staff members are highly protected and have personal bodyguards (Harrold, 2015). It is, however, interesting to point out the irony of the situation when after the January $8^{\text {th }}$ attack, the whole of France was expressing sympathy for the French and stressing the human right of free speech without consequences with the "\#jesuischarlie" movement. Now Charlie Hebdo is considered a "rag" that deserves to disappear and should be forbidden to say such things, as clearly shown in the free comment section of Arnaud (2015).

Today, the dark and ironic type of French humor represented by Charlie Hebdo might be on probation (Dogan, January 2010). Strong criticism has come from the United States and other countries, and television now imposes a new law of political correctness (Mathieu, 2015; Dogan, January 2010). A new generation of comedians in France has become americanized through globalization and calls for a new kind of humor, mainly through stand- up shows, which have become more prevalent in the last decade (Vauth, 2014; Krefting, 2014). This generation asks for a new vision of French humor, less dark and less intellectual (Vauth, 2014). The topics have changed from political topics to everyday life (such as the content offered by humorist Gad Elmaleh). Some artists have gotten into trouble with the law because of jokes that have crossed the new line of the political correctness (Dogan, January 2010).

Humor in France today can be categorized into three types: 1) cynical and critical humor toward society; 2) suburban humor, which is a somewhat politically correct humor, such as Jamel and the Jamel Comedy Club; and 3) situational humor, which mainly presents funny and unbelievable situations (Vauth, 2014). In sum, classic, dark French humor is still alive, though not in the sense of the seventeenth century, and is visible in 
shows such as Les Guignols de l'info or in movies famous for their funny dialogues, such as the Taxi ${ }^{10}$ movies, in which one of the main character is a police commander who is incredibly racist and dumb, or Le prénom ${ }^{11}$, a movie in which a group of friends fights through wit and jibes during a family dinner because one of them has announced that he will call his soon-to-be-born son "Adolph.” While French has become milder and less caustic, it still maintains many of its original characteristics.

\section{Humor in the United States}

French humor wishes to shock and strike minds; by contrast, U.S. humor is designed to make people laugh without offending anyone (with a few exceptions). The audience for each type of humor differs by age and social class, and consumers of humor may move from one type to another depending changes in their life situation. Humor in the United States emerged after the American Revolution as a form of identification and separation from British humor (Limon, 2009; Michelson, 2013). Krefting (2014) says that defining "the 'American' sense of humor" is "mired in the contested terrain of who counts as American and far too many gross generalizations" (p. 9). By saying so, this author underlines the problem of the term "American": Is it an adjective for the continent(s), or does it refer only to the United States of America? In addition, if we consider 'American' humor as the humor of the United States, the adjective is again too broad.

Clearly defining U.S. humor is difficult because U.S. culture is comprised of cultures from all over the world. Limon (2009) explains that U.S. humor comes from "the contretemps between New England Calvinism and secularism, Jewish culture, black culture, and so on.” (p. 307). U.S. humor is thus a complicated composite of several humors mixed together from several generations, thanks to the various origins of Americans and their cultural background. For instance, humor used by African Americans is entirely different from than the one of Italian Americans. It is also what makes U.S. humor so peculiar and unique.

\footnotetext{
${ }^{10}$ Taxi (1998) directed by Gérard Pirès, written and produced by Luc Besson, and Taxi 2 (2000), Taxi 3(2003), Taxi 4 (2007) directed by Gérard Krawczyk, written and produced by Luc Besson.

${ }^{11}$ Le prénom (2011), directed by Mathieu Delaporte and Alexandre de ka Patellière.
} 
There are major categories of humor that can be distinguished in the United States. The first type is Puritan Humor, defined as 'Calvinist Humor' by Michelson (2013) - even though the term is seen as an oxymoron by many, as Calvinists do not appear to tolerate any humor. (Dunne, 2007.) This type of humor is in fact very subtle and family-friendly (Krefting, 2014): it is proper and suitable for children and innocent ears. In his book about Calvinist Humor, Michael Dunne (2007) provides many examples taken from different authors. One example is taken from O'Connor's A Stroke of Good Fortune (1988): “Standing up straight, she was a short woman, shaped nearly like a funeral urn. She had mulberry-colored hair stacked in sausage rolls around her head" (p. 17). The humor resides in the comparisons that are unflattering and peculiar as comparing a head to a funeral urn is highly unusual, as is comparing hair to sausages. The family-friendly character of it, however, is very clear: children can listen to this type of humor and laugh, and nobody, except maybe the girl described, would take offense at the joke. This humor is, however, so proper that for some, such as Limon (2009), Calvinist Humor is not humorous at all.

Krefting (2014) contrasts the nice and proper Puritan Humor to a very less proper one: Shock Humor, the sole intent of which is to shock listeners. For instance, she mentions the comic Michael McDonald who said, "She forgets that her abortion is still alive" (p. 4) out loud next to a woman with a screaming child. One can easily understand how calling a child an abortion can be shocking in the U.S. society- especially when it implies that given the result, she should have chosen the abortion instead of having the child. This type of humor is particularly negative given the opposition to abortion among believers of the Christian faith (70.6\% of the population, according to the PewResearch center ${ }^{12}$ ). According to the numbers gathered by the polling website Gallup (http://www.gallup.com/poll/1576/abortion.aspx), in 2015, 44\% of Americans are pro-life, 19\% believe abortions should be completely illegal, and $51 \%$ think they should be legal only under certain circumstances. As this example demonstrates, Shock Humor aims at sensible chords, and it is so shocking that one can either get very offended, or laugh at the boldness and audacity of the words.

\footnotetext{
${ }^{12}$ Data available on http://www.pewforum.org/religious-landscape-study/
} 
In addition of these two types, Krefting (2014) mentions another type of humor: Charged Humor. This humor is described as a humor which aims at passing a message and fighting against unfairness or discrimination (Saloy, 2001; Pegg, 2007; Limon, 2009). Krefting (2014) is more specific and defines it as a humor that "relies on identification with struggles and issues associated with being a second-class citizen and rallies listeners around some focal point be that cultural, corporeal, or racial/ ethnic similarities." (p.5). Charged Humor is therefore a weapon of the less powerful that help people gather to fight against a common problem. Given its attempt to undermine an authority, this type of humor could be compared to the French satire and caricatures described above. Limon (2009) also noted this similarity and explained that, though the term. Charged Humor was specific to stand-up comics, it already existed under the form of satire from the end of World War II to the late 1960s. Satires were the weapon of the oppressed and powerless against the untouchables, such as the government or powerful people. Krefting (2014) gives the following example, extracted from Louis CK’s special "Hilarious," (2010) filmed live at the Pabst Theater in Milwaukee, Wisconsin:

We have White people problems. That's what we have, White people problems. You know what that is? It's where your life is amazing so you just make shit up to be upset about [laughter]. People in other countries have real problems, like, “Oh shit, they're cutting off all our heads today" [laughter]. We make up shit to be upset about like [in a sullen voice]: "How come I have to choose a language on the ATM machine - this is bullshit” [loud laughter and applause] (Krefting, 2014, p. 26)

According to Krefting's analysis, Louis CK belittles white people's problems by making them sound trivial and rather self-centered: they are first world problems. It aims at urging viewers to situate their problems within a larger social context in order to be happy with what they have.

Charged Humor focuses on pointing out the disparities between privileged and non-privileged groups in the United States. The audience may have varied reactions to this humor based on their social status and their vision of society. Charged Humor is present throughout the United States, but it is not always appreciated 
because it is too similar to political incorrectness given its blatant identification of discrimination. According to Krefting (2014), the distaste for this type of humor is the reason why today's market favors male humor over that of women who tend to use Charged Humor a lot more than men. Charged Humor enacts social criticism and for some, this criticism is a victimization or a strike too close to home. Because of this, only a few women succeed in the humor industry when men tend to have long-term success. Unfortunately, this result prompts the popular misconception that men are funnier than women, as it was debated in Vanity Fair (January 2007), in an article written by $\mathrm{C}$. Hitchens.

A final type of humor in the United States is Black Humor. Originally, Black Humor rose in the dangerous racial climate of slavery and discrimination and the idea was to laugh so they wouldn't have to cry (Saloy, 2001). Black Humor takes on different forms: parody, animal tales, proverbs, urban narrative, but it is most of all an oral tradition. The Dozens is the most used form of verbal black humor: it is an insult game, used in the past to toughen hearts to the abuse of society (Saloy, 2001). Chimezie (1976) presents the game as a descendent of a Nigerian game called Ikocha Nkocha, whose name could be translated as "making disparaging remarks." Interestingly enough, this insult game used to be common in Scottish medieval society, and was called 'Flyting' (Byock, 1983). Abrahams (1962) presents examples of this kind of game in his article "Playing the Dozens":

Participant 1: "I hear your mother plays third base for the Phillies."

Participant 2: "Your mother is a bricklayer and stronger than your father."

Participant 1: "Your mother eats shit."

Participant 2: "Your mother eats shit and mustard." (Byock, 1983, p. 210)

This type of humor is usually sexist, denigrating, stereotypical, self-mocking, and even boastful, and is very popular nowadays on the internet under the form of "Yo Mama" jokes. 
Humor in the United States is still evolving today. Stand-up comedies are becoming more and more popular and exist in many variations and styles, which include talk shows like Late Show with David Letterman (CBS, 1993 to 2015) or the Ellen DeGeneres Show (NBC, 2003 to present) (Krefting, 2014). Those one-man shows have given a rise to Black Humor thanks to great comics such as Bill Cosby, Eddy Murphy, or Whoopi Goldberg, and Black Humor is very present in popular commercial culture through networks such as Comedy Central and BET (Saloy, 2001). However, U.S. humor is turning very virulent (Lemon, 2009) and is losing its reputation of Puritanism as the popularity of shock humor has risen.

\section{Ambiguous Reactions to French Humor in the United States}

As demonstrated previously, humors are different according to the country it originated from. Mark Twain himself addressed the problem in his work How to Tell a Story:

The humorous story is American, the comic story is English, the witty story is French. The humorous story depends for its effect upon the manner of the telling; the comic story and the witty story upon the matter. (Twain, 1897, p. 4)

This quote not only underlines that the types of humor vary according to the country; but also that U.S. humor, called humorous, is fundamentally different from the English or French humor. Therefore, the humor of one country might not be well received in another country, as some previous examples already demonstrated.

According to the School of Advertisement (Paris, France), exporting humor is difficult, especially when French humor is being exported to the United States (Vauth, 2014). This point can easily be proved by the successful exportation of some movies. For instance, two French comedies have been highly successful in the French box office recently: Intouchables (directed by Nakache \& Toledano, 2012) and Qu'est ce qu'on a fait au bon Dieu? (directed by De Chauveron, 2014). The first was praised for realistically depicting French society (Mathieu, 2015; Berreby, 2012; Deimling 2012; Lauter, 2012); however, in the United States, it was criticized for being racist - The Los Angeles Times reported that The Variety critic Jay Weissberg wrote that the film "flings about the kind of Uncle Tom racism one hopes has permanently exited American screens." (Lauter, 
2012). He also complained that the main character who is black "is treated as nothing but a performing monkey (with all the racist associations of such a term)" (Lauter, 2012). The second film was simply refused for exportation because it was "racist," and "not really funny" (Mathieu, 2015). These examples show that French humor is not only different from humor in the U.S., but that is also not fully accepted or understood, and it also touches on societal hot points in the United States that are different than those in France.

Some other comedies, of course are more widely accepted, but only if the U.S. is allowed to create its own version- and can thusly correct any details that would not be accepted. Two easy examples would be the classic comedy Un Indien dans la ville (directed by H. Palud in 1994), which tells the story of a man who goes to Amazonia to find his wife and make her sign divorce papers in order to remarry, but then discovers that she has had his kid who was brought up in the traditional indigenous way and ends up having to bring the said son to Paris and deal with his cultural adaptation, and Les Visiteurs (directed by JM. Poiré in 1993), which tells the tale of a feudal lord and his squire who find themselves sent in the future by mistake, when they were trying to go back in the past in order to stop themselves from accidentally murdering the lord's fiancée's father. Those two movies were remade later in a French-American collaboration, in order to be adapted to the U.S. public. Therefore, Jungle 2 Jungle was directed by J. Pasquin in 1997 and tells the story of a father who has to bring his Amazonian son to New York. When the humor of the original movie was more based on the language (puns, punch lines, and bad language) and the situation, the humor of the second version rests more upon the exaggerated performance of the actors than the language, which is more polite. The Visitors in America was directed by JM. Poiré in 2001 and retells the exact same story as its French version, with the exception that everything takes place in Chicago and the language is nicer (less bad words), there is no offensive stereotypes, and no attack on the black postman, calling out "a Saracen!" It is interesting to note that those two movies were not very successful, neither in France nor in the U.S., when the original French versions were both a hit according to the website Allociné (French IMDB), both scoring rewards.

According to a market analysis done by the School of Advertisement, U.S. Americans value French culture for its gastronomy and its fashion, but they consider French people snobs, cranky, rude, and always 
complaining (Vauth, 2014). This is explained by the difference of origins of the French and U.S. humor: U.S. humor was born from a melting pot of different European humors and is mainly composed of exaggerations and Jewish humor like that of Woody Allen or Jerry Seinfeld (Heitman, 2002). French humor, by contrast, was created in salons of the $17^{\text {th }}$ century and always possessed a critical function from the beginning (ZuroskiJenkins and Coleman, 2014). French humor is satirical; it unveils the truth and condemns (Gardes, 2002). Furthermore, U.S. Americans have a rather strict policy of political correctness, and therefore, if one wants to be culturally sensitive, one avoids jokes about women, homosexuals, ethnicity, disabilities, etc. (Heitman, 2002). In order to avoid offending others, U.S. Americans often feel the need to add "just kidding" after making a humorous comment (Vauth, 2014; Pegg, 2007). French humor, on the other hand, tolerates humor against women, disabilities etc. in certain situations (Cantorovitch, 2002). Although the country's culture is considered to be the creator of the famous behaving rules (French etiquette) since Versailles (Heitman, 2002), and has the desire of making people laugh, it is usually done at the expense of someone else (Heitman, 2002). This kind of humor is considered offensive in America, as it is too close to sarcasm to be appreciated (Vauth, 2014). French people promote the idea of being able to laugh about everything without taking offense as long as the humor is not used to hurt or discriminate. The difference between the U.S. and French understanding of humor is that U.S.-Americans focus on what is said whereas the French focus on the intention behind the words and context of the joke. The understanding of humor is thusly anchored in cultural habits.

Today there are similar points between French and U.S. humor, certainly because of globalization and the export of humorous products from one country to another. While the United States had a strong tendency of thriving off political correctness - with the notable exception of 'Black Humor' -more recently it has opened itself to 'Shock Humor'. 'Shock Humor' is a dark type of humor that borders the cynicism that French people enjoy so much. France is likewise moving toward political correctness and is discovering and enjoying U.S. stand-up comedies and one-man shows presenting less intellectual, situational humor. Furthermore, today in the U.S. the problem of avoiding irony so as not to offend has been bypassed by television shows such as The 
Simpsons $^{13}$ and South Park ${ }^{14}$, which openly criticize today's U.S. society through intensive use of dark humor, satire and irony in an animation sitcom (Pegg, 2007). Both those series presents fictional humanoid characters as their heroes in a fictional society which happens to have similar problems as today's U.S. society but also represents and names several real life people (often dubbed by the real person) to whom no mercy is given. For instance, in Season 14 Episode 13 of South Park, 'Coon vs Coon and Friends', Justin Bieber is very graphically squished by a giant Cthulhu; or in Season 10, Episode 3 'Cartoon Wars Part 1,' terrorists send a video to the United States featuring president George Bush, Jesus and U.S. citizens defecating on each other (Southpark.wikia.com). And yet, both those shows have been airing for ages - The Simpsons has had 507.8k viewers (https://www.simpsonsworld.com/) for its latest season (season 23), and South Park is celebrating the beginning of its $19^{\text {th }}$ season.

While French humor may have started as something entirely different from U.S. humor, today the difference is becoming less noticeable. Despite the fact that some major humoristic French works are being rejected in part in the United States, there will always be a U.S. audience that will appreciate this type of humor. Considering again Intouchables, it is clear that although there were many comments on the racist nature of the movie, many U.S.-Americans still appreciate the movie.

The same analysis can be made about France, where U.S. humor is rejected for being too simplistic and yet it is implementing itself through French comedies, live comic shows or on television. The solution to the apparent discrepancy between the audience and the type of humor can be bridged by choosing comic material that fits the socio-cultural background of the audience. In order to do so, one must study the future audience and then decide what type of humor would be accepted and what type of humor would be rejected because it would be considered as offensive or not good enough. However, the bigger the audience, the harder it is to satisfy

\footnotetext{
${ }^{13}$ The Simpsons, created by Matt Groening in 1989, originally broadcasted by Fox.

${ }^{14}$ South Park, created by Trey Parker and Matt Stone in 1997, broadcasted on Comedy Central.
} 
everyone; as we live in a heterogeneous society, it must be taken into account that there will always be one to not appreciate the humor that was so carefully selected in hope of pleasing everyone. 


\section{Chapter III: Methodology}

The purpose of the study was to determine the effect that the use of humorous authentic video programming has on the learning of intermediate learners of French. This is an ideal medium to teach about culture because it is both interesting and motivating to students, as detailed in the Introduction of this study. The chosen series, Scènes de ménage, has eight main characters divided into four couples at different stages of their relationships: one couple is in a live-in partnership, another one is married with a baby, the other is married with one child who has moved out, and the oldest couple is married and retired. All characters have extreme personalities, from the over-stressed mother to the mean old man whose only pleasure in life is to annoy other people. They all play tricks on their partners, argue, or end up fighting for very trivial but life-like reasons. This comedy is a critique of the couples' lives and their everyday quarrels, and as such, is authentic, recent, and culturally-relevant, based on the French origins of the genre.

Given the content of the shortcom, the aim of this thesis was to study the effect of the shortcom on learner 1) enjoyment, then translated in terms of motivation, 2) self-confidence, in order to draw conclusions on their affective filter, and 3) socio-cultural competence in the form of culture on one hand, and specifically humor on the other, through the implementation of episodes of Scènes de ménage in an intermediate level French. The study is shaped by the following research questions:

1. Did the use of humorous videos of Scènes de ménage improve the students' motivation for the class and regarding the four basic skills of language learning?

2. Did the use of humorous videos of Scènes de ménage improve the students'self-confidence, therefore lowering their affective filter?

3. Did the use of humorous videos of Scènes de ménage expand the students' understanding of the target culture? 
The research explores students' opinion of the use of humor in class in order to seek to understand students' motivation and behavior in French class. All participants were subjected to two conditions - lessons with the experimental factor and lessons without the experimental factors - and were asked to comment on their experience. The study encompassed a non-equivalent design, with a pre-test and a post-test survey distributed to one set of participants.

\section{Setting and Participants}

The sample consisted of forty students in two university intermediate French classes (French 203) in a large state institution in the United States. This sample was selected through convenience sampling, as the participants were chosen because they were in the two classes of the investigator of the study. A quick traditional survey at the beginning of the course helped gather information on the participants. They were sixteen males and twenty-four females, and included native speakers of English (39) and one speaker of Swedish who was part of an exchange program. The group consisted of young adult students, all over 18 years of age. All of the students were undergraduates in the institution, ranging from freshmen to seniors. The students were placed in 203 level because they had already passed the 101 and 102 levels at the same institution or in another, or had a language level sufficient to enter the level by taking the institution's online placement test. They had various previous experiences in French - different teachers and different methods used in class previously. Some might have started to learn French in secondary schools, when others started at university.

The students' participation was on a voluntary basis; no extra credit nor any kind of reward or remuneration were involved. Their anonymity was kept during the whole experiment, as well as during the data analysis, thanks of the use of playing cards randomly distributed instead of names. As the participants were made aware of so and were asked to therefore answer as truthfully as possible, the data collected should be unbiased. 


\section{Instrumentation}

The instruments in this study consisted of two questionnaires and the grades of the students. On the first day of the course, the students completed a pre-study survey (Appendix F) regarding their perceptions on their motivation, their confidence, their opinion about culture and humor in a language class, their previous experience with French television programming in or out of a classroom setting, as well as their prior experience with French and French learning. After completing the final unit, participants were given a poststudy survey (Appendix G) that sought to measure the evolution of the participants' motivation through a rating of their level of enjoyment, their confidence, and their understanding of French culture and humor, with a special comment section in which they elaborated on their ratings and provided any further insight on their experience with French humor. The post-study questionnaire was divided into sections. The first section surveyed students about how the use of the shortcom affected their motivation for learning French in three of the four language skills. Reading was excluded because when study was designed, the investigator did not intend on introducing reading texts that directly dealt with the video programming. Ultimately, however, the use of subtitles with the videos had an influence on students' affective filter with regard to reading. The second section of the post-study survey examined the effect of the use of the shortcom on students' affective filter in all four language skills.

These surveys were designed to answer the three research questions: 1) Did the use of humorous videos of Scènes de ménage improve the students' motivation for the class and regarding the four basic skills of language learning? 2) Did the use of humorous videos of Scènes de ménage improve the students' selfconfidence, therefore lowering their affective filter? 3) Did the use of humorous videos of Scènes de ménage expand the students' understanding of the target culture?

Finally, the students' grades throughout the semester were analyzed to study the progression of their results. Those grades include grades from journals, homework, participation, and quizzes, and are divided by chapter. 


\section{Procedures}

\section{General Conditions of the Experiment}

Data collection took place during the Fall 2015 semester. The participants completed the pre-study survey regarding their perception of their motivation, confidence, and opinion about culture and humor in a language class, their previous experience with French television programming in or out of a classroom setting, as well as their prior experience with French and French learning. During the course of the semester, the students were instructed in alternative chapters: two and a half chapters were instructed without the use of the French shortcom Scènes de ménage, and two and a half chapters were instructed with the support of those videos. The chapters without the video programming serve as the control, whereas the chapters with videos were the experimental chapters. After completing the last chapter, participants were given the post-study survey, which aimed at measuring the evolution of their motivation, confidence, and understanding of French culture and humor and included a special comment section in which they could elaborate on their ratings and provide any further insight on their experience with the videos used in class.

The first chapter of instruction was based on Chapter 10 of Liaisons and focused on relationships between people; students learned how to express their feelings, and discussed lifestyles, relationships, and personal characteristics. This chapter was taught without videos, and was divided in six lessons completed over six days. The vocabulary themes were personal characteristics, personal relationships, and personal expression; the grammar points were the arbitrary pronominal verbs, the mutual pronominal verbs, and the pronominal verbs in the past. In order, the lessons were themed on: (1) Lifestyles, (2) Friendship, (3) Love Relationships, (4) Great Past Love Stories, (5) Modern Communication Means, and (6) Communication With Others. This chapter also included one journal assignment and concluded with a scenario activity, in which students practice their speaking skills in group discussions based on the chapter's topics.

The second chapter of instruction was based on Chapter 11 of Liaisons and focused on active life; students learned to talk about transportation, traveling, and clothing. This chapter was taught with the support of 
six short videos of Scènes de Ménage (video 1 to 6 in Table 1) that corresponded with the themes of the chapter and was taught in six days. The vocabulary themes were means of transportation, holidays and vacations, and clothing. The grammar points included the future, relative pronouns 'qui', 'que', 'dont' and 'où,' and indefinite adjectives and pronouns. I chose to present my first trip to the U.S. as a common thread for the four lessons. The order of the lessons were shaped thematically in terms of the preparation for the trip, the planning of the trip (what was supposed to happen), the problems one can encounter during a trip (what really happened), clothes, and fashion week in Paris. This chapter also included one journal assignment and one reading.

The third chapter of instruction was based on Chapter 9 of Liaisons (displaced on purpose due to its easy content) and focused on Arts and Media. Students learned how to talk about possibilities, expectations, and hypothetical situations, and discussed varied forms of art. This chapter was taught without videos and was divided in five lessons completed over five days. The vocabulary themes were visual arts, literature and shows, and television and cinema; the grammar points were the conditional, the conditional in hypothetic and other sentences, and demonstrative pronouns. In order, the lessons were: (1) Art and Museums in Paris, (3) Versailles, (4) Music and Literature in Versailles, (5) T.V. and Cinema, and (6) Everyone's Favorite T.V. Programming. This chapter also included one journal assignment, one reading, and one scenario activity in which students practiced their speaking skills in group discussions based on the chapter's topics. The chapter concluded with the midterm exam, in which students practiced their comprehensive, presentational, and interpersonal skills on a theme related to fashion and inventions.

The fourth chapter of instruction was based on Chapter 12 of Liaisons and focused on health. Students discussed health and hygiene, compared animals and humans, and learned expressions of volition, necessity, and emotions. This chapter was taught with the support of four short videos of Scènes de Ménage (video 7 to 10 in Table 1) that corresponded with the themes of the chapter, and one song video on body parts, and was taught with six lessons over six days. This chapter was interrupted by a lesson focusing on Halloween, as October $31^{\text {st }}$ occurred during the chapter. The vocabulary themes were (1) Personal Hygiene, (2) All The Creatures, and (3) Staying Fit; the grammar points were the reflective pronominal verbs, regular verbs in the subjunctive, and 
irregular verbs in the subjunctive. I chose to re-arrange the order of the small units, and therefore, in order, the lessons were based on the following themes: animals, the human body, daily routine, diseases and health troubles, health instructions, and the health situation in France. This chapter also included one journal assignment, one reading, and one in-class essay (draft), preceded by an in-class essay workshop.

The fifth chapter of instruction was based on the Final chapter of Liaisons which focused on the theme of "Innovations" and only had two sub-sections: one focused on technology, and the other one on the environment. In this final chapter, the students discussed science, technology, and medical inventions, debated about environmental and social problems and leant expressions of opinion and doubt. I chose to treat those two different parts as two small chapters, and in order to balance the amount of chapters with and without videos, I decided to use the support of videos for one of these parts. The technology section of the Final chapter was taught in two lessons without the support of videos. The vocabulary theme was technology and the grammar point was expressing an opinion using the subjunctive. In order, the lessons were based on the themes (1) Modern Technology and (2) Great Inventions in France and in the World. This section also included one journal assignment, and concluded on a scenario activity in which students practice their speaking skills in group discussions based on the chapter's topic. The environment section of the Final chapter was taught with the support of two short videos of Scènes de Ménage (video 11 and 12 in Table 1) that corresponded with the themes of the chapter and one song video about the environment, and was taught with two lessons over two days. The vocabulary theme was environment and society and the grammar point was about differencing the subjunctive and the indicative moods. In order, the lessons were themed on (1) The Environmental and Social Problems and on (2) Finding Solutions. This section also included the final version of the essay, and concluded with the final exam, in which students practiced their comprehensive, presentational, and interpersonal skills on a theme related to traveling and eco-tourism. 


\section{Experimental and Control Chapters}

The first four chapters included three smaller units, each containing a vocabulary lesson and a grammar lesson, and the fifth chapter included two smaller units with one vocabulary lesson and one grammar lesson. The lesson plans for both the control chapters and the experimental ones were constructed from the content of the chapters 9, 10, 11, 12, and Final chapter from the class textbook Liaisons: An Introduction to French (2013), but most activities were self-made or constructed from materials created or assembled by the instructor and other colleagues and used with their permission. These activities varied between group work individual work and traditional and game activities: puzzles, surveys, questions to answer, pair and share activities, interviews, mimes, etc.

All lesson plans adhered to the curriculum and syllabus requirements of the class as defined by the supervisor of the program; they all involved a slideshow presenting vocabulary or a grammar point, and a worksheet with the activities of the day was given to the students to be completed. The classes were taught using a communicative approach, which demanded a great degree of spoken oral communication activities, and emphasized the implicit instruction of grammar points. Each lesson contained an oral activity, interactional activities, oral activities or written activities corrected orally that increased in difficulty, and concluded with a final presentational activity, in which students had to write a few lines related to the topic of the day, using the vocabulary and/or grammar point that had been practiced previously. Prior to each lesson, students were required to complete online homework on a platform that uses the activities of the Liaisons book and workbook.

Students were first given the pre-study survey, and the course started with the instruction of the five chapters described above. Each chapter contained quizzes, homework, and journals. The semester also included, in a varied order, three scenarios activities, a mid-term and final exams in the IPA style, one essay, , and three readings, all of which were not included into the study. At the conclusion of the course, the students were given the post study survey. 


\section{The Shortcom Used in the Experimental Chapters}

The videos used in the experimental chapters were all short clips (2 to 3 minutes) from Scènes de ménage. A careful selection was made to eliminate the clips that might not be appealing to students, yet care was taken to not eliminate completely the special features of French humor. Because of cultural differences, it was important for the motivational factor that the students accepted the humor of the target culture, and therefore enjoyed it (Porcher, 2002). Therefore, special attention was given to the properness of the video clips during the selection. The videos were presented upon selection to other GTA colleagues to get a general consensus in terms of content. One video presenting an inappropriate relationship between a brother and a sister ${ }^{15}$ was approved by French teaching colleagues but rejected by other language teaching colleagues; the video was however kept in the experiment as it clearly defined a line crossed in cultural humor (video 12 in Table 1).

This selection also helped choosing episodes that were relevant to the themes addressed in the classroom, as humor seems to only be fully efficient when relevant to what needs to be remembered (Yin Piaw, 2014). The videos were chosen according to the vocabulary themes of the unit rather than the grammar points, due to the methods used in class which demands that lessons be connected to one another through a common theme. As the themes of the chapters are based on the vocabulary topics, it was impossible to find clips that answered the grammatical points studied as well as the theme of the chapter. Therefore, the videos were used to practice vocabulary, listening and speaking skills. When possible, the grammatical objectives were included in the treatment of the video, but the grammatical point were not represented in the video.

The video clips were shown several times, sometimes passage by passage, sometimes the whole content all at once, depending on the length of the clip and the activities following it. Each showing was accompanied by an activity that addressed a particular communicative objective. Subtitles were created thanks to the program

\footnotetext{
${ }^{15}$ In one episode of the series, the brother is staying over the young couple for a while because he broke up with his girlfriend. However, he behaves very inappropriately with his sister. In the selected extract, the boyfriend gets up in the morning and discovers that the brother and the sister are taking a shower together to "save hot water", as if it was the most natural thing in the world.
} 
Aegisub, and added to the video clips, sometimes immediately and sometimes after one viewing, depending on the type of activities done in supplement of the video. The addition of subtitles aimed at improving vocabulary retention, as a study by Jones (2004) proved that learners of a foreign or second language were more likely to retain new vocabulary if they see a written form of the word in addition of hearing it. 
Table 1

\begin{tabular}{|c|c|c|c|}
\hline \multirow[t]{2}{*}{ VIDEO } & \multirow[t]{2}{*}{ SEASON } & \multicolumn{2}{|c|}{ SUM UP } \\
\hline & & ACTIVITIES & OBJECTIVES \\
\hline \multirow[t]{2}{*}{1} & \multirow[t]{2}{*}{4} & \multicolumn{2}{|c|}{$\begin{array}{l}\text { Emma and Fabien are driving, and Fabien makes a little speech on how cars are a source of freedom and how you can do whatever you } \\
\text { wish. Turns out, they are simply lost, and Emma turns on the GPS. }\end{array}$} \\
\hline & & $\begin{array}{l}\text { 1) Discussion: what means of transportation do you use? Talk } \\
\text { about public transportations in the city; which ones exist, which } \\
\text { one they use, do they like it? } \\
\text { 2) Video - comprehension questions: what is the relationship } \\
\text { between the two characters? How do you know? } \\
\text { 3) What is Fabien's problem? Il a } \\
\text { 4) in groups: Explain in your own words what it means } \\
\text { 5) Do you have a "public transportation face"? What is it? Why? }\end{array}$ & $\begin{array}{l}\text { - Practice the means of transportation vocabulary } \\
\text { - Justify your interpretation with clues from the video } \\
\text { - Find exact quotation in an audio-visual document } \\
\text { - Find specific elements in an audio-visual document } \\
\text { Projection from the video to the students' own lives }\end{array}$ \\
\hline \multirow[t]{2}{*}{2} & \multirow[t]{2}{*}{4} & \multicolumn{2}{|c|}{$\begin{array}{l}\text { Fabien comes home and ignores Emma who is asking him questions, standing in a corner and not moving, a frown on his face. Emma } \\
\text { comments that he is in his "public transport mode" and wakes him up. Fabien turns back to his usual cheerful self. }\end{array}$} \\
\hline & & $\begin{array}{l}\text { 1) Discussion: who owns a car? Who uses it to go to school? What } \\
\text { else do you use it for? (mention of traveling) } \\
\text { 2) Picture of the scene: what do you see? Do they look happy? } \\
\text { Where are they going? } \\
\text { 2) Video - comprehension questions: what is the gist of this video? } \\
\text { 3) List the advantages of the car according to Fabien } \\
\text { 4) Is Emma agreeing with him? How do you know? And you? } \\
\text { Give another advantage for the car, in your own opinion. } \\
\text { 5) group activity on pro/con of different means of transportation }\end{array}$ & $\begin{array}{l}\text { - Practice the means of transportation vocabulary } \\
\text { - Justify your interpretation with clues from the video } \\
\text { - Understand the gist of an audio-visual document by making } \\
\text { conjunctures using the visual and oral clues } \\
\text { - Find specific elements in an audio-visual document } \\
\text { Projection from the video to the students' own lives }\end{array}$ \\
\hline
\end{tabular}


Emma and Fabien are driving and discuss the games they used to play in the car during family trips. Fabian mentions playing bingo with car plates, and Emma makes him sick describing how they tried to guess the names of the dead animals on the road.

1) Comprehension questions: what are they talking about; why are they talking about it (what started the conversation)?

2) Table to complete on the two "games" presented: form of the game, aim of the game, how to win, and what is the difficulty of it. 3) Discussion question: where you will go away during the Fall break, will you play games during the trip? What game will you play?
- Practice the lexical field of the road (car, roads, road signs, license plates...)

- Practice the future tense (writing form + oral answer)

- Discuss the car identification system in France (special plates with region numbers)

- Understand the gist of an audio-visual document by making conjunctures using the visual and oral clues

- Find specific elements in an audio-visual document

- Projection from the video to the students' own lives

Huguette and Raymond are driving at night, on the way to their vacation spot. Raymond comments that he always feels like he has forgotten something, and Huguette reassures him that she took the mini T.V. and put it in the trailer. Both suddenly turn and realize that they forgot the trailer... or lost it somewhere on the way.

1) Discussion with the students on problems they've met during travels after a presentation of the problems the teacher had when traveling to the U.S. for the first time -> mentioning the worry of forgetting things

2) Comprehension questions: what is Raymond looking for? Why? 3) Fill in the blank: Where is the trailer? Raymond says that they are two possibilities: the trailer is either or

4) In pairs: choose one of this possibilities and hypothesize what Raymond and Huguette will do.
- Discuss students' previous experiences in traveling - the problems they met

- Practice the traveling vocabulary (plane, hotel, road trip...)

- Look for specific elements in an audio-visual document

- Find exact quotation in an audio-visual document

- Elaborate and hypothesize on the content of an audio-visual document

- Practice the if...+ future structure

- Review the future tense 
Raymond is singing in the kitchen, dressed up as an English gentleman. Huguette asks why he is dressed so and Raymond confesses that it was to go with the cane the doctors gave him to help his arthritis. Huguette is denied the opportunity to accompany him because she is not dressed well, so she leaves to change her clothes. She comes back dressed up like the Queen of England to a baffled Raymond, and they both leave while talking with very exaggerated British accents.

1) Two comprehension questions: why is Raymond dressed like this? Why does Huguette change her clothes?

2) class work on describing the clothes worn by the characters

3) class discussion on French vision of "the British style"
- Practice clothing and color vocabulary

- Find information to hypothesize on events presented in an audio-visual document

- Discuss French and British culture and compare with American culture

- Find specific elements in an audio-visual document

5 Marion comes in dressed as Madonna and does a little dance. Cédric enters dancing, very proud of his costume choice: Michael Jackson. But his glove gets stuck into his zipper during a dance move and they cannot get it unstuck. They start fighting because they are running late, and Cédric ends up going to the costume party with the glove stuck, and his hand in it in front of his crotch.

1) Marion's dance - oral debate on who she is dress as and why she is dressed up so. Oral description of her attire.

2) Cédric enters - who is he dressed as? Description of the costume.

3) Rest of the video - comprehension questions: what happens?

What is the solution?

4) Discussion: if it happened to you, what would you do?
- Review clothing vocabulary

- Practice the construction with relative pronouns

- Find information to hypothesize on events presented in an audio-visual document

- Use the pictures and aural clues to understand what happened

- Review of "if ... + future" structure

- Projection from the video to the students'own lives 
Liliane and José are eating breakfast in their kitchen, when José suddenly suggests they adopt a dog because of the postal calendar which has a picture of a puppy. José explains that it is a lot of responsibilities, at least as much as a child. Liliane agrees, and then suggest they have another child, then. José cuts her short saying they will adopt a dog, and an ecstatic Liliane stars baby-talking to the puppy on the calendar while José looks desperate.

1) Picture of the first scene - discussion: what are they doing, what time of the day is it, what do you see on the table, what are they eating?

2) Conjecture in pairs: what "fight" could break out?

3) First part - what is Liliane's suggestion? What is José's objection? Find the three examples mentioned. In pairs, find some other responsibility for an animal.

4) Second part - why is José accepting in the end?

5) What animal would you adopt if you could? Why? (conclusion of the lesson)
- Introduction of the conditional

- Practice of the animal names and vocabulary (tail, etc.)

- Discuss French breakfasts

- Discuss the postal calendar traditions

- Use context clues to hypothesize on events presented in an audio-visual document

- Look for specific elements in an audio-visual document

- Find exact quotation in an audio-visual document

- Conclude the lesson on a personal presentation

- Projection from the video to the students'own lives

3 Liliane is in the bathroom, opens the trash, and see that her volumizing shampoo bottle is in it, empty. She calls José to ask if he used it all, and José comes in with super volumized hair. Liliane looks traumatized, and José simply admits his deed, apologizes, and leaves, without even noticing his hair.

1) Comprehension questions: where does Liliane find the shampoo bottle? What is the problem?

2) Conjecture: this shampoo is special, and this unauthorized use will have consequences...which ones?

3) What exact words does José use to admit his deed?

4) What was the shampoo's effect?

5) Create a definition: "shampooing volumateur"

6) Group work: like in the movie Amelie Poulain, find an idea of a nasty prank you could do to your roommates by replacing a product with another and describe the consequences
- Practice body parts

- Review conditional

- Use context clues to hypothesize events presented in an audiovisual document

- Find specific elements in an audio-visual document

- Find exact quotation in an audio-visual document

- Practice the definition activity: instead of asking for the English word, students have to describe in French the object or action they cannot name

- Projection from the video to the students'own lives 
Liliane and José are in the bathroom. Liliane finishes drying her hair and runs out of the bathroom because she is late. José picks up the hair-dryer and starts playing with it - first as if it is a gun, then as if it is a megaphone, and finally starts blowing the air inside his mouth. Liliane comes back in a hurry because she forgot her powder; she opens the powder case and José, who had stopped playing, turns on the dryer by mistake and the powder flies everywhere and covers Liliane's jacket. José runs outside the bathroom and Liliane yells threats.

\section{-no subtitles-}

1) What are Liliane and José doing at the beginning of the video?

2) What three "games" is José playing once Liliane is gone? Pair work: what other similar "games" can you name?

3) Liliane comes back - why?

4) What exact word does Liliane use to threaten José?

5) Did you have similar routine problems with a roommate? What other routine problems did you experience?

3 Raymond and Huguette are sitting in the couch - Huguette has a defibrillator in her hands, and Raymond's hair is dressed up on his head. Huguette explains that she thought he was dead because he wasn't snoring while sleeping. She then say that she will put away the defibrillator - which they now know works-and will then help him find his teeth. Raymond puts a finger in his mouth and realizes that he is missing a few fake teeth.

1) Group work before the video - choose a health problem old people tend to have, look up the word in French, then give a definition to the class.

2) Picture of Raymond with his crazy hair - conjecture: what could have happened to him?

3) Picture of Huguette with the defibrillator - what is she holding? SO, what might have happened, then?

4) Video - why did Huguette use the defibrillator? What did Raymond loose In the shock? Where?

5) Find two precise French expressions ('t'es malade?'and 'je rêve!') and find an English equivalent
- Practice the routine vocabulary

- Practice the reflective pronominal verbs

- Find information to hypothesize on events in an audio-visual document

- Find exact quotation in an audio-visual document

- Find specific elements in an audio-visual document

- Projection from the video to the students'own lives

- Practice creating definitions

- Practice of health and disease vocabulary

- Review body parts

- Find information to hypothesize on events in an audio-visual document

- Correct hypothesis when receiving new information

- Find specific elements in an audio-visual document

- Find exact quotation in an audio-visual document 
Fabien is singing while doing the dishes when Emma enters with a case full of fruits. Fabien notices that the apples and other fruits in there are half rotten or very badly bruised, and Emma makes a speech on how it was her duty to buy those because nobody would buy them and they would be thrown away, which is wasteful. Fabien then asked what the fruit he is holding is - small, long, dark, - and Emma answers that it is a pear, obviously. Or maybe an avocado.

1) Class discussion: how do you pick your food in supermarkets?

Do you buy organic or environmentally-friendly products? Which ones? Do you waste food?

2) Vocabulary work on pictures: what is it? (model, apple, pear, avocado)

3) Comprehension questions: what did Emma buy?

4) Fill in the blank: Fabien is flabbergasted because....

5) What is Emma's justification?

6) Discussion and fill in the blank - I think/ don't think that this solution.... Because....

7) Discussion: French law of Mai 2015 on food waste in supermarkets

8) Group work: what solutions exist or can you offer for the US?
- Practice the subjunctive tense with emotion

- Practice subjunctive vs. indicative moods

- Review fruit vocabulary

- Practice environment vocabulary

- Find specific elements in an audio-visual document

- Discuss the Mai 2015 French law

- Projection from the video to the students'own lives

- Discuss an environmental issue night, and Cédric asks when he left. The brother passes his head through the shower curtain and says that he still is here. Cédric yells, asks what they are doing, strongly objecting to what he sees, and Marion explains that it is so that to save hot water, so that Cédric can have hot water later. The scene goes on with the brother and sister making inappropriate remarks and Cédric looks more and more shocked, until he ends up running out of the bathroom why we hear Marion and her brother giggling.

1) Vocabulary: guess the meaning words using their root

2) Reflection: saving water is important, why? Do you do anything to save water? And your family? How? What other ways are there? 3) Comprehension questions: what are they talking about at the beginning? What does Cédric ask, what does Marion answer?

4) Fill in the blank: Cédric is horrified that Marion.....

5) Comprehension questions: what is Marion's justification of her act? What remarks of the brother worsen the situation?

6) Discussion: is Marion's idea good? Why? What other solution could you offer to save hot water?
- Practice conjecture on word meanings

- Discuss an environmental issue

- Practice the subjunctive tense with emotion

- Practice subjunctive vs. indicative moods

- Review fruits vocabulary

- Practice environment vocabulary

- Find specific elements in an audio-visual document

- Find exact quotation in an audio-visual document Projection from the video to the students' own lives 


\section{Data Processing and Analysis}

The results from the data collection were analyzed quantitatively based on students' survey responses in the following categories: perceived motivation, self-confidence, and perceived comprehension of French culture and humor. The students' pre-study and post-study surveys were paired thanks to a playing card number they were given and analyzed to determine the participants' perceived efficacy of the use of the humorous videos in class based on the three research questions. The data were analyzed using the software Qualtrics ${ }^{16}$. Teacher notes and student grades in participation, homework, journals, and quiz were also a component of the analysis.

${ }^{16}$ http://www.qualtrics.com/ 


\section{Chapter IV: Results}

The study was conducted during a full university semester, the questionnaires were distributed, filled, and collected, and the results were compiled and analyzed. Chapter Four provides the results of the students' questionnaires, accompanied by a discussion of their grades for each of the units. In this analysis, participants of both classes were examined as one group. Because of some students opted not to participate in the surveys, only 36 surveys were examined in the analysis, while the grades of 40 students were analyzed.

The research questions were the following:

1. Did the use of humorous videos of Scènes de ménage improve the students' motivation for the class and regarding the four basic skills of language learning?

2. Did the use of humorous videos of Scènes de ménage improve the students'self-confidence, therefore lowering their affective filter?

3. Did the use of humorous videos of Scènes de ménage expand the students' understanding of the target culture?

This chapter is organized according to data collection. The data collected in the pre-study questionnaire will first be analyzed to evaluate students' beliefs about video material in class and their level of motivation, confidence, and understanding of French culture and humor. The results of the post-study questionnaire will then be presented to evaluate how the projection of episodes of Scènes de ménage in class affected the aforementioned characteristics. Finally, students' grades will be analyzed in order to support or refute the results of the post-study questionnaire.

\section{Pre-Study Questionnaire}

The pre-study questionnaire (Appendix F) was designed to gather data regarding the students' languagelearning background. The first part aimed to determine the students' perception of their motivation in the French class, their self-confidence, and their understanding of the French culture and humor. Follow-up 
questions focused on the students' experience with French multimedia. Finally, the students answered questions related to their previous experience in French, their reasons for studying the language, and their manner of study.

\section{Previous Experience in French Learning}

The classes selected for the study were not beginner classes; therefore, it was important to gather information on the participants' previous experiences in French. First, the students were asked how much experience they had in French. The answers have been compiled in Table 1.

Table 1: Length of the Students' Previous Experience in French

\begin{tabular}{|c|c|c|}
\hline Answer & Response & \% \\
\hline$>18$ semesters & 1 & $2,78 \%$ \\
\hline 18 semesters & 1 & $2,78 \%$ \\
\hline 12 semesters & 3 & $8,33 \%$ \\
\hline 11 semesters & 1 & $2,78 \%$ \\
\hline 10 semesters & 5 & $13,89 \%$ \\
\hline 8 semesters & 1 & $2,78 \%$ \\
\hline 6 semesters & 4 & $11,11 \%$ \\
\hline 4 semesters & 6 & $\mathbf{1 6 , 6 7 \%}$ \\
\hline 3 semesters & 8 & $\mathbf{2 2 , 2 2 \%}$ \\
\hline 2 semesters & 6 & $\mathbf{1 6 , 6 7 \%}$ \\
\hline TOTAL & $\mathbf{3 6}$ & $\mathbf{1 0 0 , 0 0 \%}$ \\
\hline
\end{tabular}

The data show that experience varied among the students. Most students had two to four previous semesters of French, and several students had over 5 years (10 semesters) of experience in French learning. As level 203 is the third semester of French in university in the normal course of things, any with more than two semesters learned French previously to university, supposedly in High School, or may have lived abroad or learnt with their parents.

The second question asked about the material students used to supplement their training in French. Students were provided with options, from which they could choose several; they could also add other material to the provided list. Figure 1 sums up the collected data. 
Figure 1: Material Used by Students to Support Their Training

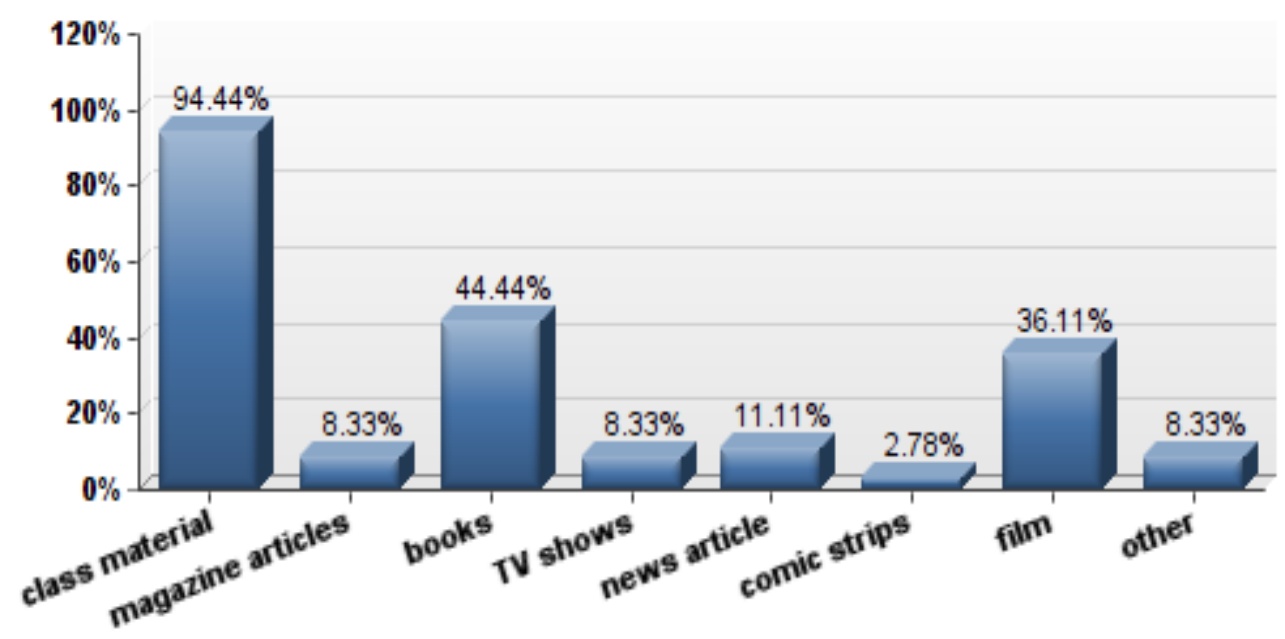

As shown in Figure 1, the students polled mainly selected three options on which their learning was based: class material, books, and films. Class material was selected by $94.44 \%$ of the students, all of whom also selected additional options. The second most common choice was books, followed by films. Students preferred films to T.V. shows, of which only $8.33 \%$ of them selected. Finally, three students selected "other." These options included music, the Duolingo language application, or unspecified material.

\section{Motivation}

In order to evaluate the students' general motivation for learning a foreign language, the participants were asked to select their level of interest in learning French in the last part of the pre-study questionnaire.

Table 2: Pre-Study Questionnaire - Students' Interest in Learning French

\begin{tabular}{|c|c|c|c|c|}
\hline$\#$ & Answer & & Response & \% \\
\hline 1 & very interested & 16 & $44 \%$ \\
\hline 2 & interested & 14 & $39 \%$ \\
\hline 3 & indifferent & 6 & $17 \%$ \\
\hline 4 & not interested & 0 & $0 \%$ \\
\hline
\end{tabular}


The results in Table 2 show that most of the polled students were interested in learning French. The majority reported that they were "very interested," and none of them expressed having no interest in the language. Seventeen percent of the students surveyed considered themselves indifferent to learning the language.

The next question was designed to reveal students' reasoning for registering for a French class. According to the instructions, students were to select their top reason for having registered, but they sometimes selected several options, which distorted the results presented in Table 3.

Table 3: Pre-Study Questionnaire - Reason to Study French

\begin{tabular}{|c|l|c|c|c|}
\hline$\#$ & Answer & Response & \% \\
\hline 1 & Academic purposes & $\mathbf{1 7}$ & $\mathbf{4 7 \%}$ \\
\hline 2 & Professional purposes & 10 & $28 \%$ \\
\hline 3 & General interest & 10 & $28 \%$ \\
\hline 4 & Communication with family & 2 & $6 \%$ \\
\hline 5 & Communication with friends & 1 & $3 \%$ \\
\hline 6 & Requirement & 16 & $44 \%$ \\
\hline 7 & Other & 1 & $3 \%$ \\
\hline
\end{tabular}

According to the collected data, most students enrolled for academic purposes, and/or in order to fulfill a prerequisite for the major or minor. This data show the common practice at academic institutions which have a two-semester or four-semester basic language study requirement. French is, however, one of several foreign languages offered to the students for them to fulfill the university language requirement. Most of the other reasons selected by the participants reflect the reasons why students chose to study French as opposed to other languages available at the university.

A smaller number of students declared that they were learning French for "professional purposes" or out of a "general interest." Finally, 9\% of students chose communication as their motivation, whether it is with family or with friends. One student selected "other" but did not specify what this other reason was. 
Consequently, even though a large number of students were learning French because they were required to, in general, the interest in the class was high.

The next section of the questionnaire addressed the students' perception of their motivation regarding the four basic skills in language learning (reading, writing, listening, and speaking). The answers in these questions were organized according to the students' perceived level of interest in learning about French culture and their overall motivation. The questions focused on the students' level of motivation before the study, in order for them to be contrasted with results from the post-study questionnaire. They were designed using a Likert scale ranging from one (strongly disagree) to five (strongly agree).

Table 4: Pre-Study Questionnaire - Students' Enjoyment in French Class

\begin{tabular}{|c|c|c|c|c|c|c|c|c|}
\hline \# & Question & $\begin{array}{c}\text { Strongly } \\
\text { Agree }\end{array}$ & Agree & $\begin{array}{l}\text { Neither } \\
\text { Agree nor } \\
\text { Disagree }\end{array}$ & Disagree & $\begin{array}{l}\text { Strongly } \\
\text { Disagree }\end{array}$ & $\begin{array}{c}\text { Total } \\
\text { Responses }\end{array}$ & Mean \\
\hline 1 & $\begin{array}{l}\text { I enjoy learning } \\
\text { French }\end{array}$ & $33.33 \%$ & $52.78 \%$ & $13.89 \%$ & $0.00 \%$ & $0.00 \%$ & 36 & 1.81 \\
\hline 2 & $\begin{array}{l}\text { I enjoy listening } \\
\text { to easy audio- } \\
\text { visual materials in } \\
\text { French }\end{array}$ & $38.89 \%$ & $41.67 \%$ & $11.11 \%$ & $5.56 \%$ & $2.78 \%$ & 36 & 1.92 \\
\hline 3 & $\begin{array}{l}\text { I enjoy talking } \\
\text { about familiar } \\
\text { topics }\end{array}$ & $25.71 \%$ & $60.00 \%$ & $11.43 \%$ & $0.00 \%$ & $2.86 \%$ & 35 & 1.94 \\
\hline 4 & $\begin{array}{l}\text { I enjoy writing } \\
\text { basic texts on } \\
\text { familiar topics }\end{array}$ & $19.44 \%$ & $52.78 \%$ & $22.22 \%$ & $5.56 \%$ & $0.00 \%$ & 36 & 2.14 \\
\hline 5 & $\begin{array}{l}\text { I enjoy reading } \\
\text { short texts on } \\
\text { familiar topics }\end{array}$ & $19.44 \%$ & $52.78 \%$ & $25.00 \%$ & $2.78 \%$ & $0.00 \%$ & 36 & 2.11 \\
\hline 6 & $\begin{array}{l}\text { I enjoy learning } \\
\text { about France and } \\
\text { its culture }\end{array}$ & $58.33 \%$ & $33.33 \%$ & $5.56 \%$ & $2.78 \%$ & $0.00 \%$ & 36 & 1.53 \\
\hline
\end{tabular}

According to the results in Table 4, the students enjoy learning French: $86.11 \%$ of the students chose "agree" or "strongly agree;" the rest of the respondents were neutral. When it comes to the basic skills of language learning (reading, writing, listening, and speaking), the majority of the students polled rated positively the statement regarding their enjoyment of listening to easy audio-visual materials, talking about familiar topics, and reading 
and writing basic texts on familiar topics. Interestingly enough, there were more students who felt strongly against listening than for any of the other skills, as $8.34 \%$ of the students selected "disagree" and "strongly disagree." Students were also less interested in writing, with 5.56\% of students selecting “disagree.” When it comes to learning about France and its culture, the majority of students selected "strongly agree" to describe their enjoyment, and $91.66 \%$ agreed that learning about culture is enjoyable for them.

\section{Affective Filter}

The second part of the pre-study questionnaire contained question concerning the students' affective filter. The questions were designed to evaluate the students' confidence in their basic language skills (reading, writing, listening, speaking) using a Likert scale. Table 5 presents the results of the survey in percentages.

\section{Table 5: Pre-Study Questionnaire - State of Students' Affective Filters}

\begin{tabular}{|c|c|c|c|c|c|c|c|c|}
\hline \# & Question & $\begin{array}{l}\text { Strongly } \\
\text { Agree }\end{array}$ & Agree & $\begin{array}{l}\text { Neither } \\
\text { Agree nor } \\
\text { Disagree }\end{array}$ & Disagree & $\begin{array}{l}\text { Strongly } \\
\text { Disagree }\end{array}$ & $\begin{array}{c}\text { Total } \\
\text { Responses }\end{array}$ & Mean \\
\hline 1 & $\begin{array}{l}\text { I am confident in my } \\
\text { ability to write a text on } \\
\text { a familiar topic }\end{array}$ & $13.89 \%$ & $61.11 \%$ & $19.44 \%$ & $5.56 \%$ & $0.00 \%$ & 36 & 2.17 \\
\hline 2 & $\begin{array}{l}\text { I am confident in my } \\
\text { ability to understand } \\
\text { what I read }\end{array}$ & $16.67 \%$ & $52.78 \%$ & $27.78 \%$ & $2.78 \%$ & $0.00 \%$ & 36 & 2.17 \\
\hline 3 & $\begin{array}{l}\text { I am confident in my } \\
\text { current listening skills }\end{array}$ & $11.11 \%$ & $44.44 \%$ & $19.44 \%$ & $22.22 \%$ & $2.78 \%$ & 36 & 2.61 \\
\hline 4 & $\begin{array}{l}\text { I am confident when } \\
\text { speaking with native } \\
\text { speakers on familiar } \\
\text { topics }\end{array}$ & $2.78 \%$ & $19.44 \%$ & $33.33 \%$ & $36.11 \%$ & $8.33 \%$ & 36 & 3.28 \\
\hline
\end{tabular}

The results of this series of questions show that students are confident in their own abilities in three of the four basic skills at their current level of proficiency. Seventy-five percent of the students admitted being confident in their writing skills, $69.45 \%$ felt confident in their reading skills, and $55.55 \%$ were confident in their listening skills. Speaking appeared to be more problematic for the participants, with only $22.22 \%$ feeling confident in their speaking skills; $44.44 \%$ stated that they did not have confidence in their speaking skills. These results 
reflect typical patterns in language classrooms, in which students tend to produce more written texts than spoken ones, and therefore feel more at ease reading and writing. Those results, however, are surprising in the way that the university's basic French program is based on a communicative method in which all skills are supposed to be practiced equally.

A compilation of those figures helps understanding the state of the learners' affective filter, as shown in Table 6.

Table 6: Students' Affective Filter in the Four Basic Language Skills

\begin{tabular}{|c|c|c|c|}
\hline & Low Filter & Neither low nor High & High Filter \\
\hline Writing & $75.00 \%$ & $19.44 \%$ & $5.56 \%$ \\
\hline Reading & $69.45 \%$ & $27.78 \%$ & $2.78 \%$ \\
\hline Speaking & $22.22 \%$ & $33.33 \%$ & $44.44 \%$ \\
\hline Listening & $55.55 \%$ & $19.44 \%$ & $25.00 \%$ \\
\hline Productive skills & $48.61 \%$ & $26.39 \%$ & $25 \%$ \\
\hline Perception skills & $62.5 \%$ & $23.61 \%$ & $13.89 \%$ \\
\hline
\end{tabular}

According to this table, more students have a low affective filter for the writing skills than for the oral skills.

Yet, we see when it comes to the specific skills in themselves that the filter is similarly low for reading and writing, but is significantly higher for the speaking than for the listening. Yet, the data also shows that the learner's filter is more likely to be lower for the perception skills $(62.5 \%)$ than for the productive skills (48.61\%). This agrees with the usual rate of acquisition: students tend to acquire the receptive skills before the productive skills. 


\section{Cultural understanding and Attitude Toward French T.V. Shows}

The next section of the pre-study questionnaire studied the students' attitude towards French culture, and more specifically French humor. Once again, the questions were designed using a Likert Scale, and the results are presented in Table 7.

Table 7 : Pre-Study Questionnaire - Student's Perception of Humor and Culture in French Class

\begin{tabular}{|l|l|l|l|l|l|l|l|l|}
\hline Question & $\begin{array}{c}\text { Strongly } \\
\text { Agree }\end{array}$ & Agree & $\begin{array}{c}\text { Neither } \\
\text { Agree nor } \\
\text { Disagree }\end{array}$ & Disagree & $\begin{array}{c}\text { Strongly } \\
\text { Disagree }\end{array}$ & $\begin{array}{c}\text { Total } \\
\text { Responses }\end{array}$ & Mean \\
\hline 1 & $\begin{array}{l}\text { I enjoy humorous } \\
\text { TV shows }\end{array}$ & $\mathbf{4 7 . 2 2 \%}$ & $38.89 \%$ & $11.11 \%$ & $0.00 \%$ & $2.78 \%$ & 36 & 1.72 \\
\hline 2 & $\begin{array}{l}\text { I enjoy authentic } \\
\text { French programming }\end{array}$ & $11.11 \%$ & $33.33 \%$ & $\mathbf{4 4 . 4 4 \%}$ & $8.33 \%$ & $2.78 \%$ & 36 & 2.58 \\
\hline 3 & $\begin{array}{l}\text { Culture motivates } \\
\text { me to learn }\end{array}$ & $30.56 \%$ & $\mathbf{4 4 . 4 4 \%}$ & $19.44 \%$ & $5.56 \%$ & $0.00 \%$ & 36 & 2.00 \\
\hline 4 & $\begin{array}{l}\text { Humor motivates me } \\
\text { to learn }\end{array}$ & $22.22 \%$ & $\mathbf{5 2 . 7 8 \%}$ & $16.67 \%$ & $5.56 \%$ & $2.78 \%$ & 36 & 2.14 \\
\hline $\begin{array}{l}\text { I believe I have a } \\
\text { good understanding } \\
\text { of French culture }\end{array}$ & $11.11 \%$ & $\mathbf{5 2 . 7 8 \%}$ & $22.22 \%$ & $11.11 \%$ & $2.78 \%$ & 36 & 2.42 \\
\hline $\begin{array}{l}\text { I believe I have a good } \\
\text { understanding of } \\
\text { French humor }\end{array}$ & $5.56 \%$ & $\mathbf{3 6 . 1 1 \%}$ & $\mathbf{3 6 . 1 1 \%}$ & $19.44 \%$ & $2.78 \%$ & 36 & 2.78 \\
\hline
\end{tabular}

This table shows that the great majority of participants enjoyed humorous programs and considered humor a motivational factor for learning. However, the participants are split when it comes to stating that they understand French humor well: $41.67 \%$ of students reported that they have a good understanding and $36.11 \%$ of students reported that they did not know if they have a good understanding of it. About $20 \%$ of students state that they do not understand French humor well. Also, the majority of students were undecided about whether or not they enjoyed French programming. This number very likely means that very few participants watching French T.V. shows.

As this data covers a lot of information, it is better to analyze the data separately. In Table 8, part of this data were computed in a different way, in order to highlight the motivating power of culture as compared to the one of humor in French language learning 
Table 8: Motivational Factors for Learning French

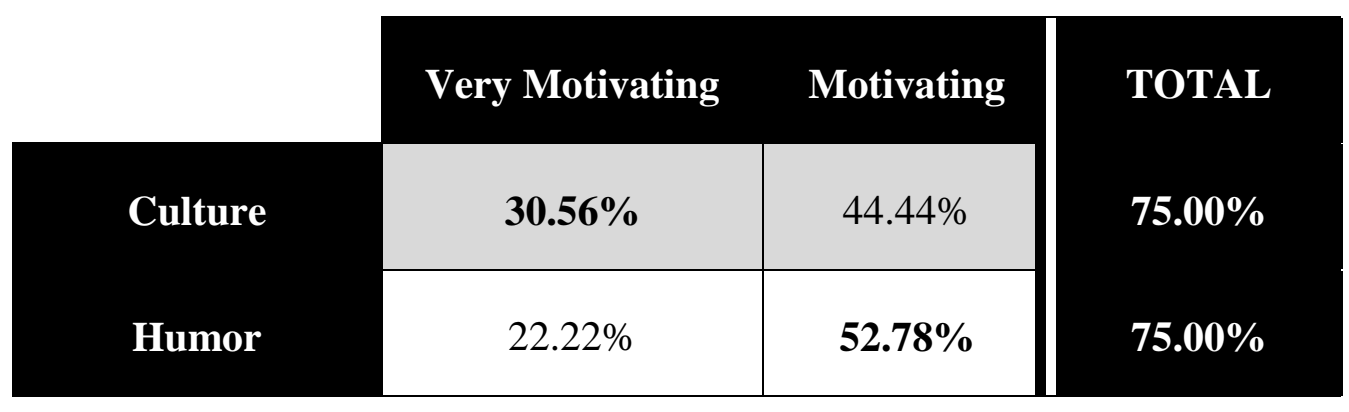

According to Table $8,75 \%$ of students surveyed believed culture and humor to be a motivational factor in French language learning. The data also shows that more students think culture and humor to be more of a motivating factor than a very motivating factor. Yet, more students reported culture has a very motivating factor $(30.56 \%)$ than students reported humor as a very motivating factor $(22.22 \%)$. Therefore, humor and culture are motivating to an equal amount of students, but their power of motivation is not equal to all the students.

In turn, the computed data of Table 9 present the students' opinion about their understanding of French humor specifically, as compared to a more general understanding of French culture.

Table 9: Students' Understanding of French Culture and Humor

\begin{tabular}{|c|c|c|c|}
\hline & Good Understanding & Very Good Understanding & TOTAL \\
\hline French Culture & $52.76 \%$ & $11.11 \%$ & $63.89 \%$ \\
\hline French Humor & $36.11 \%$ & $5.56 \%$ & $41.67 \%$ \\
\hline
\end{tabular}

This new computing of data shows that the participants believe to better understand French culture in general than the specific part of French culture that is French humor. It also highlights the fact that among the students who believe that they understand French culture and humor, this understanding is more basic than very good. However, for the students who believed having a very good understanding of French culture and/or French humor, more students have a very good understanding of French culture than of French humor. Therefore, 
French humor seem to be more problematic than French culture, which explains why in the previous data, culture was considered as having a more motivating power than humor.

Finally, the last part of this data concerned the students' attitude towards French culture and humor in audio-visual materials. Table 10 shows the data concerning the type of T.V. programming most enjoyed by the learners: authentic humorous shows or other authentic programming.

Table 10: Learner's Perception of French T.V. Programming

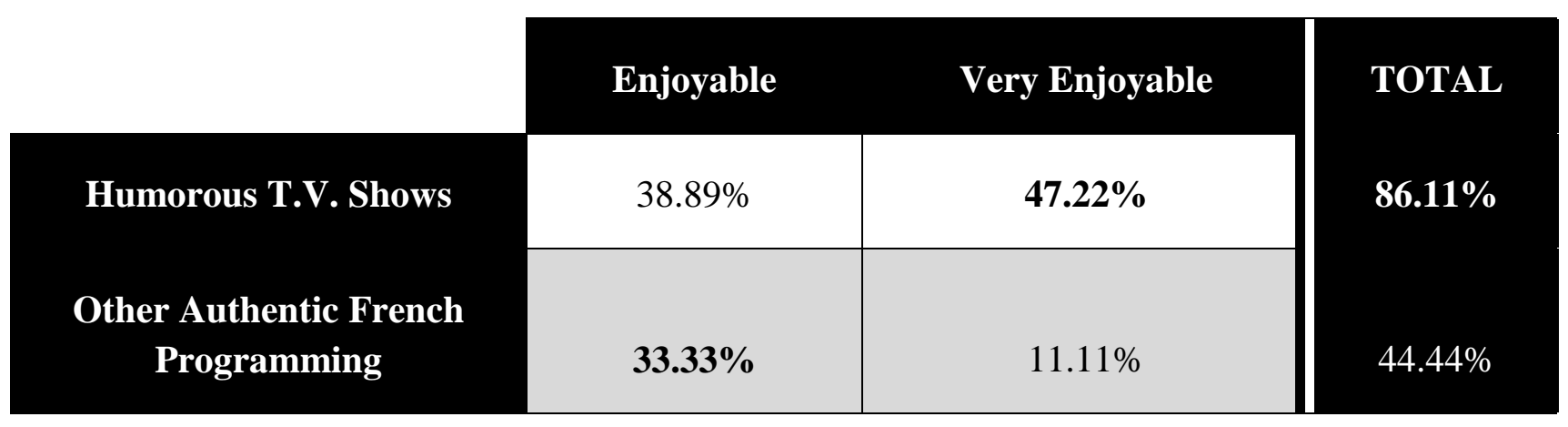

Table 10 shows humorous T.V. shows seem to be a lot more enjoyable for students as compared to other type of authentic programming: among the students finding humorous shows enjoyable, more found them to be very enjoyable than simply enjoyable, whereas among the students finding other type of programming enjoyable, more found them simply enjoyable than very enjoyable. In addition, close to $90 \%$ of the participants found humorous T.V. shows to be enjoyable, when a little less than $50 \%$ found non humorous T.V. shows to be enjoyable. Therefore, in the context of T.V. programming, humor seem to be more enjoyable than culture.

This set of questions targeted the participants' previous experience with French T.V. shows, as it would influence the results of the previous set of data and because this experience might be a determinant element for the study as it is centered on a French T.V. show. The questions were designed using the Likert scale, and the results are summarized in Table 11. 
Table 11: Students' Previous Experience with French T.V. Shows

\begin{tabular}{|l|l|l|l|l|l|l|l|l|}
\hline$\#$ & \multicolumn{1}{|c|}{ Question } & $\begin{array}{c}\text { Strongly } \\
\text { Agree }\end{array}$ & Agree & $\begin{array}{c}\text { Neither } \\
\text { Agree nor } \\
\text { Disagree }\end{array}$ & Disagree & $\begin{array}{c}\text { Strongly } \\
\text { Disagree }\end{array}$ & $\begin{array}{c}\text { Total } \\
\text { Responses }\end{array}$ & Mean \\
\hline 1 & $\begin{array}{l}\text { I watch TV shows } \\
\text { from France }\end{array}$ & $2.78 \%$ & $5.56 \%$ & $19.44 \%$ & $\mathbf{5 8 . 3 3 \%}$ & $13.89 \%$ & 36 & 3.75 \\
\hline 2 & $\begin{array}{l}\text { I watch French TV } \\
\text { shows }\end{array}$ & $2.78 \%$ & $2.78 \%$ & $22.22 \%$ & $\mathbf{5 5 . 5 6 \%}$ & $16.67 \%$ & 36 & 3.81 \\
\hline $\mathbf{3}$ & $\begin{array}{l}\text { I watch French TV } \\
\text { shows with French } \\
\text { subtitles }\end{array}$ & $2.78 \%$ & $2.78 \%$ & $27.78 \%$ & $\mathbf{5 0 . 0 0 \%}$ & $16.67 \%$ & 36 & 3.75 \\
\hline $\begin{array}{l}\text { I watch French TV } \\
\text { shows with English } \\
\text { subtitles }\end{array}$ & $8.33 \%$ & $22.22 \%$ & $16.67 \%$ & $\mathbf{3 6 . 1 1 \%}$ & $16.67 \%$ & 36 & 3.31 \\
\hline $\begin{array}{l}\text { I can get the gist of } \\
\text { authentic French TV } \\
\text { shows }\end{array}$ & $8.33 \%$ & $22.22 \%$ & $\mathbf{3 6 . 1 1 \%}$ & $25.00 \%$ & $8.33 \%$ & 36 & 3.03 \\
\hline $\begin{array}{l}\text { I watch French TV } \\
\text { shows because I like }\end{array}$ & $5.71 \%$ & $11.43 \%$ & $\mathbf{3 7 . 1 4 \%}$ & $34.29 \%$ & $11.43 \%$ & 35 & 3.34 \\
\hline $\begin{array}{l}\text { French culture } \\
\text { I watch French TV } \\
\text { shows because I like }\end{array}$ & $2.78 \%$ & $16.67 \%$ & $\mathbf{3 6 . 1 1 \%}$ & $33.33 \%$ & $11.11 \%$ & 36 & 3.33 \\
\hline \begin{tabular}{l} 
French humor \\
\hline
\end{tabular} & & & & & & \\
\hline
\end{tabular}

The results of these questions show that the majority of students surveyed do not watch French-language T.V. shows. It appears that most of those who do watch them do so with English subtitles (30.55\% for "Agree" and "Strongly Agree") or no subtitles at all, as only 5.56\% stated that they watched French T.V. shows with French subtitles ("Agree" and "Strongly Agree").

The majority of participants had no opinion about French T.V. shows because they reported not watching them. Table 12 gathers the data on the motivation of learners who did report watching French T.V. shows. The percentage of students watching T.V. shows from France / French T.V. shows for another reason than French humor or French culture has been calculated from the total percentage of students watching French T.V. shows or T.V. shows from France (27.78\%) minus the one of student declaring doing so for French Humor or French Culture. 
Table 12: Reasons for Students to Watch French T.V. Shows or T.V. Shows From France

\begin{tabular}{|c|c|c|c|c|}
\hline & Very Much So & Yes & TOTAL & For Another Reason \\
\hline For Humor & $2.78 \%$ & $16.67 \%$ & $19.45 \%$ & $8.43 \%$ \\
\hline For Culture & $5.71 \%$ & $11.43 \%$ & $17.14 \%$ & $10.64 \%$ \\
\hline
\end{tabular}

As shown in this table, the participants watching French T.V. shows (that can come from an oversea territory or department, such as the islands of Mayotte and French Polynesia) or T.V. shows from France seem to do it more for French humor (19.45\%) than for French culture (17.14\%). Since the addition of the two total percentages results is more than the $27.78 \%$ of students declaring watching French T.V. shows or T.V. shows from France, some participants have declared that they were watching those shows for both French humor and French culture. However, as shown in the "For Another Reason" column, some participants declared doing so for specifically another reason than French humor or French culture, though the questionnaire did not ask for this reason.

In an additional question, students were asked to comment on how watching French multimedia could improve their communicative skills. Five participants chose not to comment, two of whom specified that they did not watch T.V. shows or could not go to the film viewings organized by the teacher. One other student did not understand the question and talked about the performance of the teacher; another simply answered that shows for young children were the most helpful, but did not specify how or why. The answers of the last two students were not taken into account, and therefore only 29 answers were analyzed.

Among the different answers, several trends for why students did or did not consume French-language videos emerged, mainly element linked to oral skills. Five students said that videos helped with listening practice. Twelve students mentioned that hearing native speakers speak was beneficial; three mentioned 
specifically potential improvement on pronunciation, and six said it helped getting used to the speed and flow of native speakers.

Some other students underscored that videos were useful for learning vocabulary or expressions. Six students claimed that videos showed how to use words or expressions in real situations or outside the classroom environment; two explained it was good practice to listen for familiar words or expressions; one student believed that it helped increased the vocabulary banks because of new words or expressions in context, and another said it helped to have a better understanding of the meaning of certain words used in a natural setting. Two students also underscored the possibility of getting used to and learning slang or dialects.

Some students specified that watching authentic video programming helped them to develop techniques for understanding French videos better. Five students recognized the usefulness of subtitles, three of whom specified English subtitles for vocabulary comprehension and retention, and two of whom did not specify the language for the subtitles. Three students also stated the use of body language and gestures to improve their comprehension. One student admitted to watching only well-known English movies in French in order to improve language skills. Finally, three students mentioned the exposure to culture and two talked about the motivational benefits of humor in audio-visual material.

\section{Post-Study Questionnaire}

The post-study questionnaire (Appendix G) was designed to examine how the use of episodes of Scènes de ménage in class affected the students' motivation, affective filter, and understanding of French culture and French humor. The questions were designed using the Likert scale ranging from one (strongly disagree) to five (strongly agree). In a free-comment section, the students were asked to explain their answers of Strongly Agree/Disagree. 


\section{Motivation}

The first set of questions in the post-study questionnaire addressed students' perception of the effect of Scènes de ménage on their motivation. The students had to evaluate the effect on their motivation for French language learning in general, for French culture learning, and for three of the four language skills (listening, writing, and speaking as well as vocabulary). Reading was excluded from the motivation results because the investigator did not create post-viewing activities specifically related to the video programming and therefore did not expect to measure effects on students' reading comprehension. Reading was included in a separate section of the survey to measure the effect of the shortcom on students' affective filter with regard to reading. This measurement was based on students' reading skills employed while reading subtitle accompanying the video. The results are depicted in Table 13. 
Table 13: Effect of Scène de Ménage on Students'Motivation

Strongly

Agree

\section{Neither Agree nor} Disagree

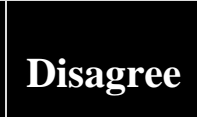

Disagree

\section{Strongly}

Disagree

$8.33 \%$

$0.00 \%$

2.19

Total Responses

Mean
$27.78 \%$

me to learn French.

33.33\% $30.56 \%$

$8.33 \%$

$0.00 \%$

Scènes de Ménage motivated

me to learn French culture

(recognize differences

related to written and $25.00 \%$

$\mathbf{4 4 . 4 4 \%}$

$16.67 \%$

$13.89 \%$

$0.00 \%$

36

2.19

spoken communication, rely

on cultural knowledge to

interpret texts).

Scènes de Ménage motivated

me to practice my listening

3 skills (comprehend texts

related to basic personal and

$33.33 \%$

$44.44 \%$

$19.44 \%$

$2.78 \%$

$0.00 \%$

36

1.92

social needs and familiar knowledge).

Scènes de Ménage motivated me to practice my writing

skills (create messages in context using series of $16.67 \%$ $27.78 \%$

$25.00 \%$

$30.56 \%$

$0.00 \%$

36

sentences and formulaic expressions).

Scènes de Ménage encouraged me to study more vocabulary

5 (vocabulary of everyday topics, personal interest, or of $25.00 \%$ $\mathbf{3 6 . 1 1 \%} \quad 30.56 \%$ $8.33 \%$ $0.00 \%$ 36 topics that have been studied).

Scènes de Ménage motivated me to practice my speaking skills (use facial expressions

6 and gestures, repeat words, simplify, use known language to compensate missing vocabulary...).
$30.56 \%$
$27.78 \%$
$33.33 \%$
$8.33 \%$
$0.00 \%$
36
2.19

According to Table 13,61.11\% of students agreed with the statement that Scènes de ménage motivated them to learn French, and only $8.33 \%$ disagreed. Students also mainly agreed that Scènes de ménage motivated them to learn about French culture. The motivation for developing the four basic language skills was also positively affected by the use of episodes in class. The motivational factor of Scènes de ménage appears to have been more 
efficient concerning the students' listening skills over the other three skills. Over $44 \%$ of the students agreed with the statement that Scènes de ménage motivated them to improve their listening skills, and over $33 \%$ agreed more strongly. Only $2.78 \%$ did not think that it motivated them. Students did not feel as strongly motivated to improve their writing skills, but an average of $44.45 \%$ agreed that they felt more motivated as opposed to $30.56 \%$ who disagreed. Scènes de ménage also seem to have encouraged the students to improve their reading skills through studying more vocabulary skills, as the majority of them selected that option and only $8.33 \%$ disagreed with the statement. Finally, a majority of students also felt motivated to improve their speaking skills $(58.34 \%)$, though over $33 \%$ of them held no opinion.

These results show that the episodes of Scènes de ménage had an overwhelmingly positive effect on motivation as observed by students in French class.

\section{Affective Filter}

The second set of questions in the post-study questionnaire addressed the students' level of confidence in class and the effect of the episodes of Scènes de ménage had on it, in order to determine the state of their affective filter. The question was divided according to the four basic language skills and aimed at evaluating the level of the students' affective filter. The results are summarized in Table 14. 
Table 14: Effect of Scènes de Ménage on Students' Confidence in Class

\begin{tabular}{|c|c|c|c|c|c|c|c|c|}
\hline \# & Question & $\begin{array}{l}\text { Strongly } \\
\text { Agree }\end{array}$ & Agree & $\begin{array}{c}\text { Neither } \\
\text { Agree nor } \\
\text { Disagree }\end{array}$ & Disagree & $\begin{array}{l}\text { Strongly } \\
\text { Disagree }\end{array}$ & $\begin{array}{c}\text { Total } \\
\text { Responses }\end{array}$ & Mean \\
\hline 1 & $\begin{array}{l}\text { Scènes de Ménage helped } \\
\text { me feel more confident in } \\
\text { my listening skills } \\
\text { (comprehend texts related } \\
\text { to basic personal and social } \\
\text { needs and familiar } \\
\text { knowledge). }\end{array}$ & $25.00 \%$ & $\mathbf{5 5 . 5 6 \%}$ & $11.11 \%$ & $5.56 \%$ & $2.78 \%$ & 36 & 2.06 \\
\hline 2 & $\begin{array}{l}\text { Scènes de Ménage helped me } \\
\text { feel more confident in my } \\
\text { reading skills (comprehend } \\
\text { texts related to basic personal } \\
\text { and social needs and familiar } \\
\text { knowledge). }\end{array}$ & $11.11 \%$ & $\mathbf{5 0 . 0 0 \%}$ & $22.22 \%$ & $13.89 \%$ & $2.78 \%$ & 36 & 2.47 \\
\hline 3 & $\begin{array}{l}\text { Scènes de Ménage helped } \\
\text { me feel more confident in } \\
\text { my speaking skills (use } \\
\text { facial expressions and } \\
\text { gestures, repeat words, } \\
\text { simplify, use known } \\
\text { language to compensate } \\
\text { missing vocabulary...). }\end{array}$ & $8.33 \%$ & $44.44 \%$ & $27.78 \%$ & $16.67 \%$ & $2.78 \%$ & 36 & 2.61 \\
\hline 4 & $\begin{array}{l}\text { Scènes de Ménage helped me } \\
\text { feel more confident in my } \\
\text { writing skills (create } \\
\text { messages in context using } \\
\text { series of sentences and } \\
\text { formulaic expressions). }\end{array}$ & $8.33 \%$ & $25.00 \%$ & $33.33 \%$ & $30.56 \%$ & $2.78 \%$ & 36 & 2.94 \\
\hline
\end{tabular}

Table 14 shows that the great majority of students felt more confident in their listening skills thanks to Scènes de Ménage. Results on this question show that overall, $80.56 \%$ students agreed (strongly or not) with the statement that Scènes de Ménage helped them feel more confident in their listening skills. A majority of students also agreed that Scènes de Ménage helped with their confidence in their reading skills, though a higher number disagreed with the statement (16.67\%). A smaller number of students agreed that Scènes de Ménage was helpful in developing their confidence in their speaking skills. They also agreed, albeit to a lesser degree, that Scènes de Ménage was helpful in developing their confidence in their writing skills. It is interesting to note that for the confidence in the writing skills, the number of students that chose to "disagree" is similar to the 
number that chose to "neither agree nor disagree." The influence of Scènes de Ménage on the writing skills seems to be difficult for students to explain conclusively.

Figure 2: Students' Confidence in the Four Basic Language Skills after Watching Episodes of Scènes de Ménage

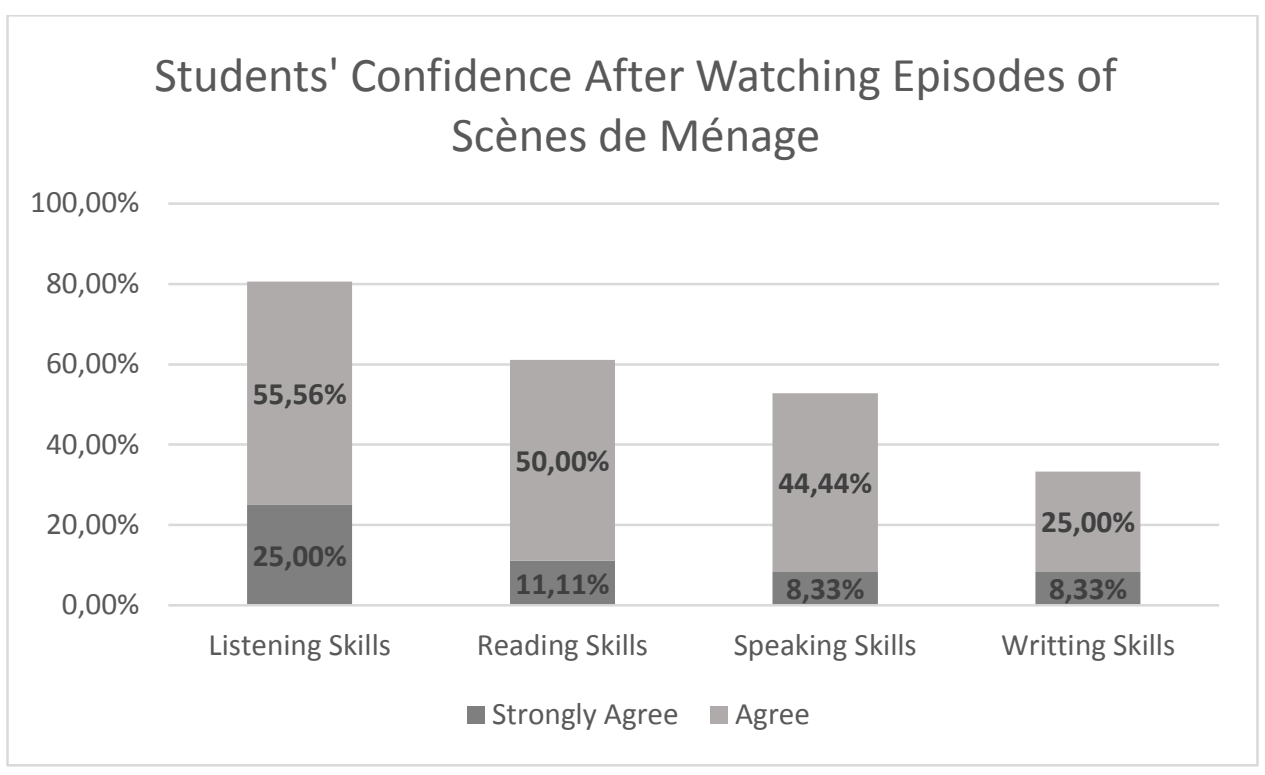

Figure 2 shows the percentage of students' agreement to the statement of feeling more confident in the individual language skills after having watched Scène de ménage. According to Figure 2, Scène de ménage helped lower the affective filter of students in listening skills for about $80 \%$ of the students. The affective filter was also lowered with regard to reading skills and speaking skills, though for fewer students (about $60 \%$ and $50 \%$ of the students). The affective filter with regard to writing skills was lowered for only about $30 \%$ of the students.

\section{Culture and Humor}

The last set of questions of the post-study questionnaire addressed the impact of Scènes de Ménage on the students' grasp of French culture and French humor by evaluating their enjoyment, understanding, and eagerness to watch additional humorous or authentic (or cultural) French T.V. shows. The data has been computed in Table 15. 
Table 15: Effects of Scènes de Ménage on Students' Understanding of Culture and Humor

\begin{tabular}{|c|c|c|c|c|c|c|c|c|}
\hline \# & Question & $\begin{array}{c}\text { Strongly } \\
\text { Agree }\end{array}$ & Agree & $\begin{array}{l}\text { Neither } \\
\text { Agree nor } \\
\text { Disagree }\end{array}$ & Disagree & $\begin{array}{l}\text { Strongly } \\
\text { Disagree }\end{array}$ & $\begin{array}{c}\text { Total } \\
\text { Responses }\end{array}$ & Mean \\
\hline 1 & $\begin{array}{l}\text { Scènes de Ménage improved } \\
\text { my understanding of French } \\
\text { culture. }\end{array}$ & $25.00 \%$ & $44.44 \%$ & $19.44 \%$ & $11.11 \%$ & $0.00 \%$ & 36 & 2.17 \\
\hline 2 & $\begin{array}{l}\text { Scènes de Ménage improved } \\
\text { my understanding of French } \\
\text { humor. }\end{array}$ & $33.33 \%$ & $50.00 \%$ & $11.11 \%$ & $2.78 \%$ & $2.78 \%$ & 36 & 1.92 \\
\hline 3 & $\begin{array}{l}\text { Scènes de Ménage helped me } \\
\text { enjoy French culture. }\end{array}$ & $36.11 \%$ & $44.44 \%$ & $11.11 \%$ & $8.33 \%$ & $0.00 \%$ & 36 & 1.92 \\
\hline 4 & $\begin{array}{l}\text { Scènes de Ménage helped me } \\
\text { enjoy French humor. }\end{array}$ & $38.89 \%$ & $41.67 \%$ & $13.89 \%$ & $5.56 \%$ & $0.00 \%$ & 36 & 1.86 \\
\hline 5 & $\begin{array}{l}\text { Scènes de Ménage made me } \\
\text { want to watch more } \\
\text { authentic French } \\
\text { programming. }\end{array}$ & $36.11 \%$ & $30.56 \%$ & $16.67 \%$ & $16.67 \%$ & $0.00 \%$ & 36 & 2.14 \\
\hline 6 & $\begin{array}{l}\text { Scènes de Ménage made me } \\
\text { want to watch more humorous } \\
\text { French TV shows. }\end{array}$ & $33.33 \%$ & $33.33 \%$ & $11.11 \%$ & $22.22 \%$ & $0.00 \%$ & 36 & 2.22 \\
\hline
\end{tabular}

According to the results, the majority of students agreed that Scènes de Ménage improved their understanding of French culture and French humor, that it helped them enjoy French culture and French humor more, and that it made them want to watch more French T.V. shows with humor or culture (authentic T.V. shows). The majority of students agreed that the episodes shown in class helped their grasp of French culture and French humor.

On average, most students strongly agreed or agreed with the statements about French T.V. programming. Those results show that Scènes de ménage has a positive effect on student motivation and affective filter, and it contributed to the development of cultural knowledge and understanding among learners.

\section{Comparison of Results}

The above results showed that Scènes de ménage positively influenced the students in each of the research categories: motivation, affective filter, and understanding of French culture and French humor. In Figure 3 below, these elements are compared in relation to each other in order to examine which of the 
categories was most influenced by the programming or if the effect was similar in all areas included in the research questions.

Figure 3: Students' Opinion of the Positive Effects of Scènes de ménage by Category

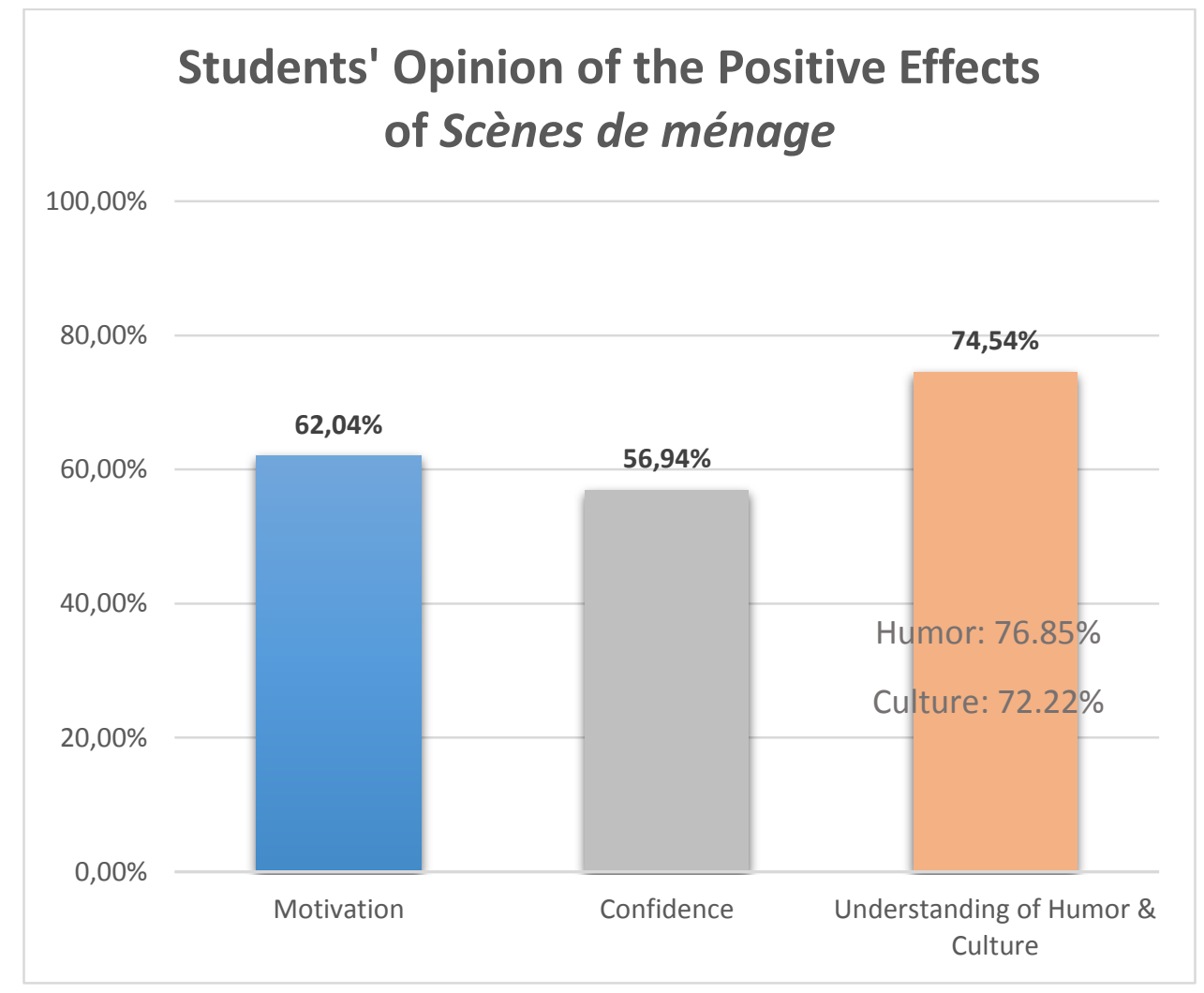

As presented in this graph, 62.04\% of the students believed that Scènes de ménage improved their motivation for the class, $56.94 \%$ of them believed it influenced their confidence, and an average of $74.54 \%$ of students believed it influenced their understanding of French humor and French culture. By comparison, we can see that Scènes de ménage mainly influenced the students' grasp of French humor and French culture, and that the students' confidence is the element that has least been affected by the projection of the episodes of Scènes de ménage in class. Scènes de ménage thusly did influence the students' motivation, confidence, and grasp of French culture and humor to a large extend, as predicted by this study's hypothesis. Interestingly, the data also highlights that according to students, Scènes de ménage improved their grasp of French humor (76.85\%) more than their grasp of French culture (72.22\%). 


\section{Students' Comments}

In the last part of the post-study questionnaire, the students were asked to comment on the element for which they chose "Strongly Agree" or "Strongly Disagree." Only 21 students out of 36 chose to comment, though three students provided remarks about the teacher's attitude in class rather than on the use of the videos. Those comments were not taken into account, and therefore only 18 comments were analyzed.

In their comments, some students explained that the videos were a great help when learning the French language. One student mentioned that (s)he felt like it improved his/her listening skills, and two mentioned their progress in vocabulary learning based on the real-life use of the words in the T.V. show. In other comments on listening skills, students' stressed the importance of repeated exposure to native speakers and to fast-paced spoken French. Three students mentioned the usefulness of subtitles to help the understanding and to help with productive vocabulary use (though it was not clarified if this means for oral or written production).

The difficulty of the activities was also referred to several times as a motivational factor. One student explained that the main motivational element was the fast rate of speech, the difficulty of which made them want to understand even more. Another student simply mentioned that the difficulty of the listening activity was a motivational factor. The difficulty in trying to understand the jokes and humor was also considered motivational by two students.

Almost all of the commenting students mentioned the humorous factor of the videos. As mentioned before, two students explained that the humor was difficult to understand at times, and the difficulty was a motivational factor in working on comprehension. Others explained that the activities accompanying the videos were fun (5), that it was a favorite activity (1), and that it was a nice change from the usual worksheet and slides. An additional four students mentioned that the video made the class more comfortable and easier for participation; three others mentioned the cultural knowledge they had gained and expressed a desire to look for other French shows (two participants) and French YouTubers (one participant). 
Some students also made negative comments. One stated that the content of the videos were "weird" and "cheesy," which suggests that the concept of French humor is still foreign for this specific student. Two students said that they could not understand the French spoken in the video because it was too fast (1) or too confusing (1). Those comments were in opposition to the previous ones, in which the students claimed that the difficulty was a motivational factor. Finally, one student mentioned that the videos did not help with writing and speaking skills unless the skills were practiced in addition to watching the video.

\section{Students' Grades}

Out of sheer curiosity, the students' grades were analyzed in order to estimate the general efficiency of the audio-visual material used in class and to confirm the efficacy of the French T.V. programming on student learning.

Table 16 presents the average grade per class for the control chapters and for the experimental chapters. The average grades were calculated based on participation, homework, journals, readings, and quizzes. Other grades, such as the mid-term and final exams, were not taken into account in the calculations because the grade could not be related to a specific chapter. For the same reasons, point reductions due to absences and extra credit were not included in the grade computation.

Table 16: Average Grade in Control Chapters and Experimental Chapters per Class

\begin{tabular}{|c|c|c|c|c|} 
& Control Chapters & Experimental Chapters & Average & Students \\
\hline Group 1 & $\mathbf{7 9 , 8 6 \%}$ & $76,87 \%$ & $78,37 \%$ & 15 \\
\hline Group 2 & $\mathbf{7 6 , 7 2 \%}$ & $74,01 \%$ & $75,36 \%$ & 24 \\
\hline
\end{tabular}

In both classes, the average grade is higher for control chapters than for experimental chapters. The difference is small and similar in both classes (2.99\% for Group 1and 2.71\% for Group 2). This difference can be credited to the different number of graded assignments in each chapter. In the control chapters, students had an average of five grades whereas in the experimental ones they had an average of seven grades. 
Figure 4 presents the students' average grades per chapter; the dark bars represent the control chapters and the lighter bars represent the experimental chapters.

Figure 4: Students' Average Grade per Chapter

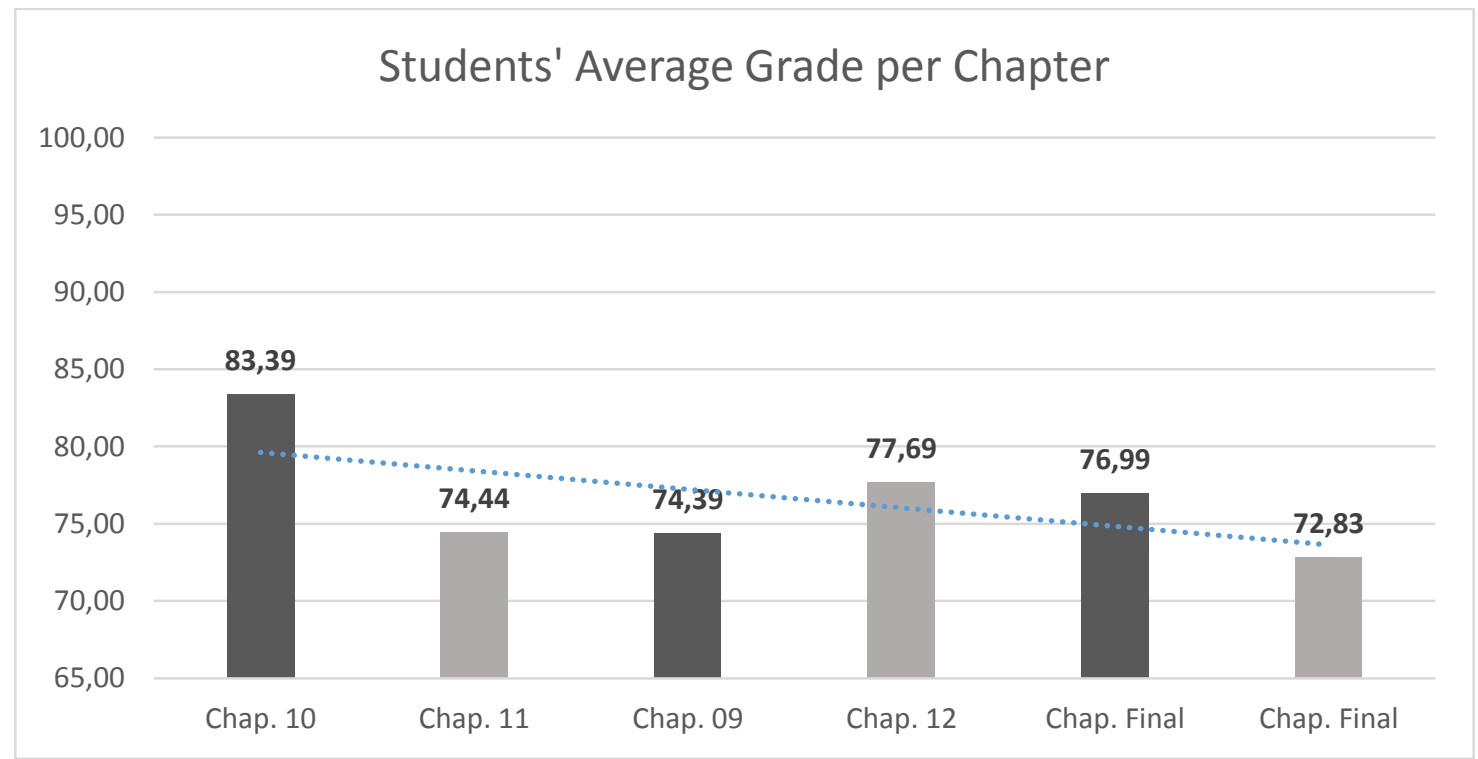

As the diagram shows, the grades seem to decrease through the course, but no clear tendency appears when comparing the average grades of control chapters to the one of experimental chapters.

Finally, Figure 5 presents students' individual average grade for the control chapters and the experimental chapters.

Figure 5: Average Grade per Students in Control and Experimental Chapters.

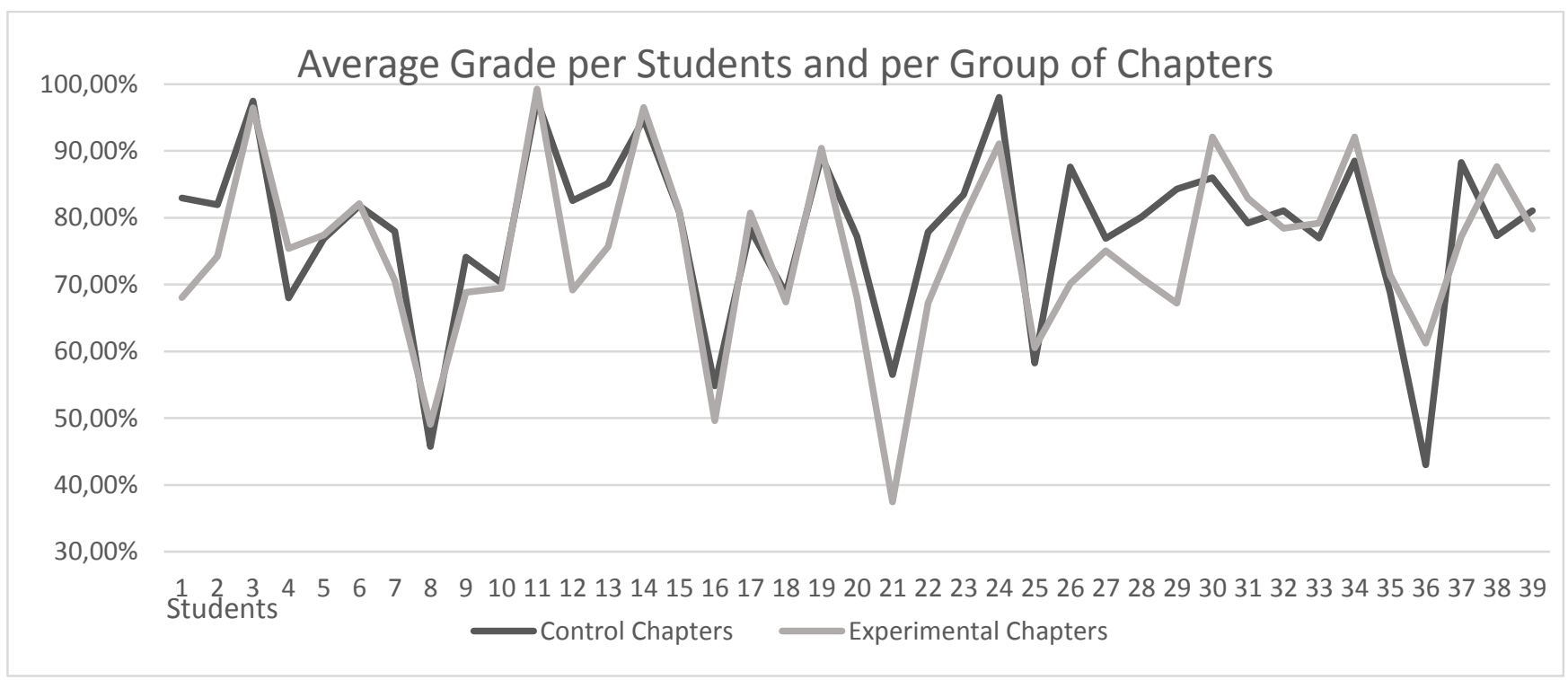


Four students (\#4, 30, 31, and 38) have better average grades for the experimental chapters, 17 have better results for control chapters $(\# 1,7,9,12,13,20,21,22,23,24,26,27,28,29,32,37$, and 39), and 18 have similar average grades in control and experimental chapters. There is therefore a tendency for students to have better grades in the control chapters.

The analysis of the grades does not correlate with the results of the motivation, affective filter, and French culture and humor analysis. If the students believed that the episodes of Scènes de ménage improved their motivation, confidence, and grasp of French culture and humor, the improvement is not observable in their academic grades. In addition, the grades were on average better for the chapters in which Scènes de ménage was not used as a teaching tool. 


\section{Chapter V：Discussion}

As the previous chapters have shown, most of the participants in the study had a positive view of the use of shortcoms in French language instruction. While individual skill areas were affected differently by the use of this authentic programming, and the effect of it on linguistic proficiency was not clear, in general students were both motivated and felt more confident in their language abilities after having worked with this authentic series. The following discussion will address individually the results of the students' surveys as they relate to each of the research questions:

1. Did the use of humorous videos of Scènes de ménage improve the students' motivation for the class and regarding the four basic skills of language learning?

2. Did the use of humorous videos of Scènes de ménage improve the students' self-confidence, therefore lowering their affective filter?

3. Did the use of humorous videos of Scènes de ménage expand the students' understanding of the target culture?

The discussion of survey results is followed by limitations of this study and areas of future research as well as concluding remarks.

\section{Discussion of Results by Research Question}

\section{Research Question 1: Did the use of humorous videos of Scènes de ménage improve the students' motivation for the class and regarding the four basic skills of language learning?}

The pre-study questionnaire, which participants completed at the beginning of the study, started with a section that highlighted the students' background in French. The data gathered showed that the students varied in experience levels in French. Some students had only had three semesters prior to entering the course and thus likely started French at the university, whereas others had taken French previously in high school, or they had relatives who spoke French. 
The data collected in the pre-study questionnaire showed that most of the learners considered themselves interested or very interested in learning French. The participants' reasons for having this interest could not be definitively determined because they sometimes selected several answers instead of choosing a main reason for registering in a French course. Yet, a clear trend in the results became apparent after analysis: Most of the students chose "academic purposes" as one of their reasons for registering in the course. French is one of many languages offered at the university, and according to the data collected in this study, the participants chose French over the other foreign languages offered because they believed it would help them in the future, whether in their academic or their professional lives. These results suggested that most of the learners were influenced by at least one extrinsic motivator for taking the course (as a benefit for a future career) even if they had other reasons, including those driven by intrinsic motivators. Most of the participants were interested in completing the course successfully in order to have it listed on a transcript or resume. A smaller number of students appeared to have intrinsic motivations for learning French, stating that they were taking the class because they were generally interested in learning French or because they were of French heritage, as they explained in the personal information sheets completed at the beginning of a course.

The pre-study questionnaire collected information not only about students' reasons for learning French but also about their views of authentic French programming and its perceived effect on their learning. A majority of learners reported not having watched French programming of any genre, and those who had said that they did not like French T.V. shows. In the post-study questionnaire, however, learners reported that Scènes de ménage made them want to watch more authentic French programs and more French comedies. This data suggested that using the shortcom in instruction motivated the learners enough to make them want to look for new material to practice, a fact that was corroborated by students' requests for recommendations for T.V. programs from the teacher.

The pre-study questionnaire also provided insight into the students' enjoyment while learning the language. The questions of the survey were worded in such a way in an effort to determine students' intrinsic motivations for learning the language. By asking them about their enjoyment of French, the investigator 
attempted to exclude extrinsic motivations, such as fulfilling a requirement or learning it for a job, from this part of the questionnaire. According to the data collected in this section, students noted enjoying learning French in each of the four language skills. They did, however, report enjoying easy listening activities (80.56\%) and speaking activities $(85.71 \%)$ the most, although some students reported that they did not enjoy listening or speaking activities at all compared to activities linked to the other skill areas. It is not surprising that the study participants noted enjoying using their listening skills more than others in class because this skill typically develops more quickly than the productive skills of speaking and writing. Given that the language of instruction is French in all of the classes in the curriculum, students have heard the language throughout the class period and worked on that skill more than the others. Because this receptive skill is, in most cases, more developed than the others, students likely derived a sense of enjoyment and experienced self-confidence in being able to demonstrate what they had mastered. The survey did, however, yield the surprising result that students experienced more enjoyment in using their speaking skills than their listening skills. Given that speaking is typically an area developed last in emerging learners of French, it was unexpected that they would enjoy communicating using that skill the most. Instead one would expect students' performance in that skill to be weaker and therefore their enjoyment in using it to be lower. That students reported greater enjoyment in practicing the weaker skill of speaking suggests that factors besides good performance and a good grade played an important role in their motivations for learning French. That is to say, intrinsic motivators were driving students' desire to learn as well as extrinsic motivators.

The post-study questionnaire focused on the effect that Scènes de ménages had on learners' motivation in three of the four language skills (listening, speaking, and writing) as well as vocabulary acquisition. Reading skills were excluded in this part of the survey because when the study was designed, in contrast to the other language skills, the investigator did not plan to link reading activities directly related to the video programming. Given that there were no targeted reading activities, measuring student motivation for reading based on the video did not appear to be a significant data point. Based on their experience with reading subtitles accompanying the video, however, the data collected in a later section of the survey showed that Scènes de 
ménage had a positive effect on their perception on their reading skills. Therefore in future research on the topic, the investigator would include a survey question linking reading skills and learner motivation. The results of the survey did show that the video program helped students feel more motivated to learn French for its content, to learn about French culture, and to practice their listening skills (77.77\%), writing skills (44.45\%), vocabulary skills (61.11\%), and speaking skills (58.34\%). Of the areas about which students were surveyed, they felt most motivated to work on their listening skills after having watched Scènes de ménages. This result may underscore their intrinsic motivation of enjoyment in working on listening (as was reported in the pre-study survey and discussed above). Given that Scènes de ménages is an authentic French program and learners are typically more motivated by authentic material, it is not surprising that participants in the study would be inspired to improve their listening skills in order to understand more of the authentic text. Additionally, however, an extrinsic motivator could also have been at play. Given that all of the course grades in the experimental units were linked to Scènes de ménages, students may have had extrinsic motivation for improving their listening. By doing so, they could have improved their performance in those units and in the course in general.

Comments in the post-study questionnaire also made clear that the learners thought that Scènes de ménages was motivating in terms of improving their cultural understanding and vocabulary acquisition. Again, the fact that the video programming was authentic would inspire students to discover and understand more authentic language and understand better the perspectives and practices of French culture represented in the video program. In all aspects of cultural learning and language skills use, Scènes de ménages appeared to have had a positive impact on students' motivations to learn French. While they expressed both intrinsic and extrinsic motivations for learning the language, both seemed to have been positively influenced by the use of the authentic video programming. 


\section{Research Question 2: Did the use of humorous videos of Scènes de ménage improve the students' self- confidence, therefore lowering their affective filter?}

The next section of the pre-study survey looked at students' self-confidence in each of the skill areas. For the purpose of this study, the concept of self-confidence was used on the students' surveys to measure the level of affective filter, given that students typically do not understand the meaning of the term "affective filter." In the pre-study survey, students reported feeling confident in their language skills by agreeing or strongly agreeing with statements about self-confidence. Their self-confidence in each of the areas broke down as follows: writing (75\%), reading (69.45\%), listening (55.55\%), speaking $(22.22 \%)$, and vocabulary $(61.11 \%)$. Students reported feeling most confident about their reading and writing skills. It is not surprising that they rated their confidence in reading higher, given that as a receptive skill it is typically developed before the productive skills, and in previous courses and the non-experimental chapters they practiced the skill by reading both in their textbooks and completing online assignments. Furthermore, their reading was positively affected by the process of reading subtitles accompanying the video. More surprising was the students' high assessment of their confidence in their writing skills. This result could be attributed to the multiple writing assignments, (some with multiple drafts) that students completed throughout the basic and intermediate language sequence. Additionally, students were given multiple opportunities to improve their writing based on ongoing feedback on journal entries and homework assignments. More surprising was that they had less confidence in their listening skills than in reading and writing. Reasons for lower confidence in their listening skills could be the fact that the investigator was also a native speaker of French, which may have raised their affective filter. Many students exhibited apprehension regarding native speakers of the language, stating informally in class that they speak too quickly. Participants noted in the surveys that they were often uneasy in listening to a native accent in contrast to an American accent from non-native teachers because it is more unfamiliar to them. The lower assessment of their confidence in listening correlates to their motivation for activities that worked on listening as discussed above. Learners identified weakness in their listening skills and therefore felt motivated to improve them. The same issue was observed with their speaking skills: Of all of the skill areas, students rated their confidence in 
speaking the lowest, which was to be expected, as speaking is typically the last skill to be developed among developing language learners. Similar to the data concerning listening, students stated that they were motivated to do more activities to develop their speaking skills in an effort to communicate better with other speakers of the language, including native speakers.

In the post-study questionnaire, students were asked if Scènes de ménage had helped them feel more confident in all of their language skills. The results to this part of the survey divided by skill were as follows: listening (80.56\%), reading (61.11\%), speaking (52.77), and writing (33.33\%). Of all of the skills, students' confidence in listening was most positively influenced by the use of authentic video programming. This result, which was the one expected by the investigator, demonstrates that students benefited from repeated exposure to authentic language through the use of the video program. Their listening was supported by images, and the humorous moments were cued by the laughter in the audience, which also helped students to understand when a joke had been made. These aspects, along with the formulaic character of the program, provided excellent scaffolding for students' listening and helped them to understand more, thereby improving their confidence.

In addition to listening skills, students reported that Scènes de ménages had helped them feel more confident about their reading skill, a result that was not aimed for when the study was initially conceived. This trend can be attributed to the presence of French subtitles in the videos on which the learners relied heavily to bolster their listening skills. While listening and reading the script, students also learned vocabulary by associating the sound to written form. Student also reported a positive effect of the video programming on their speaking skills. Students had reported a lack of confidence in their speaking skills prior to the study, but Scènes de ménage likewise bolstered student confidence in this skill area. The improvement in their confidence in speaking could be attributable to the fact that they heard the native pronunciation and cadence and felt like it was something they could replicate, rather than having to produce it alone without any example beyond that of the teacher. 
Writing was one area in which students felt like Scènes de ménages had the least impact. While some learners believed that the videos helped improve their confidence in writing, this number was smaller than in the other areas. In addition, many disagreed that the videos had improved their confidence, or they reported that they had not produced any perceivable effect in their writing skills at all. It is logical that Scènes de ménages had a lesser effect on the development of students' writing skills because most of the activities based on the videos were oral. Students did not complete writing assignments directly related to the content and language of the video. Future research studies would need to focus on writing activities that accompany the video programming to determine accurately the effect of working with the shortcom on the development of writing skills. In sum, the use of videos of Scènes de ménage in class improved the learners' self confidence in all four basic language skills, albeit not to the same degree. Therefore the programming can be said to have had a positive impact on students' perceived overall learning of French.

\section{Research Question 3: Did the use of humorous videos of Scènes de ménage expand the students' understanding of the target culture?}

The last section of both the pre-study and post-study questionnaires were directed at determining students' cultural understanding, both in general and specifically as it related to humor. In the pre-study questionnaire, the data about French culture showed that culture was a strong motivator for students to learn French and that they believed that they had a good understanding of cultural concepts. This result can be explained by the exposure the participants had had to French language learning throughout the previous semesters of instruction and the focus modern language classes placed on all aspects of culture as they are represented in the ACTFL World Readiness Standards. It is important to underscore, however, that while students believed that they had a good understanding of culture, they did not necessarily have the means by which to measure that skill accurately, given that many of them had never experienced French culture firsthand.

With regard to humor as a singular aspect of culture, the data showed that learners thought humor to be less of a motivation for learning French than culture in general. The data showed that $75 \%$ thought humor to be 
motivating for learning French, but when rating the factors that were "very motivating" for learning French, $30.56 \%$ rated French culture in general to be very motivational in contrast to $22.22 \%$ that found French humor "very motivational." This can be attributed to the fact that humor is often difficult for non-native speakers to understand, and often students' native humor is quite different from that of the target-language humor. As this thesis has shown, French humor can, in some cases, seem offensive to people in the United States who are unaccustomed to it. Nevertheless, the data revealed that at the beginning of the study students enjoyed humorous T.V. shows from the U.S. or elsewhere (86.11\%) more than other authentic programming (44.44\%). These data suggested that students would enjoy French humor as a learning tool, even if they did not understand it entirely.

The data also revealed that despite their interest in humor as well as other authentic programs, the learners generally did not watch French language T.V. shows before the study. If they did, they watched programs accompanied by English subtitles. The students' lack of interest in French programming may be explained by the fact that most French series or programs are inspired by U.S. television shows but do not reach the production standards of their American counterparts. Furthermore, discussions in classes and after French movie nights with students in the program where this study was conducted suggested that U.S.-Americans tend to criticize French T.V. because of three main features: 1) the characters are rarely painted in black and white, and students complain that they do not know who is good or bad; 2) the characters are more realistic and not "good looking" enough; and 3) the endings are often open and all the questions are not answered, which is unsettling for many.

After the study, the data showed that students agreed that watching Scènes de Ménages improved their enjoyment of French culture in general and of French humor in particular. This result showed that the videos used in class were well-selected in terms of humor and language level. Students seemed to grasp explanations of jokes and other cultural points. These positive results correlated with the result of students wanting to watch more French T.V. shows with humor or culture after the study. 
According to the same set of data, students felt that Scènes de ménages helped improve their understanding of French humor. They similarly believed that the use of the program improved their understanding of French culture in general, although to a slightly lesser degree. It is important to note, however, that humor is an integral part of culture and that even although students made a distinction between humor and culture because of the way questions were formulated in the survey, both reports indicated an improvement in students' cultural understanding because they understood humor better.

\section{The correlation with the grades}

As a point of interest, data were gathered on students' grades, in order to see if the results of the study correlated with the students' grades. The data reported that, although students noted an improvement in their motivation and self-confidence, their academic results did not reflect a similar improvement. In fact, the data showed that the students had better results on language assessments in the control chapters rather than in the experimental ones. This finding could be explained by the fact that the experimental chapters presented harder grammatical structures and concepts than the control ones. In addition, while the activities accompanying the videos targeted grammar, the videos usually did not lend themselves to an inductive approach to teaching grammar and focused more on vocabulary. The students' grades demonstrated that an improvement of motivation, self-confidence, and cultural understanding did not immediately translate into improved language proficiency, likely because the grammatical constructions of authentic video programming were out of reach for students of this level and students were unable to replicate them. Nevertheless, as input the use of humor and authentic television programming was valuable because it increased students' cultural knowledge and aural comprehension.

The fact that students' scores were lower in the units in which the shortcom was used could also be directly attributable to overall motivation. It is important to remember that for the learners driven by extrinsic motivations, the authentic material may have been less motivating because of its difficulty. Students may have also worked less on assignments related to the video because they were not graded. As Richard (2001) explains, 
authentic documents are generally more difficult to process by students than didacticized material because of difficult language, advanced vocabulary items and complex language structures. Consequently, students with a lower motivation would have been even more discouraged by the increase of difficulty in processing the input in experimental chapters because of the authentic video programming, and, as a result, they received worse grades.

\section{Limitations of the Study and Directions for Future Research}

There are several characteristics of this study that may limit the results. First, it is difficult to make generalization about the use of shortcoms in French language instruction because the study only focused on the use of one type of humorous authentic video programming. While students in general liked the program, those who reported no increase in motivation or self-confidence based on the programming may have not liked Scènes de ménage itself rather than humorous video programming or shortcoms in general. In addition, the scope of the study was too small: the number of participants was not high enough to draw general conclusions, and a longer study would have been more beneficial to set differences between the experimental and the control chapters. Future studies would need to examine the use of additional shortcoms in French instruction with a greater number of students to determine the benefits of the genre in class.

The quality of projection material may also have had an impact on the results. The classrooms were not equipped the same way, and the sound was sometimes of low quality, depending on the video clip and the classroom technology. This may have impacted some learners' understanding and motivation and resulted in their lower rating of the program. In addition, based on technological difficulties, subtitles did not always project, which limited students' comprehension in class. These problems relating to the physical characteristics of the classroom could have influenced the learners' motivation to participate in the activities, especially given the data that shows some students relied heavily on subtitles.

In addition, it would have been even better for the students to use the video programming as their only source of input in order to isolate its efficacy as a teaching resource. Because this study took place in a 
university setting, however, it was compulsory that the classes follow the established curriculum and the pace of the other classes at the same level. It was difficult to find a video with enough input (e.g. grammar structures) to cover the curricular requirements of the program and maintain the fast pace of the course. Consequently, the class instruction focusing on Scènes de ménage included PowerPoint presentations that reinforced the input introduced in all sections of the course, including those not involved in the study, in order to make sure that the participants would not be impacted in a negative way.

In order to understand how the use of authentic video programming may affect students' development of proficiency over time, a longitudinal study should be conducted with objective proficiency tests conducted both before and at the conclusion of the study. For example, it would be necessary to construct a two- to threesemester curriculum based entirely on authentic French videos in a variety of genres used to teach novice or intermediate learners of French. The results of this two-semester curriculum could then be compared to the result of traditional a two-semester curriculum. Conducting a study in this format would help isolate the efficacy of the authentic video programming as a teaching tool.

When it comes to the correlation with the grades, the grades should have been of an equal number per chapter, of a same nature, and be focused on the four basic language skills so that to be usable. A new study would be necessary to analyze the effect of the shortcom on the learners' grades.

Finally, this study only touches the topic of French humor and students' acceptance of it, and further study is necessary to see to what extent French humor can be accepted, recognized, or useful in class. It would also be helpful to examine how U.S. and French humors are compatible and incompatible to better know what to use in class - what topics are too complicated or culturally explicit for students, and which ones are entirely unacceptable in a classroom setting. Furthermore, it is important to restate that each individual student can have different reactions to a type of humor because of cultural origins or personal experiences. Ultimately diverse learners will find different types of authentic material stimulating. As cited above, one approach would be to 
use a variety of shortcoms and/or various types of authentic humor-based programming to test them for efficacy in the classroom. These could include game-shows, variety shows, late-night T.V., and reality T.V.

\section{Conclusion}

Overall, this study has helped to fill in the gaps of current research by providing an overview of the learners' views of the benefits of humorous authentic video programming in French instruction. It also provided insight into students' perspectives on how a language class could be run and their reception of authentic materials, specifically French humor. Based on the results, it is clear that humorous videos can be useful in language classrooms as a break from traditional instructional approaches because they improve learners' motivation and self-confidence. The use of authentic video programming encourages most learners to participate and be more engaged, and to work harder in the classroom. It also improves their grasp of French culture, and specifically French humor, and trains their ears to recognize sounds from other native speakers.

Laughter has always been said to be the best medicine, and this study proved that this can also be the case in language classrooms. This study showed that humorous videos can help students become more comfortable in class, promote understanding and tolerance toward a different culture, and also improve their understanding of the target language and culture. All of these factors make the shortcom an ideal tool for promoting students' interest in the target language and culture outside of the classroom and help them to become lifelong learners. 


\section{References}

\section{Bibliographie}

Abrahams, R. (1962). Playing the Dozens. The Journal of American Folklore 75(297), Symposium on Obscenity in Folklore, 209-220.

Akbulut, Y. (2007) Bilingual Acquisition and Cognitive Development in Early Childhood: Challenges to the Research Paradigm. Elementary Education Online, 6,3, 422-429.

Alessi, S.M. \& Trollip,S.R. (2001) Multimedia for Learning: Methods and Development. ( $3^{\text {rd }}$ Edition). Boston, MA: Allyn \&Bacon, Inc.

Al Surmi, M. A. (2012) Authentic ESL spoken materials: soap opera and sitcom versus natural conversation. Unpublished doctoral dissertation, Northern Arizona University, Flagstaff (AZ), United-States.

Arnaud, P. (2015, January 9) Le Paradoxe de Charlie Hebdo. Le Grand soir. Retrieved from http://www.legrandsoir.info/le-paradoxe-de-charlie-hebdo.html.

Audience du Prime e Scènes e Ménage diffusé hier sur M6. (2015) TVnews. Retrieved from http://www.leblogtvnews.com/2015/02/audience-du-prime-scenes-de-menages-diffuse-hier-sur-m6.html.

Audience : Scène de Ménages réalise un record sur M6. (2014) Jean-Marc Morandini.com Retrieved from http://www.jeanmarcmorandini.com/article-326638-audience-scenes-de-menages-realise-un-record-surm6.html\#comments.

Baradaran Torabi, F. \& Poordaryaie Nejad, A. (2014) The Role of Audio Visual Aids on Speaking Rate of Iranian EFL Learners, Journal of Social Issues \& Humanities, 2, 10, 10-15.

Beam, S. (2007). Laughing Matters: Farce and the Making of Absolutism in France. Ithaca: Cornell University Press.

Benavent G. \& Peñamaría S. (2011) Use of Authentic Materials in ESP Classroom, Encuentro 20, 89-94.

Berreby, D. (2012) Why Americans See Racism Where the French See No Problem. Big Think. Retrieved from http://bigthink.com/Mind-Matters/why-americans-see-racism-where-the-french-see-no-problem.

Byock, J. (1983) Feud in the Icelandic Saga. Berkeley: University of California Press.

Cañado, M. \& Esteban, A. (2005) Authenticity in the Teaching of ESP: An Evaluation Proposal. Journal of the Slovene Association of LSP Teachers. Retrieved from http://www.sdutsj.edus.si/ScriptaManent/2005_1/Perez_Almagro.html.

Canning-Wilson, C. \& Wallace, J. (2000) Practical Aspects of Using Video in the Foreign Language Classroom. The Internet TESL Journal, 6, 11. Retrieved from internet: http://iteslj.org/Articles/CanningVideo.2001.html.

Cantorovitch, M. (2002) Vous Riez, Oui, Mais Pourquoi ? Le Français dans le Monde, July 2002, 42-47.

« Charlie Hebdo ». Le dernier dessin de Charb : «Toujours pas d'attentats » (2015, January). L'OBS. Retrieved from http://tempsreel.nouvelobs.com/charlie-hebdo/20150107.OBS9468/charlie-hebdo-le-dernier-dessinde-charb-toujours-pas-d-attentats.html.

Cherpack, O. (2012) Audio-Lingual and Audio-Visual Methods of Teaching. Retrieved from http://confesp.fl.kpi.ua/fr/node/1060. 
Chimezie, A. (1976). The Dozens: An African-Heritage Theory. Journal of Black Studies, 6(4), 401-420.

Clarke, D. (1989) Communicative theory and its influence on materials production, Language Teaching 25, 7386.

Collentine, K. (1997) The effects of Authentic and Simulated-authentic Video Materials on the Listening Comprehension Abilities of Foreign Language Learners of Spanish. Unpublished doctoral dissertation, University of Texas, Austin (TX), United-States.

Collès, L. (2004) L'Humour en classe de FLE, In Aux frontières de la didactique du français langue étrangère : actes de la section de didactique de l'Association des Franco-romanistes allemands (pp. 145-152). Aixla-Chapelle : - .

Collins, W. \& Hunt, J. (2011) Improved Student Motivation and Confidence Through Self-access Listening, Video Forums and Talking Journals. The JALT CALL Journal 7, 3, 319-333.

Deimling, K. (2012) The Not-SO-Subtle Racism Of the New French Film 'Intouchables.' The Huffington Post. Retrieved from http://www.huffingtonpost.com/artinfo/racism-in-the-intouchables_b_1339485.html.

Demari, JC. (2004) Le courrier des internautes : Authentique, mode d'emploi. Le Français dans le monde 331, $32-33$.

Dogan, B. (January 2010) L’Humour en Liberté Surveillée? Scribium. Retrieved from https://scribium.com/belya-dogan/a/lhumour-francais-en-liberte-surveillee/.

Dogan, B. (February 2010) L'humour en France, histoire et origines. Scribium. Retrieved from https://scribium.com/belya-dogan/a/lhumour-en-france-histoire-et-origines/.

Dunne, M. (2007) Calvinist Humor in American Literature. Baton Rouge: Louisiana State University Press.

Fidler, M. (2004) Reading and Studying Culture with Electronic Materials, Revue Canadienne des Slavistes 46, $1,83-99$.

Flowerdew, J. \& Peacock, M. 2001. Research perspectives on English for academic purposes. Cambridge: Cambridge University Press.

Ford, J. (1972) Analysis of a Particular Audio-Visual Method for Teaching French Vocabulary. The French Review 45, 4: 842-845.

Gardes, JC. (2002) Rire en France et en Allemagne. Le Français dans le Monde, July 2002, 64-70.

Gilmore, A. (2007) Authentic Material and Authenticity in Foreign Language Learning, Language Teaching 40, 2, 97-118.

Gilmore, A. (2011) 'I Prefer Not Text': Developing Japanese Learners' Communicative Competence with Authentic Materials. Language Learning 61, 3, 786-819.

Grant, L. \& Starks, D. (2001). "Screening appropriate materials closings from textbooks and television soap operas". IRAL, 39, 39-50.

Guariento, W. \& Morley, J. (2001) Text and task authenticity in the EFL classroom. ELT Journal 55, $347-353$.

Guyon, A. (2002) Dessin d'humour et enseignement du français langue étrangère. Le français dans le monde, July 2002, 71-75.

Harrold, A. (2015, September 14). Charlie Hebdo publishes a cartoon of drowned Syrian toddler Aylan Kurdi. The Independent. Retrieved from http://www.independent.co.uk/news/world/europe/charlie-hebdo-covercartoon-jokes-about-death-of-drowned-syrian-toddler-aylan-kurdi-10499645.html 
Heitman, R. (2002) Interlude : l'Humour Vu des États-Unis. Le Français dans le Monde, July 2002, 7-9.

Hitchens, C. (2007, January) Why Women Aren’t Funny. Vanity Fair. Retrieved from http://www.vanityfair.com/culture/features/2007/01/hitchens200701.

House, K. (2008) Authentic materials in the classroom. In Peñamaría, S. and Martínez, R.(eds) Didactic approaches for teachers of English in an international context (53-70). Salamanca: Ediciones Universidad de Salamanca.

Hu, H.P. \& Deng, L.J. (2007) Vocabulary Acquisition in Multimedia Environment. US-China Foreign Language 5, 8, 55-59.

Jones (2004) Testing L2 vocabulary recognition and recall using pictorial and written test items. Language Learning and Technologies 8, 3, 122-143.

Jordan, R.R. (1997) English for Academic Purposes: A Guide and Resource for Teachers. Cambridge: Cambridge University Press.

Joynt, R. (2008) Using Authentic Multi-Media Material to Teach Italian Culture: Student Opinions and Beliefs, Unpublished doctoral dissertation, University of Texas, Austin (TX), United-States.

Kawecki, R. (2004) De 1'utilité des documents authentiques. Le Français dans le monde 331, 31-32.

Keller, J. M. (1984). The use of the ARCS model of motivation in teacher training. In K. Shaw \& A. J. Trott (Eds.), Aspects of Educational Technology Volume XVII: staff Development and Career Updating. London: Kogan Page.

Krefting, R. (2014) All Joking Aside: American Humor and Its Discontents. Baltimore (MD): Johns Hopkins University Press.

Lauter, D. (2012, January 1) Hit French Movie "Intouchable” has Some Crying Racism, but the reaction from some US critics has many French scratching their heads. Los Angeles Times. Retrieved from http://articles.latimes.com/2012/jan/01/world/la-fg-france-untouchables-20120102.

Limon, J. (2009) American Humor in History, American Literary History 21, 2, 306-315.

Lin, L.F. (2010) English Learners' Incidental Vocabulary Acquisition in the Video-based CALL Program. Asian EFL Journal, Special Issue, 12, 4, 51-66.

Liskin-Gasparro, J.E. \& Verguez, A. (1990) Teaching Listening Comprehension Through Video In First-Year College Spanish. IALL Journal of Language Learning Technologies, 23, 1, 37-49.

Mathieu, G. (2015) Les Américains et l'Humour Français sont-ils Incompatibles? France-Amérique. Retrieved from http://www.france-amerique.com/articles/2014/10/15/les_americains_et_1_humour_francais_sontils_incompatibles.html.

McCall, W.G. \& Craig, C. (2009). Same-Language-Subtitling (SLS): Using Subtitled Music Video for Reading Growth. In Proceedings of World Conference on Educational Multimedia, Hypermedia and Telecommunications 2009 (pp. 3983-3992). Chesapeake, VA: AACE. Retrieved from http://www.samelanguage-subtitling.com/paper-sls.html.

McCombs, M. (1969) Verbal and Object Availability in the Acquisition of Language: Implications for AudioVisual Communication. Journal of Communication 19, 54-63.

Michelson, B. (2015) The Year's Work in American Humor Studies, 2013. Studies in American Humor, Series 4, 1, 1, 41-105. 
« Mes enfants m’ont glissé des mains », raconte le père du garçon noyé. (2015, September 4).Le Monde.fr. Retrieved from http://www.lemonde.fr/europe/article/2015/09/03/la-photographe-de-1-enfant-syrien-noyetemoigne 4745032 3214.html\#meter_toaster.

Morat, B. \& Abidin, M. (2011) The Use of Video In ESL Teaching And Learning: Youtube's Potential As A Resource. Diges Pendidik 11, 2, 94-104.

Muñoz- Basols, J. (2005) Learning through Humor: Using Humorous Resources in the Teaching of Foreign Languages. The A.T.I.S. Bulletin, 42-46.

Narváez, L. (1998) Authentic Cultural Materials: The Case of Television Programs Received via Satellite. Hispania 75, 1, 207-208.

The National Standards Collaborative Board. (2015). World-Readiness Standards for Learning Languages: Fourth Edition (W-RSLL). Alexandria, VA: Author.

Pegg, S. (2007) What are You Laughing at? The Guardian. Retrieved from http://www.theguardian.com/film/2007/feb/10/comedy.television.

Polat, N. (2008) Pre-Service Teachers' General and Specific Beliefs about Authentic, Commercial and TeacherMade EFL Materials: Pedagogical and Practical Considerations. In Erozan, F. (Ed) ELT profession: challenges \& prospects: the proceedings of the 2 nd International conference on ELT, 2006, Eastern Mediterranean University (114-122). Munich: Lincom publishing.

Porcher, L. (2002) L’Humour Comme le Tango : Une Pensée Triste qui se Danse... Le Français dans le Monde, July 2002, 48-53.

Ramírez Salas, M. (2003) Selecting Appropriate Authentic Video Material for an EFL Classroom. Káñina 27, 1, 159-170.

Richards, J.C. (2001) Curriculum Development in Language Education. Cambridge: Cambridge University Press.

Saloy, ML. (2001) Still Laughing to Keep from Crying: Black Humor. Louisiana Folklife Festival booklet. Retrieved from http://www.louisianafolklife.org/LT/Articles_Essays/still_laugh.html.

Scènes de Ménage : un Record d'Audience Auprès des Ménagères.(2014) Toute la TV. Retrieved from http://www.toutelatele.com/scenes-de-menages-un-record-d-audience-aupres-des-menageres-66057.

Schmidt, R. W. (1990a). The role of consciousness in second language learning. Applied Linguistics, 11, 2, 1746.

Schmitz, J. R. (2002) Humor as a pedagogical tool in foreign language and translation courses, Humor 15, 1, 89-113.

Secules, T., Herron, C., \& Tomasello, M. (1992). The effect of video context on foreign language learning. The Modern Language Journal, 76,4, 480-490.

Sherman, J. (2003) Using Authentic Video in the Language Classroom. Cambridge: Cambridge University Press.

Skinner, B.F. (1957). Verbal Behavior. Acton, MA: Copley Publishing Group.

Spinassou, MC. (2013) Audience: Nouveau Record pour Scènes de Ménage. Le Figaro. Retrieved from http://tvmag.lefigaro.fr/programme-tv/article/serie/73745/audiences-nouveau-record-pour-scenes-demenages.html. 
Tomlinson, B. \& Avila, J. (2007) Seeing and Saying Yourself : Roles of Audio-Visual Mental Aids in Language Learning and Use. In B. Tomlinson (ed.) Language Acquisition and Development: Studies of Learners of First and Other Languages. London: Continuum, 61-81.

Tschirner, E. (2001) Language Acquisition in the Classroom: The Role of Digital Video. Computer Assisted Language Learning 14, 3-4, 305-319.

Twain, M. (1897) How to Tell a Story and Other Essays. New York: Harper \& Brothers.

Vauth, M. (2014) L'Humour Français peut-il s’Exporter ? Marketing Professionnel. Retrieved from http://www.marketing-professionnel.fr/parole-expert/marketing-international-humour-francais-export201403.html.

Wachob, P. (2011). Critical friendship circles: The cultural challenges of cool feedback. Professional Development in Education, 37, 3, 353-372.

Wagner, M. \& E. Urios-Aparisi. (2011) The use of humor in the foreign language classroom: Funny and effective?, Humor 24, 4, 399-434.

Washburn, G. (2001). Using situation comedies for pragmatic language teaching and learning, TESOL Journal, 10, 21-26.

Weissberg, J. (2011, September 29) Film Review: Untouchable. Variety. Retrieved from http://variety.com/2011/film/reviews/untouchable-1117946269/.

Weyers, J. R. (1999) The effect of Authentic Video on Communicative Competence, The Modern Language Journal 83, 3, 339-349.

Williams, R.T. \& Lutes, P. (2007) Using video in the ESL classroom. Retrieved from http://www.takamatsuu.ac.jp/library/06_gakunaisyupan/kiyo/journal.html.

Wynne, W., Weber-Fève, S., Ousselin, E. \& Vanpatten, B. (2013) Liaisons: An Introduction to French. Cengage Learning.

Yan Piaw, C. (2014) The effects of humor cartoons in a series of bestselling academic books. Humor 27, 3, 499520.

Zeller, N. \& Melvin, B. (1984) Strategies for the Use of Authentic Materials. In John, J.(Ed), Applied Language Study: New Objectives, New Methods: papers from the 1983 conference at Oklahoma State University (173-184).Maryland: Rowman \& Littlefield.

Zuroski Jenkins, E. \& Coleman, P. (2014) “The senses of Humor.” Eighteenth-Century Fiction 26, 4, 505-514.

\section{Sitographie}

- Caricatures in the 19th : Blog about the history of caricatures in France in the $19^{\text {th }}$ Century (http://tpecaricatures.canalblog.com/)

- Je suis Charlie: Page dedicated to the Charlie Hebdo attacks, hosted by the newspaper website Le Parisien. (http://atelier.leparisien.fr/sites/Je-Suis-Charlie/) 
- Qualtrics: Website to create, publish, and analyse surveys. (http://www.qualtrics.com/)

- OBS: Online news (http://tempsreel.nouvelobs.com)

- One Stop : Website dedicated for

- Simpson World: Official website of the Simposon Serie (https://www.simpsonsworld.com/)

- South Park: Official webpage for the serie South Park. (http://southpark.wikia.com) 
APPENDICES

Appendix A: Du haut en bas...ou les causes et effets

Anonymous (1814), retrieved from http://tpecaricatures.canalblog.com/

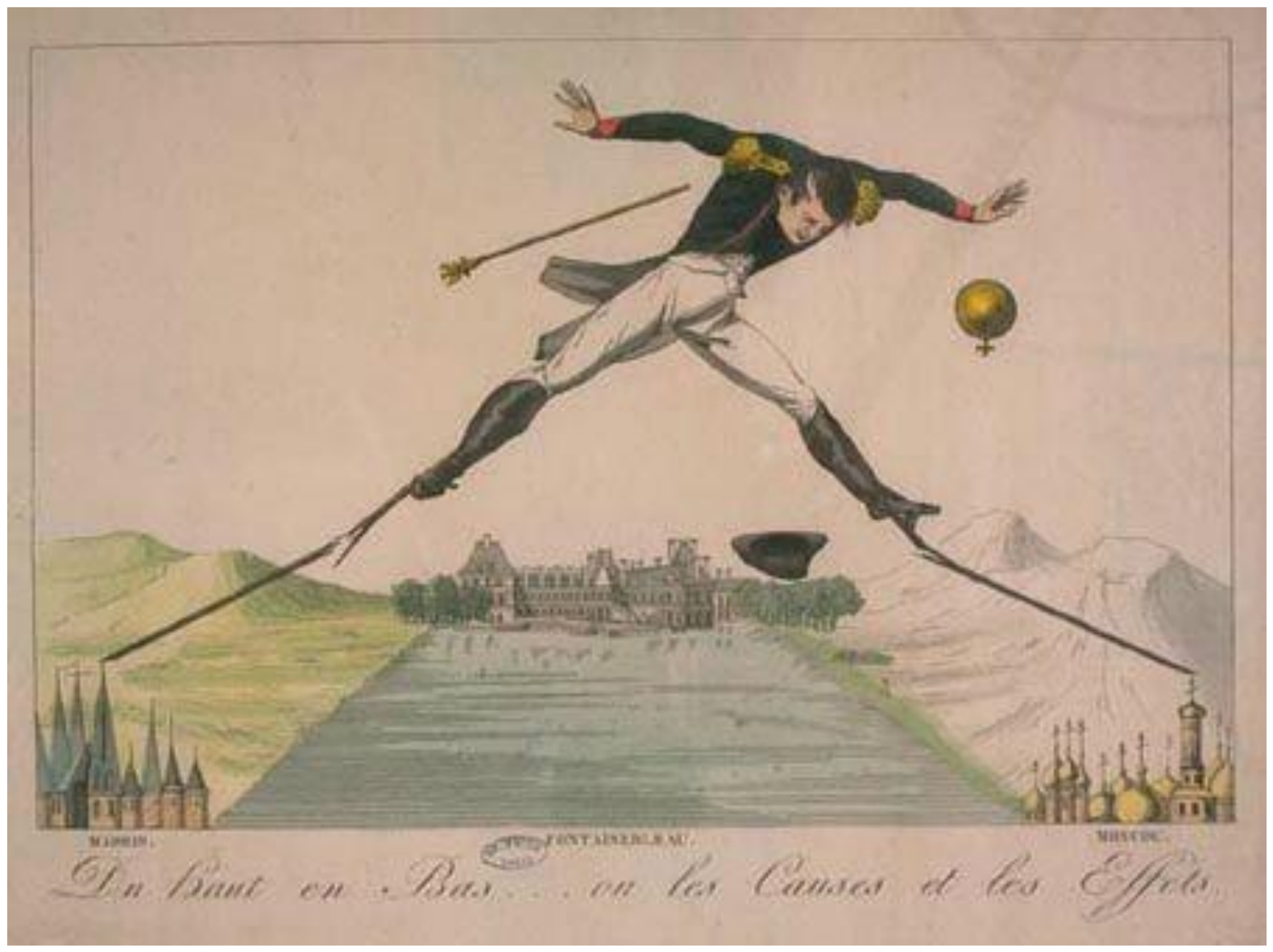




\section{Appendix B: The Little Man with a Great Appetite Sitting down to Dinner} anonymous (1806), retrieved from http://tpecaricatures.canalblog.com/

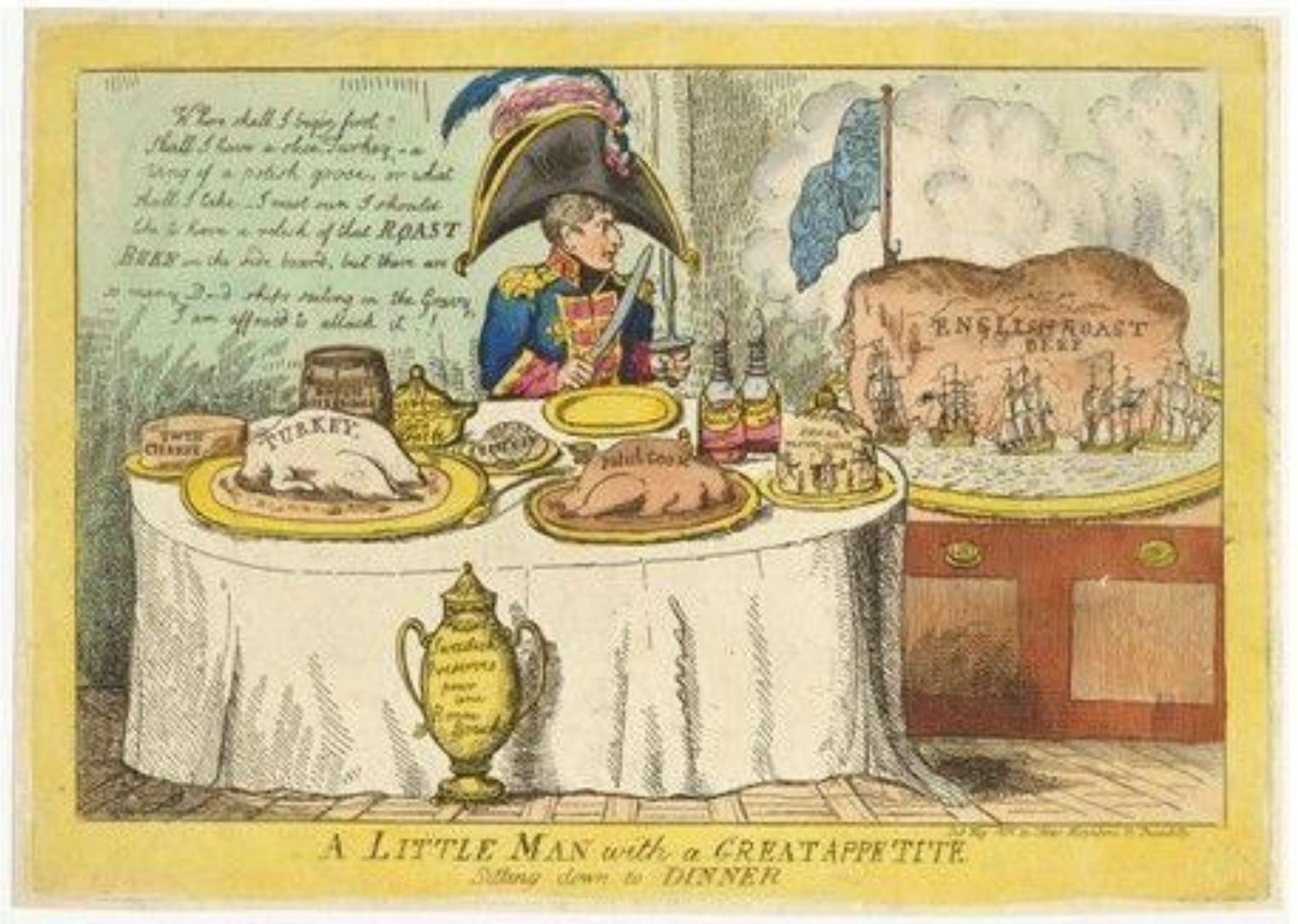

A Litdie Man with a Great Appetite Sitting down to Dinner Anonyme - 1806 
Appendix C: Toujours pas d'attentats en France

Charb (January, 2015), retrieved from http://tempsreel.nouvelobs.com

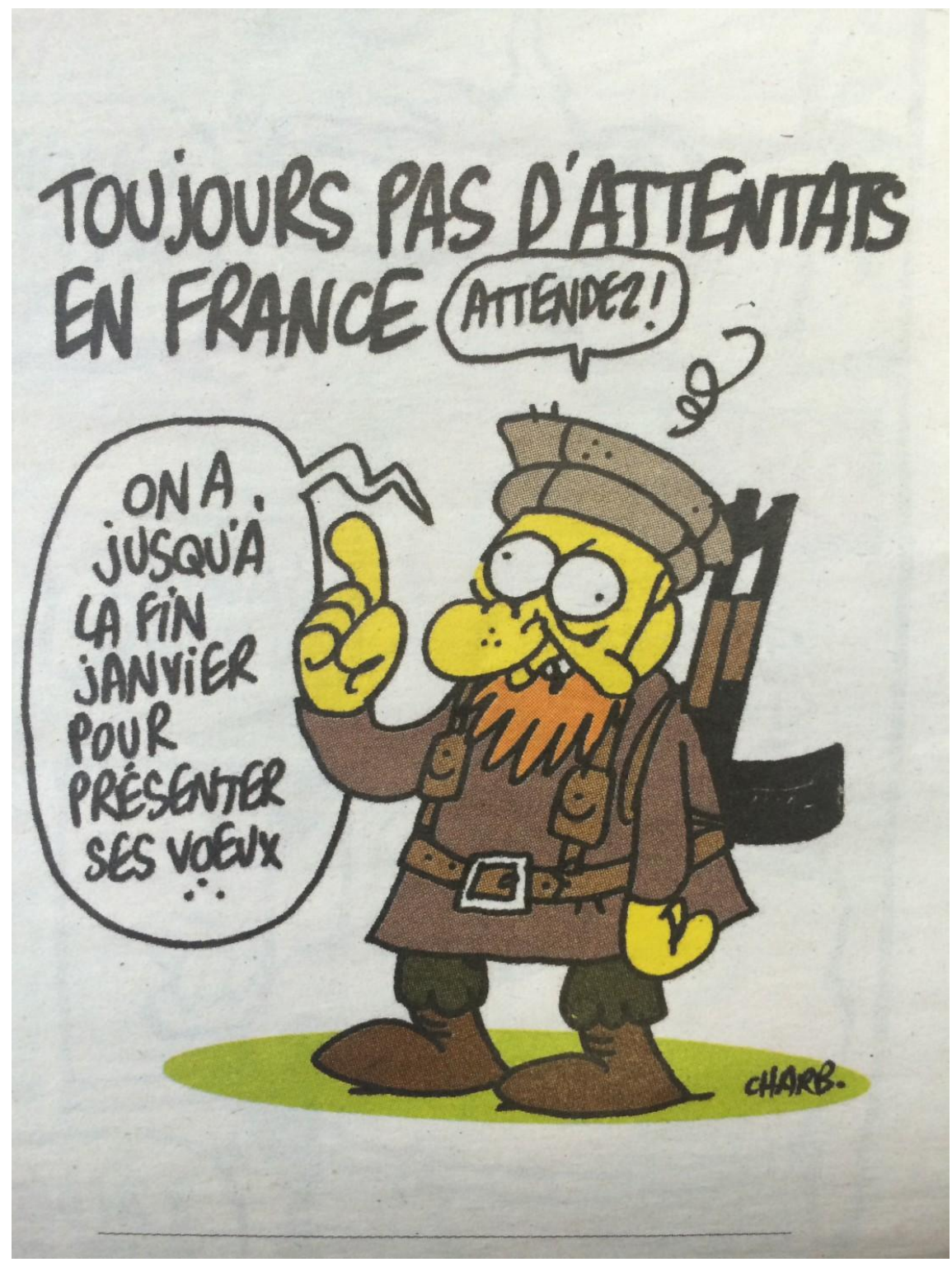


Appendix D : Si près du but...

Riss (September, 2015), retrieved from http://www.pri.org

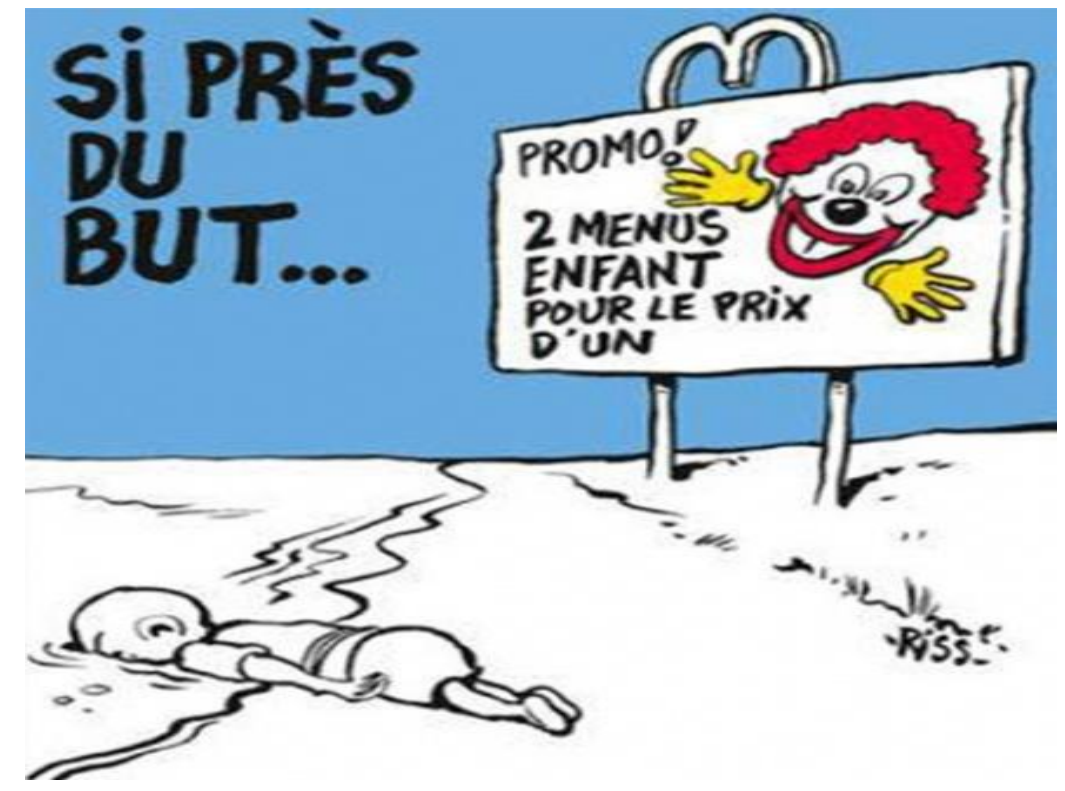

Appendix E: Preuve que l'Europe est Chrétienne

Riss (September, 2015), retrieved from http://www.mintpressnews.com

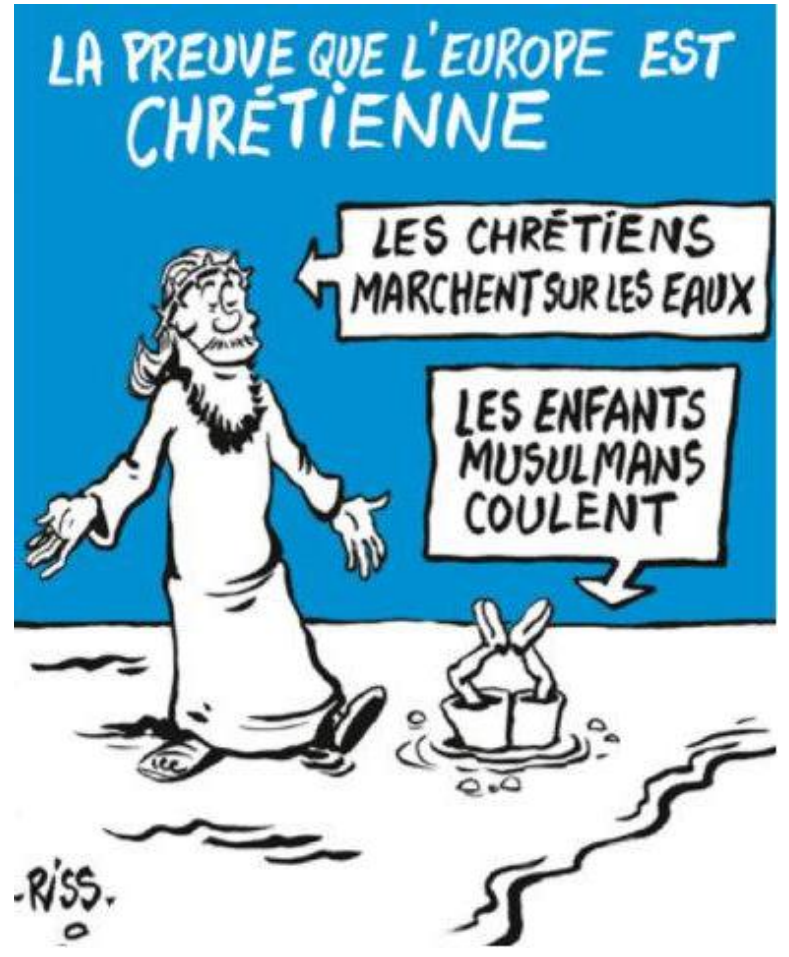




\section{Appendix F: Pre-Study Survey}

Dear Students, thank you for taking the time to answer this questionnaire. Please read the descriptor for each category and mark the one that best describes you.

This questionnaire is anonymous and will not affect your grade in anyway, so please be honest.

\begin{tabular}{|c|c|c|c|c|c|}
\hline & $\begin{array}{c}\text { Strongly } \\
\text { Agree }\end{array}$ & Agree & $\begin{array}{c}\text { Neither Agree } \\
\text { nor Disagree }\end{array}$ & Disagree & $\begin{array}{l}\text { Strongly } \\
\text { Disagree }\end{array}$ \\
\hline \multicolumn{6}{|l|}{ Motivation } \\
\hline I enjoy learning French. & & & & & \\
\hline \multicolumn{6}{|l|}{$\begin{array}{l}\text { I enjoy listening to easy audio-visual } \\
\text { materials in French (songs, TV shows...). }\end{array}$} \\
\hline \multicolumn{6}{|c|}{$\begin{array}{l}\text { I enjoy speaking about familiar topics (e.g. } \\
\text { my town, my family, my hobbies...). }\end{array}$} \\
\hline \multicolumn{6}{|c|}{$\begin{array}{l}\text { I enjoy writing basic texts on familiar } \\
\text { topics. }\end{array}$} \\
\hline \multicolumn{6}{|l|}{$\begin{array}{l}\text { I enjoy reading short texts on familiar } \\
\text { topics. }\end{array}$} \\
\hline $\begin{array}{l}\text { I enjoy learning about France and its } \\
\text { culture. }\end{array}$ & & & & & \\
\hline
\end{tabular}

\begin{tabular}{|c|c|c|c|c|c|}
\hline & $\begin{array}{c}\text { Strongly } \\
\text { Agree }\end{array}$ & Agree & $\begin{array}{c}\text { Neither Agree } \\
\text { nor Disagree }\end{array}$ & Disagree & $\begin{array}{l}\text { Strongly } \\
\text { Disagree }\end{array}$ \\
\hline \multicolumn{6}{|l|}{$\begin{array}{c}\text { Affective Filter } \\
\end{array}$} \\
\hline $\begin{array}{l}\text { I am confident in my ability to write a text } \\
\text { on a familiar topic (e.g. my town, my } \\
\text { family, my hobbies...). }\end{array}$ & & & & & \\
\hline \multicolumn{6}{|l|}{$\begin{array}{l}\text { I am confident in my ability to understand } \\
\text { what I read. }\end{array}$} \\
\hline \multicolumn{6}{|l|}{$\begin{array}{l}\text { I am confident in my current listening } \\
\text { skills. }\end{array}$} \\
\hline $\begin{array}{l}\text { I am confident when speaking with native } \\
\text { speakers on familiar topics. }\end{array}$ & & & & & \\
\hline
\end{tabular}




\begin{tabular}{|c|c|c|c|c|c|}
\hline & $\begin{array}{c}\text { Strongly } \\
\text { Agree }\end{array}$ & Agree & $\begin{array}{l}\text { Neither Agree } \\
\text { nor Disagree }\end{array}$ & Disagree & $\begin{array}{l}\text { Strongly } \\
\text { Disagree }\end{array}$ \\
\hline \multicolumn{6}{|l|}{ Culture and humor } \\
\hline I enjoy humorous TV shows. & & & & & \\
\hline \multicolumn{6}{|l|}{ I enjoy Authentic French programming. } \\
\hline \multicolumn{6}{|l|}{ Culture motivates me to learn. } \\
\hline \multicolumn{6}{|l|}{ Humor motivates me to learn. } \\
\hline \multicolumn{6}{|l|}{$\begin{array}{l}\text { I believe I have a good understanding of } \\
\text { French culture. }\end{array}$} \\
\hline $\begin{array}{l}\text { I believe I have a good understanding of } \\
\text { French humor. }\end{array}$ & & & & & \\
\hline
\end{tabular}

\begin{tabular}{|c|c|c|c|c|c|}
\hline & $\begin{array}{c}\text { Strongly } \\
\text { Agree }\end{array}$ & Agree & $\begin{array}{c}\text { Neither Agree } \\
\text { nor Disagree }\end{array}$ & Disagree & $\begin{array}{l}\text { Strongly } \\
\text { Disagree }\end{array}$ \\
\hline \multicolumn{6}{|l|}{ French Multimedia } \\
\hline I watch TV shows from France. & & & & & \\
\hline I watch French TV shows. & & & & & \\
\hline $\begin{array}{l}\text { I watch French TV shows with French } \\
\text { subtitles. }\end{array}$ & & & & & \\
\hline $\begin{array}{l}\text { I watch French TV shows with English } \\
\text { subtitles. }\end{array}$ & & & & & \\
\hline $\begin{array}{l}\text { I can get the gist of authentic French TV } \\
\text { shows. }\end{array}$ & & & & & \\
\hline $\begin{array}{l}\text { I watch French TV shows because I like } \\
\text { French culture. }\end{array}$ & & & & & \\
\hline $\begin{array}{l}\text { I watch French TV shows because I like } \\
\text { French humor. }\end{array}$ & & & & & \\
\hline
\end{tabular}




\section{You and French Language}

1. I have been studying French language for

2. Describe your interest in learning French (please check one of the option)
○ very interested
$\circ$ interested
$\bigcirc$ indifferent
$\bigcirc$ not interested

3. Which of the following reasons best describe why you are learning French? (one answer only)

$\circ$ Academic purposes $\quad \circ$ Professional purposes $\bigcirc$ general interest

- Communication with family members

○ Requirement $\circ$ Other:

4. Which materials do you use to support your learning?
- Class material
- TV shows
- Magazine articles
- News articles
- Comic strips
○ Books
o Other:

○ communication with friends

5. Which aspects of watching TV or movies in the target language help you to improve your communicative skills? 


\section{Appendix G: Post-Study Survey}

Dear Students, thank you for taking the time to answer this questionnaire. Please read the descriptor for each category and mark the one that best describes you.

This questionnaire is anonymous and will not affect your grade in anyway, so please be honest.

\begin{tabular}{|c|c|c|c|c|c|}
\hline & $\begin{array}{c}\text { Strongly } \\
\text { Agree }\end{array}$ & Agree & $\begin{array}{c}\text { Neither Agree } \\
\text { nor Disagree }\end{array}$ & Disagree & $\begin{array}{l}\text { Strongly } \\
\text { Disagree }\end{array}$ \\
\hline \multicolumn{6}{|l|}{ Motivation } \\
\hline $\begin{array}{l}\text { Scènes de Ménage motivated me to learn } \\
\text { French. }\end{array}$ & & & & & \\
\hline $\begin{array}{l}\text { Scènes de Ménage motivated me to learn } \\
\text { French culture (recognize differences } \\
\text { related to written and spoken } \\
\text { communication, rely on cultural } \\
\text { knowledge to interpret texts). }\end{array}$ & & & & & \\
\hline $\begin{array}{l}\text { Scènes de Ménage motivated me to } \\
\text { practice my listening skills (comprehend } \\
\text { texts related to basic personal and social } \\
\text { needs and familiar knowledge). }\end{array}$ & & & & & \\
\hline $\begin{array}{l}\text { Scènes de Ménage motivated me to } \\
\text { practice my writing skills (create messages } \\
\text { in context using series of sentences and } \\
\text { formulaic expressions). }\end{array}$ & & & & & \\
\hline $\begin{array}{l}\text { Scènes de Ménage encouraged me to study } \\
\text { more vocabulary (vocabulary of everyday } \\
\text { topics, personal interest, or of topics that } \\
\text { have been studied). }\end{array}$ & & & & & \\
\hline $\begin{array}{l}\text { Scènes de Ménage motivated me to } \\
\text { practice my speaking skills (use facial } \\
\text { expressions and gestures, repeat words, } \\
\text { simplify, use known language to } \\
\text { compensate missing vocabulary...). }\end{array}$ & & & & & \\
\hline
\end{tabular}




\begin{tabular}{|c|c|c|c|c|c|}
\hline & $\begin{array}{l}\text { Strongly } \\
\text { Agree }\end{array}$ & Agree & $\begin{array}{c}\text { Neither Agree } \\
\text { nor Disagree }\end{array}$ & Disagree & $\begin{array}{l}\text { Strongly } \\
\text { Disagree }\end{array}$ \\
\hline \multicolumn{6}{|l|}{ Affective Filter } \\
\hline \multicolumn{6}{|l|}{$\begin{array}{l}\text { Scènes de Ménage helped me feel more } \\
\text { confident in my listening skills } \\
\text { (comprehend texts related to basic personal } \\
\text { and social needs and familiar knowledge). }\end{array}$} \\
\hline \multicolumn{6}{|l|}{$\begin{array}{l}\text { Scènes de Ménage helped me feel more } \\
\text { confident in my reading skills } \\
\text { (comprehend texts related to basic personal } \\
\text { and social needs and familiar knowledge). }\end{array}$} \\
\hline \multicolumn{6}{|l|}{$\begin{array}{l}\text { Scènes de Ménage helped me feel more } \\
\text { confident in my speaking skills (use facial } \\
\text { expressions and gestures, repeat words, } \\
\text { simplify, use known language to } \\
\text { compensate missing vocabulary...). }\end{array}$} \\
\hline $\begin{array}{l}\text { Scènes de Ménage helped me feel more } \\
\text { confident in my writing skills ( create } \\
\text { messages in context using series of } \\
\text { sentences and formulaic expressions). }\end{array}$ & & & & & \\
\hline
\end{tabular}

\begin{tabular}{|c|c|c|c|c|c|}
\hline & $\begin{array}{l}\text { Strongly } \\
\text { Agree }\end{array}$ & Agree & $\begin{array}{l}\text { Neither Agree } \\
\text { nor Disagree }\end{array}$ & Disagree & $\begin{array}{l}\text { Strongly } \\
\text { Disagree }\end{array}$ \\
\hline \multicolumn{6}{|l|}{ Culture \& humor } \\
\hline $\begin{array}{l}\text { Scènes de Ménage improved my } \\
\text { understanding of French culture. }\end{array}$ & & & & & \\
\hline $\begin{array}{l}\text { Scènes de Ménage improved my } \\
\text { understanding of French humor. }\end{array}$ & & & & & \\
\hline $\begin{array}{l}\text { Scènes de Ménage helped me enjoy French } \\
\text { culture. }\end{array}$ & & & & & \\
\hline $\begin{array}{l}\text { Scènes de Ménage helped me enjoy French } \\
\text { humor. }\end{array}$ & & & & & \\
\hline $\begin{array}{l}\text { Scènes de Ménage made me want to watch } \\
\text { more authentic French programming. }\end{array}$ & & & & & \\
\hline $\begin{array}{l}\text { Scènes de Ménage made me want to watch } \\
\text { more humorous French TV shows. }\end{array}$ & & & & & \\
\hline
\end{tabular}

Please elaborate on the items which you marked "Strongly Agree" or "Strongly Disagree" 